\title{
The Critical Middle Years and the Relationship of Early Access to Algebra on High School Math Course Completion and College Readiness
}

\author{
Kim Victoria Smith Green \\ West Virginia University
}

Follow this and additional works at: https://researchrepository.wvu.edu/etd

\section{Recommended Citation}

Green, Kim Victoria Smith, "The Critical Middle Years and the Relationship of Early Access to Algebra on High School Math Course Completion and College Readiness" (2012). Graduate Theses, Dissertations, and Problem Reports. 275.

https://researchrepository.wvu.edu/etd/275

This Dissertation is protected by copyright and/or related rights. It has been brought to you by the The Research Repository @ WVU with permission from the rights-holder(s). You are free to use this Dissertation in any way that is permitted by the copyright and related rights legislation that applies to your use. For other uses you must obtain permission from the rights-holder(s) directly, unless additional rights are indicated by a Creative Commons license in the record and/ or on the work itself. This Dissertation has been accepted for inclusion in WVU Graduate Theses, Dissertations, and Problem Reports collection by an authorized administrator of The Research Repository @ WVU.

For more information, please contact researchrepository@mail.wvu.edu. 
The Critical Middle Years and the Relationship of Early Access to Algebra on High School Math Course Completion and College Readiness

\title{
Kim Victoria Smith Green
}
Dissertation submitted to the College of Human Resources and Education at West Virginia University in partial fulfillment of the requirements for the degree of

\author{
Doctor of Education \\ in \\ Educational Leadership Studies \\ Sebastián R. Díaz, Ph.D., J.D., Chair \\ Ernest R. Goeres, Ph.D. \\ Elizabeth A. Jones, Ph.D. \\ Patricia A. Obenauf, Ph.D. \\ Benjamin T. Brauer, Ed.D.
}

Department of Educational Leadership Studies

\author{
Morgantown, West Virginia
}

2012

Keywords: Algebra, College Readiness, Mathematics

Copyright 2012 Kim Victoria Smith Green 


\title{
Abstract \\ The Critical Middle Years and the Relationship of Early Access to Algebra on High School Math Course Completion and College Readiness
}

\author{
Kim Victoria Smith Green
}

Many students who enroll in higher education are unprepared to meet the challenges of postsecondary education. The probability that students will make a successful transition from high school to college is linked to the degree to which their secondary educational experiences have prepared them for the expectations and demands they will encounter in college. National findings provide continuing evidence that focusing on improving student achievement in mathematics will positively impact college readiness. The main problem addressed in this quantitative study was how educators can best prepare students for college readiness. Since college readiness is highly dependent upon math achievement in middle schools, postsecondary educators need additional research that explores how math curricula may ultimately impact the readiness of their college students. Therefore, seemingly benign decisions about placement of students in middle school math may ultimately impact greatly on their college readiness. In addition, the study focused on the implications of those placement decisions. Chi-square Automatic Interaction Detection (CHAID) was used to determine those variables that were most significantly associated with students' math-related college readiness as evidenced by advanced mathematics coursework taken beyond Algebra I. 


\section{Acknowledgements}

The pursuit of this degree would not have been possible without the support and encouragement of my family, friends, colleagues, and committee members. I especially want to thank the following individuals for their help and support:

To Harry "Dee” Kalbaugh, my best friend and partner, who has been my strongest supporter and ally. Thank you for helping me to reach this goal. You have been awesome.

To Lea Messman-Mandicott, my friend and cohort member, whose encouragement and support have been so helpful. You and I were brought together because of this program, and I am so thankful that we have become such good friends.

To Dr. Ben Brauer, my friend and colleague, who showed me that you can finish a doctoral program in a timely manner even if you have a demanding job and family. Thanks for serving on my committee. Your time and commitment to my project have been appreciated.

To Dr. Sebastián Díaz, my committee chairperson, who graciously agreed to serve as my chairperson and who gave me unwavering encouragement and support. Thank you for your commitment, and thank you for the time you unselfishly gave me throughout this entire process. Thank you for believing in the value of this research. You made critical recommendations, and my writing is better because of your insights. You made me a more confident student and researcher. You have been a blessing, and it has been a pleasure working with you.

To Dr. Ernest Goeres, who graciously agreed to serve on my committee and whose time and commitment to my project have been greatly appreciated.

To Dr. Elizabeth Jones, who graciously agreed to serve on my committee and who shares my passion for student assessment. Your time and commitment to my project have been greatly appreciated.

To Dr. Patricia Obenauf, who graciously agreed to serve on my committee and whose time and commitment to my project have been greatly appreciated. 


\section{Dedication}

This dissertation is lovingly dedicated to my mom, Lena Irene Rockwell Smith, and my dad, Harold Victor Smith, Sr. You have been my source of inspiration throughout my entire life. You have instilled in me strong values of diligence, faith, and hard work. Your unconditional love for me has always been evident in both word and action. I have been immeasurably blessed to have you as parents. 


\section{Table of Contents}

Chapter One: Introduction and Problem Statement ………........................................ 1

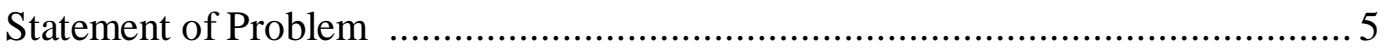

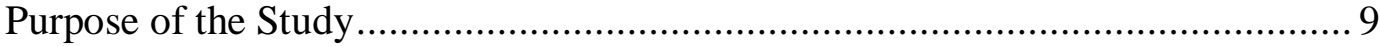

Research Question......................................................10

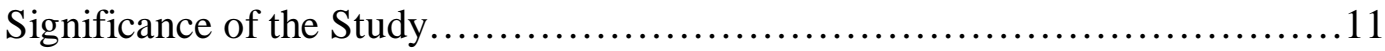

Key Terms and Concepts...................................................12

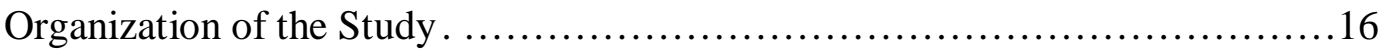

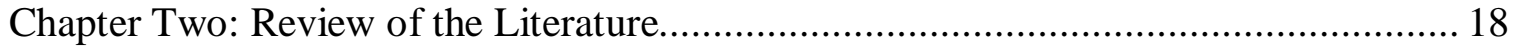

Postsecondary College Readiness .................................................................... 19

College Readiness and Pre-College Mathematics Preparation ................. 23

Readiness and Advanced Courses in Mathematics and Science .............. 26

Challenges, Functions, and Costs of College Remediation........................ 26

Community Colleges and Remedial Education ....................................... 31

Secondary Schools and Mathematical Readiness ................................................. 33

Transition from Elementary to Middle School ......................................... 33

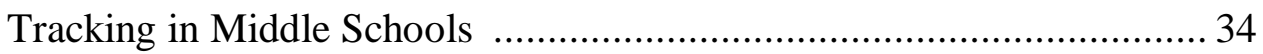

Mathematics and High Risk Groups ....................................................... 40

Middle School and College Planning ………………………………..... 43

School Counselors and Mathematics Course Taking Patterns ................. 45

Parental Involvement and Mathematic Placement ……………............... 46

Influence of Teachers upon Mathematical Achievement ......................... 49 
Chapter Three: Research Design and Methodology ….......................................... 52

Restatement of the Problem .................................................................... 52

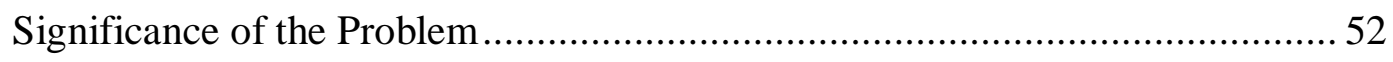

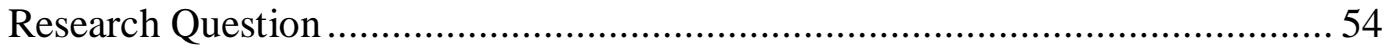

Research Design ........................................................................ 55

Institutional Approval .......................................................... 55

Population and Sample ........................................................ 56

Data Analysis Method ....................................................................... 57

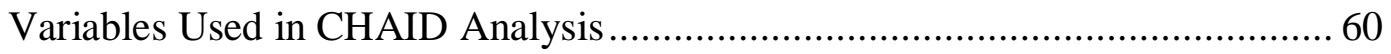

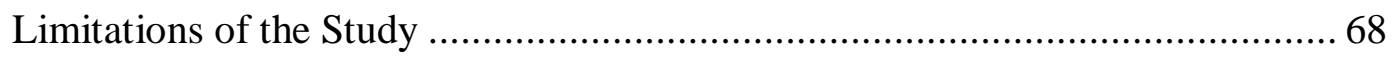

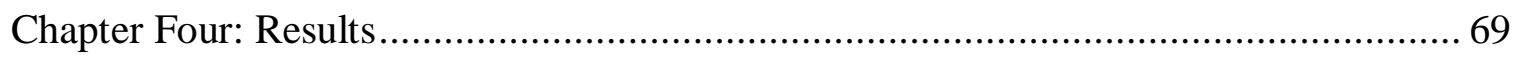

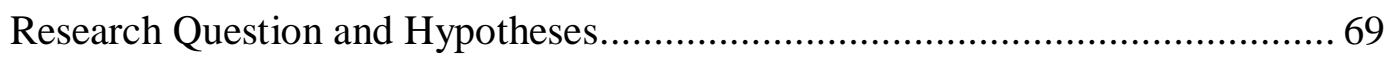

Data Selection and Procedures............................................................. 70

Exhaustive CHAID Data Analysis ..................................................... 71

Advantages of CHAID .................................................................... 72

Description of CHAID Variables ........................................................ 72

CHAID Decision Tree Process ................................................................ 73

Interpreting CHAID Results .......................................................... 74

Root Node of the Decision Tree ................................................. 77

Division of Root Node into Two Branches ....................................... 77

Second Level Node One.......................................................... 78

Second Level Node Two ............................................................. 78

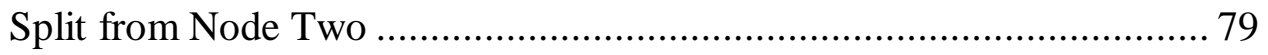


Additional Split from Node Five .................................................... 79

Interpretation of HSA Assessment Scores ......................................... 80

Third Level Node Three................................................................. 81

Node Three Splits ........................................................................ 81

MSA Scores and Nodes Eight through 10....................................... 81

Interpretation of MSA Assessment Scores....................................... 81

Relationship of Node Three to Nodes 11 through 15 .......................... 82

Interpretation of Assessment Scores ............................................. 82

Fourth Level Node 11 Split .......................................................... 83

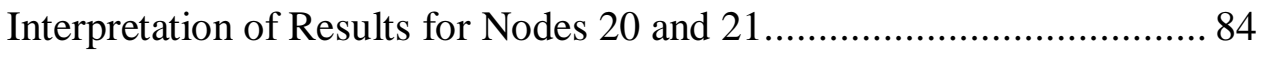

Third Level Node Four................................................................... 85

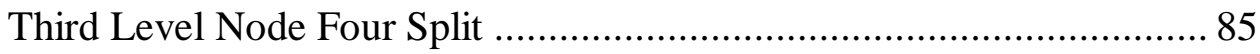

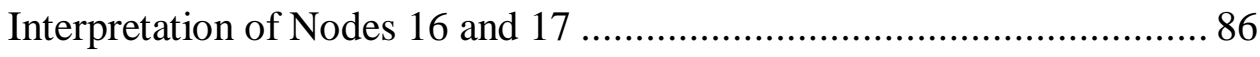

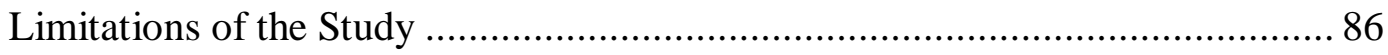

Chapter Five: Summary, Conclusion, and Recommendations

for Future Practice and Research......................................................... 88

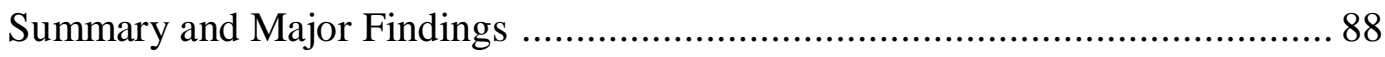

Recommendations for Future Practice...................................................... 91

Recommendations for Future Research..................................................... 99

Conclusion ...................................................................................... 102

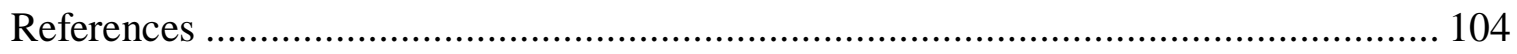

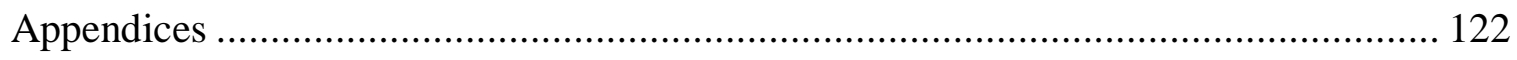




\section{List of Tables}

Table 1 Variables Used in the CHAID Analysis......................................................... 61

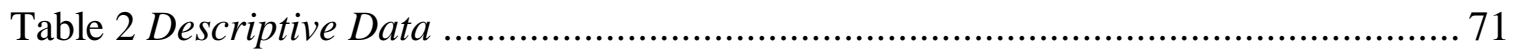




\section{List of Appendices}

Appendix A: Letter of Approval to Conduct Research............................................. 122

Appendix B: Memo of Approval from WVU Institutional Review Board (IRB).......... 123 


\section{List of Figures}

Figure 1 Exhaustive CHAID Analysis in SPSS Answer Tree (Version 3.1) .................... 75

Figure 2 Explanation of CHAID Decision Tree Nodes ............................................. 76

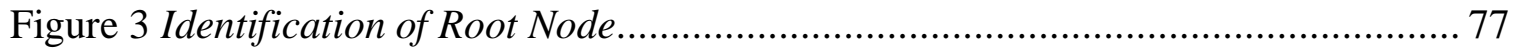

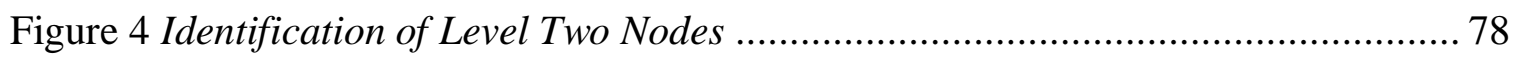

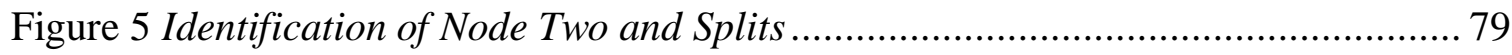

Figure 6 Identification of Node Three and Splits................................................... 80

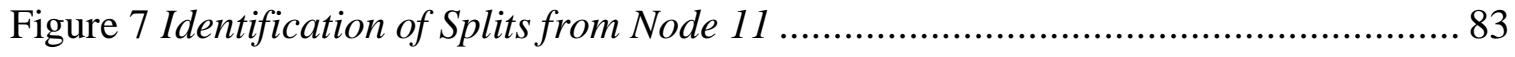

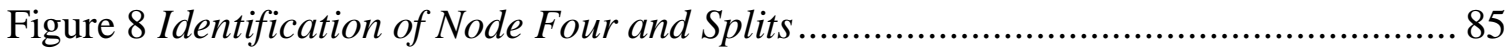




\section{Chapter One: Introduction and Problem Statement}

"Should every student pursue higher education? Not necessarily. Should every student be prepared for and have the choice to attend college or pursue other types of post-high-school education? Absolutely” (Corbett \& Huebner, 2007, p. 1). Increasingly, it is recognized that the skills and aptitudes believed absolutely necessary for "college readiness" are indeed the same skills required for career readiness. Therefore, college readiness should be an expectation and a goal for all students, regardless of their career aspirations. A recent ACT (2009) report concluded that college readiness also indicates career readiness:

While not every high school graduate plans to attend college, the majority of the fastestgrowing jobs that require a high school diploma pay a salary above the poverty line for a family of four and provide opportunities for career advancement require knowledge and skills comparable to those expected of the first-year college student. (ACT, 2009) College readiness is not a new or a recent occurrence or circumstance in our nation. The phenomenon of being unprepared for college can be viewed as a historical problem that has existed for decades. College readiness is the emphasis of the No Child Left Behind legislation and President Obama's Reauthorization of the Elementary and Secondary Education Act (U.S. Department of Education, 2010). The National Commission on Excellence in Education (1983) reported that, despite prolonged attention by educational and political leaders over the last few decades on the need to improve secondary students' readiness for college, our nation continues to struggle with alarmingly inferior high school graduation rates. Rouse and Kemple (2009) indicated that the typical American high school is failing its students in regards to both excellence and equity. Almost 16 million students attend more than 40,000 high schools in the United States; the overwhelming majority, more than 90 percent, attend public schools (Rouse \& 
Kemple, 2009). Yet, every year, nearly one million students who should graduate from high school do not. According to an analysis of the most recent data in "Diplomas Count" (2010) the national high school graduation rate has continued to decline during the past few years, from 69.2\% in 2006 to $68.8 \%$ in 2007, despite public and private efforts to increase the percentage of students who enter post-secondary education. According to the report, it was the second consecutive year of declining high school graduation rates.

The continuing failure of U.S. public schools to keep so many of their students in school—particularly their black and Hispanic students, who fail to graduate at much higher rates than whites and Asians—-must be considered one of the most urgent problems in educational policy. (Greene \& Forster, 2003, p. 1)

A high school diploma does not guarantee that students are college ready. Greene and Forster (2003) reported that more than half of the students who graduate from high school do not graduate with the minimal requirements needed to apply to a four-year college or university. Since the 1980's, colleges have required placement testing to determine a high school student's college readiness and have either required or offered developmental or remedial education for those students lacking adequate skills (Amey \& Long, 1998). Today, thousands of high school graduates who enter two-or four-year institutions must take at least one remedial course because they lack mastery of the fundamentals of mathematics. Greene and Forster (2003) used data from the U.S. Department of Education to estimate the percentage of students who graduate from high school as well as the percentage of graduates who are ready to attend a four-year college. They also produced estimates by racial/ethnic groups as well as by region and state. About $70 \%$ of all students in public high schools graduate, but only $32 \%$ of students graduate from high school prepared to attend four-year colleges (Greene \& Forster, 2003). Additionally only 51\% of 
all black students and 52\% of all Hispanic students graduate from high school, and only 20\% of all black students and 16\% of all Hispanic students graduate from high school prepared for postsecondary education (2003). The high school graduation rate for white students was $72 \%$, for Asian students, 79\%, and for American Indian students, 54\%. However, the college readiness rate for white students was 37\%, for Asian students, 38\%, and for American Indian students, 14\%. According to Greene and Forster (2003), students are classified as prepared for college or college ready if the student graduated from high school, completed certain courses in high school that colleges consider necessary for enrollment, and demonstrated mastery of basic literary skills. The probability that students will make a successful transition from high school to college is often a "function of their readiness - the degree to which previous educational and personal experiences have equipped them for the expectations and demands they will encounter in college" (Conley, 2008, p. 3). According to Achieve (2009), a non-profit education reform organization, readiness for college is also related to the knowledge, habits, and skills that are the result of a rigorous, rich, and comprehensive high school curriculum.

Research indicates that middle school is a critical time for early postsecondary preparation (Wimberly \& Noeth, 2005). Students who enter high school unprepared for the rigors of secondary course work are less likely than their peers to be college ready by the time they graduate from high school (ACT, 2009). Statistics from middle school research indicate that students have ambitious goals regarding post-secondary education; by eighth grade, over $80 \%$ of students indicate that they will earn at least a college degree and nearly half also expect to earn a graduate or professional degree (Csikszentmihalyi \& Schneider, 2000; Wimberly \& Noeth, 2005). Unfortunately, reports from the National Assessment of Educational Progress (NAEP) provide disturbing news about college readiness (Radcliffe \& Stephens, 2008). NAEP 
data indicates that many young adolescents are not adequately prepared for postsecondary education and workforce success (Radcliffe and Stephens, 2008). ACT (2009) data revealed that fewer than two in 10 students in eighth grade are on target to be ready for college-level work by the time they graduate from high school. Research from the National Science Foundation report Rising above the Gathering Storm (2007) indicated that the performance of U.S. students declines as they progress from elementary school to middle school to high school. According to a report from the National Council of Teachers of Mathematics (2000), students are not learning mathematics with depth and understanding. For example, about one-third of fourth grade and eighth-grade students performed at or above a proficient level in mathematics (National Science Foundation, 2007). Furthermore, about one-third of the fourth grade and one-fifth of the eighthgrade students lacked the ability to perform even basic mathematical processes (National Science Foundation, 2007). Eighth graders performing at the proficient or advanced levels in math increased between 1990 and 2007; however, only about 30\% scored at or above proficient (Radcliffe \& Stevens, 2008).

Recent national findings provide continuing evidence of the need to increase the focus on improving student achievement in mathematics. Adelman's (1999) work indicated that completion of an advanced high school course beyond Algebra II had greater influence on college degree completion than factors such as socioeconomic status, ethnicity, or parents' educational backgrounds. Findings from a U.S. Department of Education (2006) study indicated that taking a full schedule of academically demanding courses in high school, including mathematics beyond Algebra II, was the single most significant pre-college factor in determining if students graduated from college. When former U.S. Secretary of Education Margaret Spelling announced findings of the National Mathematics Advisory Panel, she discussed the importance 
of algebra and the relationship of doing well in algebra to college readiness and college success (Vogel, 2008).

Much research has been written about the key role that secondary schools play in providing a rigorous program of study and guiding early preparation for postsecondary education (Wimberly \& Noeth, 2005, viii). Less attention has been paid to the importance of the middle school years and the role it plays in the preparation of students for post-secondary education or career success following high school (ACT, 2009). "Given the long term course taking and postsecondary planning that college and workplace readiness require, students must begin the college readiness process as early as middle school” (Wimberly \& Noeth, 2005, p. 20). Academic readiness for college and career can be greatly enhanced when students develop behaviors in middle school that contribute to successful academic performance (ACT, 2009). Moreover, research indicates that the level of academic achievement that students acquire by eighth grade has a greater impact on college readiness than anything that happens academically in high school (ACT, 2009). Findings of The Forgotten Middle indicated that there is a defining point for students in the college and career readiness process; students who are not on target for college and career readiness by the eighth grade may severely impact their future academic readiness (ACT, 2009).

\section{Statement of Problem}

The main problem addressed in this study is how educators can best prepare students for college readiness. An integral factor in the college readiness process is career awareness: knowledge that students possess about college and preparation for higher education such as the critical relationships that exist among pre-college academic course selections and college and career choices, college selection, and college admissions requirements. At the middle level, 
students begin to make important academic decisions that may affect high school course selections and preparation for higher education. Since college readiness is highly dependent upon math achievement in middle schools, post-secondary educators need more research that explores how middle school math curricula may ultimately impact the readiness of their college students.

Research from the National Middle School Association (2003) suggested that declining achievement and attitudes toward mathematics involves how students are placed in mathematics courses at the middle school level. In many school districts, students who leave elementary school as low achievers in math are scheduled into low-track placements with students that have been determined as having similar abilities. Low-track classes typically feature a focus on basic level skills. The classes are taught by teachers who are the least qualified, and there is a prevalent climate of low expectations (Heubert \& Hauser, 1999). Students who are placed in lower-ability math classes have fewer opportunities to take advanced high school mathematics which can significantly impact college readiness; therefore, the transition to middle school and mathematics placement during grade six may critically impact postsecondary degree attainment (Akos et al., 2007). The differences in math course selections, math content, and prerequisites that are introduced during middle school may make later movement to advanced mathematics courses much more difficult (Dauber et al., 1996). Essentially, tracking and placement decisions in middle school mathematics may create or cause achievement gaps. Tracking students may not only significantly contribute to low math performance at the middle level, it may significantly impact the number of upper-level high school mathematics courses that students take at the secondary level, hindering their capacity to meet the admission requirements to a four-year 
college (Oakes, 2005). Therefore, administrative decisions about placement of students in middle school mathematics may ultimately impact college readiness.

Traditional mathematical programs tend to place emphasize on performance goals and less on mastery goals. Classroom instruction focuses on the lowest levels of cognition, such as knowledge, recall, and comprehension. Other scholars suggest that mathematical programs in the public school sector must widen their goals to include, among others, algebraic thinking, statistical reasoning, probability, and problem solving in order to maximize students’ opportunities for success in the $21^{\text {st }}$ century (English, 2002). Opportunities for all students to access these key mathematical concept and processes should be a principal goal of all mathematics programs at the elementary and secondary education levels. The value of learning mathematics in today’s global society_ — “a society of extraordinary and accelerating changes— has never been greater and will continue to increase dramatically” (McKinney \& Frazier, 2008, pp. 207-208). Taylor (1989) reported that a lack of algebra skills limits the opportunities students have for education and careers. Schoenfeld (2002) stated that a "lack of mathematical competence and credentials constitute a barrier to full participation in the economic mainstream” (p. 3).

Research suggests that middle school is a critical period for early postsecondary awareness and preparation (Wimberly \& Noeth, 2005). The implication for school systems is that administrators, school counselors, and educators must partner together to initiate the process of integrating college awareness and college readiness into the curriculum throughout middle and high school; in addition, school leaders must ensure that the curriculum is rigorous, comprehensive, and relevant to accelerate the rise of all students to being ready for college (Baker, Clay, \& Gratama, 2005). Therefore, it is imperative to focus on critical factors that take place at both elementary and secondary schools that can potentially advance or impede all students’ paths toward college 
enrollment, degree attainment, and career success. One major factor involves the use of tracking practices that many school districts in the United States employ that impose restrictions on whether or not students have access to upper-level mathematics courses. When "mathematics sequence is differentiated in middle school, some students are limited in quantity and quality of mathematics curricula to which they may have access in high school” (Akos et al., 2007, p. 239). Essentially, the tracking and placement in middle school mathematics may create or cause achievement gaps. Tracking students may not only significantly contribute to low math performance at the middle level, it may significantly impact the number of upper-level high school mathematics courses that students take at the secondary level, hindering their capacity to meet the admission requirements to a four-year college (Oakes, 2005).

The differences in math course selections, math content, and prerequisites that are introduced during middle school may make later movement to advanced mathematics courses much more difficult (Dauber et al., 1996). Students who are not encouraged to take algebra are enrolled in a grade-level math course. Students who do not have an algebra class during middle school take algebra in grade nine. The course pattern for these students typically includes algebra in ninth grade, geometry in tenth grade, and a return to a more advanced algebra in grade eleven (Schoenfeld, 2002, p. 6). In this traditional curriculum, algebraic and geometric problems are not applied together, but as separate courses. Subsequently, only students who have access to Algebra I by the seventh or eighth grade will have the opportunity to take the highest levels of math offered at the secondary level—calculus (Burns, Heubert, \& Levin, 2004). A traditional mathematics curriculum encourages “differential participation” (Schoenfeld, 2002, p. 3). It becomes an issue of inequality and injustice, impacting students' educational opportunities and college readiness. 
Administrators, school counselors, educators, and parents underestimate the capabilities of adolescents. Muller and Beatty (2008) stated that since higher-level mathematics is the foundation for success in college and careers, educators must change the way they approach mathematics, and they must understand the importance of higher-level mathematics for every student. The report Making the Mathematics Curriculum Count (2007) suggested that increasing mathematics rigor across the nation will require widespread changes within school districts. Therefore, rather than placing only the most advanced students in algebra in middle school or worrying about whether students with less mathematical proficiency will receive lower grades, possibly, it would be more beneficial to expose all students to algebraic concepts and mathematical reasoning skills during elementary and early middle school grades so that all students have a greater level of preparedness for algebra during their middle school experience.

\section{Purpose of the Study}

The purpose of this study was to examine the math course patterns of high school seniors who completed either Algebra I or a general math course during middle school. In addition, this study investigated if these same students took more advanced math and science courses in high school, including advanced placement (AP) courses such as AP Calculus, AP Biology, and AP Physics, and dual enrollment courses such as College Algebra and College Statistics and Probability. This study also examined whether homogeneous grouping or tracking during the students’ middle school experience adversely affected math course patterns of high school graduates.

Debates about providing access to algebra for all students are pertinent and timely educational issues in the context of college readiness (Schoenfeld, 2002). "In the United States, poor children and under-represented minorities (African American, Native Americans, and 
Latinos) tend to earn lower grades and to stop taking mathematics courses much earlier than others” (Schoenfeld, 2002, p. 3). In addition, Schoenfeld (2002) reported that access to and treatment in mathematics courses also differs by gender. Gamoran and Hannigan (2000) suggested that, although not all students pass algebra, most students seem to benefit by the exposure to algebraic processes, abstract thinking, and problem solving. Therefore, the study was designed to advance current knowledge that will benefit students and their parents, teachers at the elementary and secondary levels, educational leaders and policy makers. To accomplish these goals, the following research question was developed for this dissertation:

\section{Research Question}

1. Which factors (math achievement, high school algebra score, curricular rigor, sequencing of math courses, and school attendance) are most closely associated with math-related college readiness as evidenced by advanced mathematics coursework taken beyond Algebra I for students in Allegany County Public Schools, Allegany County, Maryland?

The following null and alternative hypotheses are used to address this research question: Null Hypothesis

$\mathrm{Ho}_{1}$ : There is no statistically significant degree of association, as evidenced by CHAID analysis, between math-related college readiness, and a set of independent variables including math achievement, high school algebra score, curricular rigor, sequencing of math courses, and school attendance.

\section{Alternative Hypothesis}

$H a_{1}$ : There is a statistically significant degree of association, as evidenced by CHAID analysis, between math-related college readiness, and a set of 
independent variables including math achievement, high school algebra score, curricular rigor, sequencing of math courses, and school attendance.

\section{Significance of the Study}

One of the strongest factors associated with attainment of a college degree is the completion of advanced secondary mathematics courses. According to Smith (1996), algebra is the gatekeeper course to advanced study in mathematics. Research indicates that the level of academic achievement that students attain by grade eight has a larger impact on their college readiness by the time they graduate from high school than anything that happens academically in high school (ACT, 2009). Adelman (1999) concluded that completion of advanced high school courses beyond Algebra II had greater influence on college degree completion than factors such as socioeconomic status, ethnicity, or parents' educational backgrounds. Given the implications of K-12 math achievement for college readiness, further research is needed to guide future program and policy planning and implementation at the elementary and secondary levels, and at postsecondary institutions. Educational policy makers can use the findings and recommendations from this study to identify effective programs and strategies designed to support student achievement and success in middle school and thus in turn impact readiness for and student achievement in college. Substantially increasing the number of middle school students on target for college and career readiness by the end of eighth grade would potentially

increase the benefits of high school and students' level of preparedness for college (ACT, 2009). Thus, the transition from middle school to high school would become just as critical as the transition from high school to post-secondary education (ACT, 2009). 


\section{Key Terms and Concepts}

1. Algebra: Algebra is a branch of mathematics that substitutes letters and other symbols for numbers.

2. Advanced Placement (AP): Advanced Placement or AP courses are collegelevel courses that a student can take in high school. Students can receive college credit for taking the courses. However, some colleges will not grant college credit for advanced placement courses.

3. At-Risk Students: Students who have the highest chance of dropping out of school because of habits or barriers they must overcome.

4. Best practices entry-level college courses: "These courses require students to engage significantly with the course content and topics and to use key cognitive strategies” (Conley, 2010, p. 21).

5. Classification skills: Classification is a logical operation that involves grouping objects on the basis of a common characteristic (Ojose, 2008).

6. Cognitive Development: Cognitive development is the "process of acquiring intelligence and increasingly advanced thought and problemsolving ability from infancy to adulthood” (http://dictionary.reference.com/)

7. College Awareness: College awareness is knowledge that students have about college and preparation for higher education such as the relationship of secondary academic course selection to college and future career choices, college selection, and the college admissions process.

8. College Readiness: College readiness is defined "operationally as the level of preparation a student needs to enroll and succeed—without 
remediation—in a credit-bearing general education course at a postsecondary institution that offers a baccalaureate degree or transfer to a baccalaureate program” (Conley, 2009, p. 5).

9. Cultural Capital: Cultural capital, within an educational context, can be defined as investing or activating one’s social class in order to form social and cultural resources (Lareau, 1987).

10. Curriculum: A curriculum is a particular course of study in a school, college, or university.

11. Developmental Courses: Instructional classes designed for students who are deficient in competencies necessary for college work; usually these courses are neither included in subsequent grade point average calculations nor are they counted toward fulfillment of certificate or degree requisites (NCES, 2002).

12. Dropout: One who withdraws from school, whether high school or college, before graduating (Wiley, 2010).

13. Graduation Requirements: Each state requires that students earn a specific number of credits in core academic classes such as English, mathematics, science, social studies, as well as elective courses. In addition, states often require students to successfully pass a standardized exam or assessment.

14. Habits of Mind: A collections of dispositions that drive intelligent behavior when the answer is not known (Maryland State Department of Education, 2008). 
15. Heterogeneous Grouping: Heterogeneous grouping relates to classroom arrangements in which groups of students of differing intellectual abilities learn together in one classroom (National Middle School Association, 2003).

16. Homogeneous Grouping: Homogeneous grouping or ability grouping (also known as tracking) is based on educators' assessments of students' ability levels and skills (National Middle School Association, 2003).

17. Individualized Education Plan (IEP): describes the educational program that has been designed to meet a student's unique needs. Each child who receives special education or related services must have an IEP.

18. Key Cognitive Strategies: Intentional behaviors students must be able to use repeatedly over "an extended number and variety of situations so that students learn when and where to employ them” (Conley, 2010, p. 33)

19. Limited English Proficiency (LEP): The term refers to students who are unable to communicate effectively in English because it is not their primary language.

20. Math Literacy: Mathematical literacy is a person's capacity to identify and understand the role that mathematics plays in the world, to make sound judgments regarding mathematics, and to engage in mathematics in ways that address the needs of that individual (Organization for Economic Cooperation and Development, 1999).

21. Middle School: The middle school level is between elementary and high school, typically including grades five through eight or six through eight. 
22. No Child Left Behind (NCLB) legislation: No Child Left Behind refers to a federal law enacted under the George W. Bush administration. NCLB legislation attempts to accomplish standards-based education reform in an effort to increase accountability for states, school districts, and schools. The law provides more opportunities to parents for school choice and places a greater emphasis on mathematics and reading in schools. NCLB is written so that it requires $100 \%$ of students, including special education students and those from socio-economic disadvantaged backgrounds, within a school to reach the same set of state standards in mathematics and reading by the year 2014 (U.S. Department of Education, 2008).

23. Post-secondary remediation: Remediation at the college level is often referred to by a number of names, including developmental, basic skills, compensatory, or preparatory education (Tomlinson, 1989).

24. Remedial education: Remedial education is defined as a class or activity intended to meet the needs of students who do not possess the skills or experience necessary to complete college-level work. Remedial education is also commonly referred to as "developmental education, skills courses, or college preparation courses” (Attewell, Lavin, Domina, \& Levey, 2006).

25. Science: Science is defined as the "observation, identification, description, experimental investigation, and theoretical explanation of natural phenomena” (The American Heritage Dictionary, 1982, p. 1099). 
26. Socioeconomic Status: An individual or family’s socioeconomic status is based upon income, education level, occupation, and social status in the community.

27. Succeed: "Completing entry-level courses or core certificate courses at a level of understanding and proficiency that make it possible for the student to consider taking the next course in the sequence or the next level of course in the subject area or of completing the certificate” (Conley, 2010, p. 21).

28. Trends in International Mathematics and Science Study (TIMSS): The study provides information on mathematics and science achievement in the United States and other countries.

29. Tracking: Tracking or homogeneous grouping is the organization of students for instruction within a classroom, based on the students' ability and achievement levels (Hallinan, 1994).

\section{Organization of the Study}

This dissertation is organized into five chapters. The research study begins in chapter one and provides an introduction of the topic, overview of the problem, purpose of the study, definition of terms, and significance of the study to higher education. The remaining four chapters are organized as follows: Chapter two is an extensive review of the most relevant literature on college readiness, college remediation, mathematics readiness and achievement, the relationship of secondary schools to math college readiness, and the influence of school counselors, parents, and teachers upon students' math course selections and academic achievement. Chapter three describes the research design employed in the study, including a description of the sample, the instruments, data collection and analysis techniques, and possible 
limitations of the study. Chapter four presents the findings by analyzing the study population in light of the research question and null hypothesis. Chapter five discusses the results, relates those results to prior research, and points out implications and recommendations for practice, policy, and subsequent research. 


\section{Chapter Two: Review of the Literature}

Algebra for everyone has become a popular phrase in the literature; however, research indicates that current school systems in the United States do not provide equal learning opportunities for all students (Schoenfeld, 2002). In 1999, Clifford Adelman published his research findings on what factors contribute most to bachelor's degree completion of students in a report called Answers in the Toolbox. Adelman's (1999) work indicated that completion of an advanced high school mathematics course beyond Algebra II had greater influence on college degree completion that factors such as socioeconomic status, ethnicity, or parents' educational backgrounds. Completing mathematics beyond Algebra II substantially increases, by more than 50 percent, the likelihood that a student who enters higher education will earn a bachelor's degree (Adelman, 1999). Algebra, the first experience that students have with higher mathematics, is known as a gateway course to more advanced mathematics (Smith, 1996; Silver, 1997). If completion of algebra is crucial to postsecondary readiness and degree completion, then it is a reasonable assumption that all school systems in the United States should provide equal access and opportunities to students, regardless of their prior math performance, for algebra beginning at the middle school level. Therefore, the literature review is organized around the following topical areas: 1) college readiness and its relationship to secondary school mathematics preparation, 2) factors relevant to mathematics placement at the middle school level and the potential benefit of all students taking algebra during middle school, 3) the effects that tracking has on preventing students from achieving their full potential for learning mathematics during high school, and 4) the role of school counselors, parents, and teachers upon course selections in mathematics and math achievement. An examination of the literature suggests the potential impact that unequal access to rigorous mathematics curricula has upon students’ 
subsequent enrollment in advanced mathematics and science courses during high school, as well as cites relevant findings that illustrate the potential impact that unequal access to algebra has upon math-related college readiness.

\section{Postsecondary College Readiness}

Today's prevalent climate of accountability is driving school reform across the nation. Federal and state governments are holding secondary schools to more rigorous academic standards for all students. One of the predominant goals of the national secondary curriculum reform to redesign high schools is increasing the number of students who graduate ready for college (Olsen, 2006). Conley (2005) reported that secondary schools focus more on ensuring that students are eligible for college admission requirements rather than ready for college-level work. Conley, one of the leading researchers in the field of college readiness, suggested that there is a wide gap that exists between what students learn in their secondary school experience and the knowledge, skills and habits of mind that students need to succeed in college. Conley argued that secondary school systems developed in isolation from post-secondary systems and this isolation has caused gaps in college expectations and college readiness. According to Conley data from the National Survey of Student Engagement (NSSE) indicated that most high school graduates are unprepared for the rigors of college. Secondary schools that are successful in ensuring that students are college ready have a logical, coherent, and rigorous curriculum that increases in intensity as they progress through high school.

Conley (2005) led a two-year study at the University of Oregon which brought together more than 400 faculty and staff members from 20 leading research universities to identify college readiness standards in entry-level, credit bearing courses (Olsen, 2006). Results of the study indicated that one of the principal themes is the significance of the "habits of mind" students need to acquire during their secondary school experience (Olsen, 2006). These habits of 
mind include "critical thinking, analytical thinking, and problem solving; an inquisitive nature; the willingness to accept critical feedback and to adjust on the basis of that feedback; openness to possible failures from time to time; and the ability and desire to cope with frustrating and ambiguous learning tasks” (Olsen, 2006, p. 4). Conley (2010) indicated that the study’s findings suggest a major disconnect between the expectations of high school teachers and college teachers. "College instructors are more likely to emphasize a series of key thinking skills that students typically do not develop intensively in high school” (Conley, 2010, p. 43). In higher education, the instructors expect students to think critically and analytically, to make inferences, to support arguments with evidence, and to solve complex problems, to conduct research, and to "generally think deeply about what they are being taught” (Conley, 2010, p. 43) as much as or more than specific content knowledge taught in the class.

Although a number of states and higher education faculty and staff have attempted to define college readiness by describing the skills and aptitudes that high school graduates should possess upon their entrance to college, having a clear and specific definition of what is meant by college ready is difficult to establish because there are numerous definitions, with no broad unanimity on which one is the most fitting (Olsen, 2006). Roderick, Nagaoka, and Coca (2009) reported that ensuring that students are prepared for college requires an understanding of what it means to be college ready and must begin by being "explicit about precisely which sets of knowledge and skills shape college access and performance and how best to measure those skills” (p. 189). According to Roderick et al., (2009) the three most typical methods colleges use for defining readiness are coursework required for college admission, test scores, and grade point average (GPA). Achieve (2009) defined college readiness as being "prepared for any postsecondary education or training experience, including study at two- and four-year institutions 
leading to a postsecondary credential” (p. 1). ACT (2005b) defined college readiness as the level of background knowledge that a student needs to be prepared to enroll and succeed, without remediation, in a credit-bearing course at a two-year or four-year institution or technical/vocational training program. In the ACT (2010) report The Condition of College and Career Readiness, college readiness was defined as students having approximately a 75\% chance of earning a grade of $\mathrm{C}$ or higher or a $50 \%$ chance of earning a grade of B or higher in first-year college courses such as English and Algebra. Patrick Callan, Center for Public Policy and Higher Education, defined college readiness as "the ability to do credit-bearing work in the most accessible higher education institutions in the state the day you enroll” (Olsen, 2006, p. 5).

Other definitions of college readiness appear in the literature. Greene and Forster (2003) stated that college readiness is a combination of three factors: the student must have graduated from high school, taken advanced courses in high school that reflect the minimum admissions requirements for college, and demonstrated basic literacy skills. A high school diploma is only one component of the formula for college readiness. Greene and Forster (2003) indicated that high school coursework should include a minimum of four years of English, three years of math, and two years each of a natural science, social science, and a foreign language if the student seriously plans to master college-level work after high school. A student passes the third test of readiness if National Assessment of Educational Progress (NAEP) reading scores exceed a basic level of literacy (Greene and Forster, 2003); NAEP reading achievement levels are designated as basic, proficient, and advanced, and scores are determined by student performance on a variety of reading questions.

Conley (2010) defined college readiness as the "level of preparation a student needs in order to enroll and succeed—without remediation—in a credit-bearing course at a postsecondary 
institution that offers a baccalaureate degree or transfer to a baccalaureate program” (Conley, 2010, p. 21). Conley further suggested that college readiness is also the result of other skills that students should gain from their learning experiences in secondary education, including cognitive skills, content knowledge, thinking skills, and "college knowledge” (p. 4) which encompasses an understanding of how postsecondary institutions operate. The importance of understanding postsecondary systems and the cultures, norms, values, and traditions operating within colleges and their relationship to students' academic and social integration and subsequent success are also supported in the research of Kuh et al. (2007) and Napoli and Wortman (1996).

Baker, Clay, and Gratama (2005) suggested that college readiness consists of three critical components: college awareness, college eligibility, and college preparation. In addition, the authors asserted that all three components must work together in a cooperative and harmonious manner throughout the students' secondary experience in order to guarantee their postsecondary success (Baker et al., 2005).

Regardless of which definition for college readiness is commonly adopted, all colleges will make significant gains if parents and students know the distinctions between college entry requirements and college readiness (Spence, 2009). Students who have expressed interest in pursuing college have mistakenly assumed, along with their parents, that meeting high school graduation requirements indicates that they are college ready (Conley, 2010). Furthermore, community colleges will make significant gains in instituting their integrity and quality through "establishing distinctions between admission and readiness standards by adopting common and significant statewide readiness standards” (Spence, 2009, p. 100). Spence acknowledged that concerns about "access — the tensions between access and sending signals about readiness (or 
placement) — is a major reason that community colleges have been reluctant to join statewide college readiness initiatives across the nation” (p. 100).

College readiness and pre-college mathematics preparation. Creating conditions that foster college readiness are established years before students attend college. Research indicates reports that there is no substitute for rigorous precollege preparation in elementary and secondary school, particularly in the areas of math and reading (Kuh et al., 2007). In Student Success in College: Creating Conditions That Matter, Kuh and associates (2010) reported that the most significant predictors of post-secondary school success are academic preparation and motivation. Adelman's (1999; 2006) research on college completion also indicated that a combination of the students' high school courses, motivation, and academic performance significantly influences degree attainment. Unfortunately, a high percentage of high school graduates across the nation do not enter college academically prepared to meet the rigors of college and they do not possess high levels of intrinsic motivation, a driving force that enables individuals to achieve goals. High school students vary in the degree to which their high school experience prepares them for postsecondary schooling. Students’ preparation for college or lack thereof has a significant effect on the transition to college and whether they succeed. Conley (2010) indicated that "only 60 percent of students from minority groups and low-income families can expect to graduate from high school, only one in three will enroll in college, and only one in seven will earn a bachelor's degree” (p. 28).

Research provides evidence of the impact of advanced mathematics upon postsecondary enrollment and completion; students who take rigorous mathematics courses are more likely to go to college than those who do not (Adelman, 1999; 2006). Adelman indicated that advanced mathematics is the major factor associated with bachelor degree completion. In fact, research on 
course-taking patterns has consistently shown that enrollment in advanced-level mathematics is related to college attendance, persistence, and degree attainment (Adelman, 1999; 2006). Furthermore, Adelman (1999) reported that "of all the components of curriculum intensity and quality, none has such an obvious and powerful relationship to ultimate completion of degrees as the highest level of mathematics one studies in high school” (p. 6). Students who complete highlevel mathematics and science courses beyond the required graduation requirements are more prepared for college and careers than those who only complete mathematics and science courses required in the core curriculum (ACT, 2009). Findings from an ACT (2009) study emphasized the need for states and secondary schools to focus their direction on the skills and knowledge essential for college readiness; the report also indicated that lack of college readiness is most evident in the areas of math and science. Although the ACT report indicated a modest increase in students attaining proficiency on all four benchmarks, the report also suggested the need for improvement in college readiness, particularly in math and science. Only 42 percent of the nearly 1.5 million graduates who took the exam are prepared for college-level algebra (ACT, 2009). Across the country, the percentage of students meeting or exceeding the ACT College Readiness Benchmarks in Mathematics and Science is higher for those students taking advanced courses than for those students taking the core or less (ACT, 2009). An ACT College Readiness (2008) report indicated that 78 percent of high school graduates did not obtain the readiness benchmark levels for one or more entry-level college courses in mathematics. The report concluded that students obtaining a readiness standard in a subject have a 75 percent chance of earning a C and a 50 percent chance of earning a B in an entry level college course (2008). Conley, (2008) reported that students who are attentive to details and possess an understanding 
of the concepts, principles, and techniques of algebra are more likely to succeed in college level math courses:

Students who exhibit college readiness possess more than a formulaic understanding of mathematics. They have the ability to apply conceptual understanding in order to extract a problem from a context, solve the problem, and interpret the solution back into the context. They know when and how to estimate to determine the reasonableness of answers and can use a calculator as a tool, not a crutch. (p. 8)

Algebra is recognized as the gateway to advanced mathematics courses (Smith, 1996;

Silver, 1997) and completion of Algebra II is significantly correlated with college success (Achieve, 2006). Students who successfully complete Algebra II are less likely to need remediation upon entry to college and are more likely to remain in college and earn a bachelor's degree (Fong, Huang, \& Goel, 2008). Evan, Gray, and Olchefske (2006) reported that successful completion of Algebra II was particularly relevant for improving college readiness among minority students. Moreover, students' enrollment in upper level math courses beyond Algebra II is an important influence on degree attainment because students with advanced math skills can be expected not only to perform better during each successive grade level, but are expected to take additional math courses as they move toward their senior year in high school. Zelkowski's (2010) research on secondary course enrollments in mathematics indicated that continuous enrollment in high school mathematics is linked to college completion. According to Zelkowski (2010) focusing on "the continued development of critical thinking skills through challenging mathematics courses” (p. 18) is essential during all four years of high school.

Research from The Toolbox Revisited discussed the impact of challenging coursework upon college readiness (Adelman, 2006). Completing high-level mathematics courses in high 
school, including Algebra II, pre-calculus, trigonometry, and calculus are the best predictors of succeeding academically in college (Adelman, 2006). Adelman supported completion of a minimum of 3.75 years of mathematics, with the highest level of math taken to include trigonometry, pre-calculus, or calculus. Students who study advanced courses such as trigonometry and calculus are better prepared for college-level math courses. Schiller and Muller (2003) reported "the mathematics courses students take in high school affect their academic achievement and their admission to competitive postsecondary schools and professional programs” (p. 300).

Readiness and advanced courses in mathematics and science. Completion of Advanced Placement (AP) coursework in mathematics and science in high school is also linked to pre-college preparation and college readiness. Adelman (2006) recommended that students complete coursework in at least two or more AP mathematics and science courses. The National Science Foundation (2007) indicated that college readiness among high school students will increase if the number of students who take AP courses in mathematics and science increases. Kuh (2007) reported that if students perform poorly in advanced mathematics classes (precalculus, trigonometry, and calculus), "interventions later usually have only modest effects on their chances to complete a baccalaureate degree” (p. 4). According to the National Science Foundation (2007), high school students who pass an AP exam are three times more likely to persist until degree attainment than those who do not pass the AP exam. For African American students, the percent is even greater; passing an exam makes it four times more likely that the student will earn a college degree (National Science Foundation, 2007).

Challenges, functions, and costs of college remediation. "The needs of American high school students for remediation after high school have become a matter of increasing interest and 
concern among policymakers” (Conley, 2010, p. 15). Each year, thousands of students enter college academically underprepared for the rigors of college level work (Greene \& Forster, 2003). Although nearly two-thirds of high school graduates enter college each year, nearly fifty percent of these students require some type of remedial or developmental coursework (Horn \& McCoy, 2009). Students who are required to take two or more remedial or developmental courses are unlikely to earn a college degree (Olsen, 2006). Strong American Schools (2008) reported that although an overwhelming majority of students who enroll in college expect to obtain a bachelor's degree, those students who are required to take remedial classes are far more likely to dropout than students who report to college academically prepared. Nationally, only 20 percent of students who take two remedial classes, excluding a remedial reading course, earn a bachelor’s degree or higher (Conley, 2010, p. 27). More than one-fourth of four-year college students who are required to take three or more remedial classes depart from college after the first year (Adelman, 2006).

The literature indicates a variety of reasons why students lack college readiness. Levin and Calcagno (2008) reported that large numbers of students that are accepted into colleges lack academic skills that are basic to learning, such as those used in mathematics, reading, and writing. Kirst and Bracco (2004) asserted that students are entering college unprepared for college-level work due, in part, to a "historical split between levels of our educational system and the subsequent lack of communication and connection” (p. 2) between secondary and postsecondary educational systems. According to Conley (2010), high school grades are not good predictors of whether incoming freshmen are prepared for college-level work. A 2007 report from the California State University (CSU) system indicated that the average grade point average of students requiring remediation at their institute was a B average, nearly 3.15 on a 
four-point scale (Conley, 2010, p. 27). Conley (2010) reported that it is extremely frustrating for students and parents when students do well in high school, earning satisfactory to above average grades, yet are placed in remedial classes in college because they are not adequately prepared for college-level work even though their high school grades suggested that the students were ready for college.

Developmental or remedial education has become an essential component of higher education for students who are underprepared academically for college-level work (Attewell, Lavin, Domina, and Levey, 2006). According to Grubb and associates (1999) remediation is defined as a class or activity intended to address the needs of students do not have the skills or experience to complete college-level work. Remedial classes are designed to meet students' academic deficiencies by teaching them concepts and skills that they were unable to master during their secondary education, thus preparing students for success in credit-bearing courses at the college level (Bettinger \& Long, 2008). According to McCabe (2003), remediation represents a nationwide endeavor to provide minimum levels of reading, writing, and math skills. Day and McCabe (1997) described remediation as critically important for individuals who lack minimum competencies in fundamental subjects.

Conley (2010) reported that many students are required to take some type of remedial coursework in mathematics before they can take credit-bearing courses in mathematics. According to Conley, students who are college ready have more than a "formulaic understanding of mathematics: they have the ability to apply conceptual understanding in order to extract a problem from a context, use mathematics to solve a problem, and then interpret the solution back into the context” (p. 37). Unfortunately, the rate for successfully passing college level mathematics courses is low. In fact, the number of students required to take some type of 
remedial or developmental postsecondary coursework in mathematics is staggering. Research indicates that more students require remediation in mathematics more than any other subject (Adelman, 2006). About one third of high school graduates in the U.S. who enroll in college are required to take one or more remedial mathematics courses (Strong American Schools, 2008).

Colleges and universities in the United States devote significant resources for remedial or developmental mathematics instruction. Students who report to college unprepared for collegelevel mathematics are not allowed to enroll in credit-bearing mathematics courses until they complete prerequisite remedial courses or exhibit that they can manage college-level mathematics without remediation (Achieve, 2006). About one third of high school graduates in the U.S. who enroll in college are required to take one or more remedial mathematics courses (Strong American Schools, 2008). This poses a particular challenge at the community college level where an open admissions policy allows students with academic deficiencies to enroll.

Although most American colleges and universities offer some form of remedial or developmental education; the issue of college remediation has increasingly sparked controversy (Attewell, Lavin, Domina, \& Levey, 2006). Bettinger and Long (2005) reported that there is a growing argument about the effectiveness of remedial programs. Proponents of remediation discuss the practical and economic factors, while opponents of remediation argue that secondary schools should have adequately prepare students for college and careers, eliminating the need for remediation at the postsecondary level. Gaither (1999) supported preserving and widening remedial education at postsecondary institutions because it provides students with access to higher education, and it is a practical and economical way to help underprepared students remain in college. Soliday (2002) wrote that remedial courses help underprepared students attain the skills needed to succeed at college. Other supporters of college remediation point out that 
remediation helps minority students, students from lower socioeconomic families, and students for whom English is a second language (ESL) have access to college, as well as the opportunity to earn a college degree (Attewell et al., 2006). Gaither (1999) indicated that college graduates earn approximately one million dollars more over the duration of their lives than high school graduates earn (Gaither, 1999).

Conley (2010) asserted that "essentially all students should be capable of pursuing formal learning opportunities beyond high school” without remediation (p. 1). Conley further declared, "relying on remedial education to solve the problems of inadequate preparation in high school does not seem to be a viable policy” (p. 29). Finally, Conley suggested that remedial education does not effectively help students, particularly first-generation college students, move through college to degree completion in a timely or efficient manner.

The costs of college remediation to students, the institutions, and states are significant. First, remediation is costly to students because the courses usually do not confer college credit. In addition to the tuition and fees that students have to pay for non-credit courses, it is also important to consider the loss of time and the potential earnings that students lose when they are enrolled in remedial coursework (Brenneman \& Haarlow, 1998). Finally, it is important to consider the economic and social costs that occur as a result of students leaving college without a degree. On a national level, the cost of developmental or remedial education is monumental. Conservative estimates placed the cost of remedial programs at postsecondary institutions at one to two billion dollars annually, and the public and private costs at nearly 17 billion dollars annually (Brenneman \& Haarlow, 1998). According to a Strong American Schools report (2008), the cost of remediation in public colleges exceeds two billion dollars. In addition, total remediation costs per students are “estimated to be between $\$ 1,607$ and $\$ 2,008$ for public two- 
year institutions and between $\$ 2,025$ and $\$ 2,531$ for public four-year institutions” (p. 3).

Moreover, the total costs to students and families are estimated at nearly 800 million dollars in tuition and fees for developmental education (Strong American Schools, 2008).

Community colleges and remedial education. Community colleges serve as a pathway to a bachelor's degree for students whose family, financial, or personal circumstances prevent them from attending four-year institutions (Boylan, Bonham, \& White, 1999). Community colleges also function as the primary location in which developmental or remedial education for traditional-age and adult students who are not prepared for college-level work takes place (Bettinger and Long, 2005). Developmental education has become an essential component within community colleges. Under-prepared students are provided instruction in basic reading, writing, and math skills in order to help them master college-level curriculum. Although colleges attempt to increase students' academic readiness in a variety of ways, developmental education courses are the most evident form of remediation in community colleges.

One factor influencing the increasing demand for remedial education at community colleges involves their open access policy that allows students to enroll regardless of academic readiness. Spence (2009) reported that community colleges' open-door policy can lead to a public perception that community colleges lack appropriate criteria for admission; however, Spence (2009) indicated that although community colleges have an open access policy, college readiness standards are applied after the students' entry. Conley (2010) reported that remediation rates at community colleges are very high; some campuses have nearly 80 percent of their students taking remedial classes, particularly in mathematics (Conley, 2010). In addition, the majority of students enrolled in remedial courses, particularly those at community colleges, 
have multiple roles: student, often parent, and part time or full time employee (Boylan et al., 1999).

Developmental education at community colleges consists of a range of services that include remedial courses, tutoring opportunities, and learning centers (Boylan et al., 1999). However, institutional policies relating to developmental education in the United States are not consistent. At some institutions, developmental education is mandatory; at other institutions developmental education is voluntary (Horn \& McCoy, 2009). Oudenhoven (2002) reported that remediation is just one component of developmental education at community colleges; however, it has emerged as the most controversial part of developmental education programs. Kirst and Bracco (2004) suggested that open access institutions, such as two year community colleges, have the most significant problems with student readiness and completion (p. 3).

Researchers suggests that a main argument for maintaining remedial education at community colleges involves philosophical reasons for making community colleges the venue for remedial education (Bettinger \& Long, 2005). Many states, including Arizona, Florida, South Carolina and Virginia, do not offer remedial education at their public four-year universities (Bettinger \& Long, 2005). Other states, including California and New York, are making policy changes that will move remedial education to their community colleges (Bettinger \& Long, 2005). The more selective a four-year institution is, the less likely it needs to offer all types of developmental education, particularly remedial coursework. (Boylan et al., 1999).

A second argument for maintaining remedial education at community colleges involves the considerable savings that can result in taking the courses at community colleges, rather than at four-year institutions (Bettinger \& Long, 2005). Given the increasing needs of remedial education and the lower costs of community colleges, utilizing the state's community colleges as 
the main avenue for remedial education appears to be a cost-effective measure (Melguizo, Hagedom, \& Cypers, 2008). While proponents of maintaining remedial education at two-year institutions point out the substantial savings that can occur, opponents indicate that community colleges are not adequately equipped or funded to provide the educational services needed to support students who are not college ready (Astin, 2000). Moreover, critics point out that remedial courses at community colleges have large class sizes and are taught by individuals who are not highly qualified, such as adjunct or part time faculty (Bettinger \& Long, 2005).

\section{Secondary Schools and Mathematical Readiness}

The transition from elementary school to middle school is a crucial stage for mathematics placement. Elementary schools typically use within-class ability grouping which allows students to demonstrate their mathematical abilities within a heterogeneous setting (Mulkey, Catsambis, Steelman, \& Crain, 2005). In the elementary setting, all students are expected to gain a firm understanding of the mathematical skills and concepts presented (Dauber, Alexander, \& Entwisle, 1996). However, when students enter middle school, many school districts in the United States institute a formal tracking system because they believe it increases students’ achievement. Track placement is highly dependent on standardized tests, teacher opinions and recommendations, and parental influence (Unseem, 1992). Spears (1994) found that teachers who supported tracking by ability tended to be more subject focused, while those who supported eliminating ability grouping were more student centered.

Transition from elementary to middle school. Research indicates that students encounter major declines in academic achievement in the transition from elementary school to middle school (National Middle School Association, 2003; Gutman \& Midgley, 2000;

Anderman, Maeher, and Midgley, 1999). In the transition from elementary to middle school, 
students face many changes: teacher expectations, instructional approaches, work expectations, and reading levels of textbooks. In particular, students' attitudes, motivation, and self-concepts of ability towards mathematics and achievement appear to be seriously affected during the transition (Akos, Shoffner, \& Ellis, 2007). Research from Rising above the Gathering Storm (2007) indicated that the performance of American students declines as they progress from elementary school to middle school to high school.

Tracking in middle schools. One factor associated with declining achievement and attitudes toward mathematics involves how students are placed in academic classes at the middle school level. In many school districts, students who leave elementary school as low achievers in math are scheduled into low-track placements with students that have been determined as having similar abilities. Low-track placement such as tracking or homogeneous grouping involves separating students by academic ability into groups for all subjects. In this tracking system, students are assigned to a course according to whether their achievement is considered high, average, or low. Typically, students attend classes with only those students who have been grouped with them. Usually, these low-track placements are referred to as sections. The level of tracking within schools or school systems varies greatly. In some school systems, there is some fluidity in movement. Students may be assigned to a lower section or more advanced class for a subject and a higher section or a lower section for another subject.

Low-track classes typically feature a focus on basic level skills. Tracking "sequesters students into smaller, usually more homogeneous, reference groups where they are offered a restricted slate of courses” (Mulkey et al., 2005, p. 139). The classes are taught by teachers who are the least qualified, and there is a climate of low expectations (Heubert \& Hauser, 1999). In addition, Burns, Heubert, and Levin (2004), suggested that low-track placements reflect a 
number of assumptions: students cannot learn beyond a basic skill level, effective teachers are wasted on low achievers, and high expectations will hurt the self-esteem of lower-achieving students. The differences in math course selections, math content, and prerequisites that are introduced during middle school may make later movement to advanced mathematics courses much more difficult (Dauber et al., 1996). In those school systems that track or group students by ability level, it unlikely that students assigned to lower-level math classes will be changed to higher-ability sections without parental or school counselor intervention.

Students that are placed in lower-ability math classes have fewer opportunities to take advanced high school mathematics which can significantly impact college readiness; therefore, the transition to middle school and mathematics placement during grade six may critically impact postsecondary degree attainment (Akos et al., 2007). According to a report from the National Council of Teachers of Mathematics (2000), students are not learning mathematics with depth and understanding during their middle school experience. About one-fifth of the eighth grade students lacked the ability to perform even basic mathematical processes (National Science Foundation, 2007). Only one-third of eighth-grade students performed at or above a proficient level in mathematics (National Science Foundation, 2007). While the number of eighth grade students performing at the proficient or advanced levels in math increased between 1990 and 2007; only about 30\% scored at or above proficient (Radcliffe \& Stevens, 2008).

Research indicates that homogeneous grouping or tracking is not the best way to help all students, including students who leave elementary schools with basic math skills, develop a deep understanding of mathematics (Akos et al., 2007). Akos et al., (2007) examined mathematics sequence and found that some students are limited in quantity and quality of mathematics courses to which they may have access in high school (p. 239). Oakes (1992) argued that 
tracking has a negative effect on the motivation and opportunities of students placed in lower tracks. Essentially, the tracking and placement in middle school mathematics may create or cause achievement gaps. Tracking students may not only significantly contribute to low math performance at the middle level, it may significantly impact the number of upper-level high school mathematics courses that students take at the secondary level, hindering their capacity to meet the admission requirements to a four-year college (Oakes, 2005).

Kulik and Kulik (1984a) reported that students tend to learn more mathematics if they are placed in an accelerated track, even when their different ability levels are taken into consideration. Burris et al. (2006) reported that the "higher performance of students in high-track classes may very well stem from rigorous curricula and high expectations, not from the grouping practices in which students are sorted and selected” (p. 132). Hoffner (1992) examined whether tracking during middle school impacted the types of mathematics courses that students took during high school. Hoffner (1992) concluded no positive long-term effects for students in lower mathematics tracks; when he compared lower-tracked students to low-achieving students who were part of a heterogeneous setting, the lower-tracked students performed significantly worse than the non-tracked students. Burris et al. (2006) suggested that a "combination of detracking and "high-track" curricula is the best means of increasing student achievement" (p. 133).

Roe and Radebaugh (1993) conducted a study at a middle school that had eliminated ability grouping in core areas such as mathematics, language arts, and reading. According to Roe and Radebaugh (1993), teachers indicated that eliminating ability grouping improved the climate and culture within the classroom. Other research on secondary school mathematics tracking has indicated that it tends to adversely impact students in low-level courses compared with students in higher-level courses (Zevenbergen, 2005). Students in low-tracked mathematics 
courses are less likely to go to college, less likely to actually attend college, and have lower self efficacy (Riley, 1997). Moreover, studies suggest that mathematics tracking tends to widen achievement inequalities between high and low-tracked students (Oakes, 1992).

Findings from an ACT report, The Forgotten Middle: Ensuring that All Students are on Target for College and Career Readiness before High School (2008) indicated that when students' skills are improved during middle school, the results by the end of high school can be striking. Results provide evidence that if students' academic preparation increases by the end of middle school, their levels of readiness for college can increase substantially in high school. Moreover, students’ progress must be monitored so that academic deficiencies can be identified early and interventions can begin during middle-school (ACT, 2008). Moreover, ACT (2008) researchers concluded that although intervention is not the only solution to the college readiness problem, it is a key factor in ensuring that students will have the core skills they need to graduate from high school with the knowledge and skills required for postsecondary education.

Another crucial component of ensuring that students make a successful transition from elementary to middle school math involves the vertical alignment of the mathematics curriculum. Students will adapt to the transition from elementary school to middle school math if the math curricula has been aligned, and school systems have connected content, instructional materials, and class room environments (Schielack \& Seeley, 2010). The transition from basic math skills to algebraic concepts is an extremely difficult one for many students (Star \& Rittle-Johnson, 2009). However, curriculum alignment and improvements in the mathematics curriculum are essential if our schools plan on offering advanced math instruction, such as algebra, to middle school students. Curriculum alignment and improvements in algebra instruction are also needed if the United States is going to keep pace with other countries (Schmidt, Cogan, \& McKnight, 
2010). Internationally, the focus for eighth-grade students in many countries, with the exception of the United States, is algebra and geometry (Schmidt et al., 2010). Nevertheless, not all school districts in the United States are teaching what is considered eighth-grade content; in fact, the normal content covered in some eighth-grade classes is considered sixth-grade content internationally (Schmidt et al., 2010). Moreover, other countries are typically two grade levels ahead of the United States in terms of the rigor of their mathematics curriculum (Schmidt et al., 2010). Therefore, in addition to variations in students' opportunities to learn mathematics, there is variation in the mathematical content students learn by eighth grade (Schmidt et al., 2010).

Gamoran and Hannigan (2000) reported that completion of Algebra I by eighth grade increases mathematical ability of the middle school students. Competence in algebra is increasingly recognized as an important accomplishment in a student's middle school experience (Star \& Rittle-Johnson, 2009). For many students, Algebra I is the first math class that requires abstract thinking and critical thinking skills that are important for a deep understanding of mathematics (Vogel, 2008). Smith (1996) and Silver (1997) called algebra the gatekeeper course to advanced coursework in mathematics. Recommendations from a recent study on middle school education identified the need for all students to take an essential algebra course by the end of eighth grade (Maryland State Department of Education, 2008). Furthermore, Maryland's State Department's report, The Critical Middle: A Reason for Hope (2008) found that the "best preparation for the 21st Century's global economy is a strong background in math, for today's science and technical subjects require advanced mathematics, and algebra is the gatekeeper course for it” (p. 13).

Atanda (1999) indicated that students who took algebra in eighth grade were more likely to enroll in higher-level math classes in high school than those students who did not enroll in 
algebra in eighth grade. Kuh (2007) suggested that students who "do not attain grade-level proficiency in math by the end of the eighth-grade are much less likely to be college ready at the end of high school” (p.4). Moreover, an understanding of algebra by the end of one's middle years was instrumental for higher-level mathematics courses to be taken in high school; thereby increasing their chances that they would be college ready by high school graduation (Kuh, 2007).

Offering algebra to all students by grade eight can begin to address the decline of achievement in high schools in the United States. However, many school districts limit the number of students who have access to Algebra I by grade eight. Only those students who have demonstrated readiness or above-average mathematical ability and skills are permitted early access to algebra. This is due to homogeneously grouping students rather than heterogeneous grouping students at the middle school level. In homogeneous settings, students are grouped by ability which is usually determined by test scores, grades, teacher and school counselor recommendations, and parental influences. This grouping practice involves tracking high achieving and low-achieving students. Early access to Algebra I in middle school is, therefore, typically accessible to only the most advanced math students. Unfortunately, the sequential nature of mathematics prevents students from studying calculus in high school unless they study Algebra I by eighth grade; however, students who are willing to take more than one advanced course during their senior year in high school may be able to take calculus (Spielhagen, 2006).

Students who take a challenging curriculum, beginning in the middle school, tend to perform better academically in high school and are better prepared for college than those who take less rigorous courses (ACT 2004a). “A challenging curriculum helps students to stay focused throughout high school, builds their academic skills, helps them develop effective study habits, and keeps them engaged in school-related activities” (Wimberly \& Noeth, 2005, p. 4). 
Moreover, middle school students who take rigorous courses such as algebra can enroll in advanced mathematics courses in high school that align with courses necessary for college admission and success (Wimberly \& Noeth, 2005). Unfortunately, many middle school students do not take courses that will adequately prepare them for high school.

Mathematics and high risk groups. Many middle school students, particularly lowincome and minority students, lack mathematical fluency and math literacy skills necessary to function in an increasingly global economy (Kenney \& Silver, 1997). Mathematics achievement of economically disadvantaged students continues to struggle to maintain pace with students from higher socioeconomic households even after enactment of the 2002 No Child Left Behind legislation. Berry (2003) indicated that some improvement in the math achievement of lowincome students at the middle school level has occurred, but the improvement occurred only in the area of basic skills competence as opposed to higher order thinking skills and problem solving. Kenney and Silver (1997) found that most students can demonstrate basic mathematical facts ability, but experience difficulty with problem-solving applications and analysis.

School procedures for placement in mathematics courses may not be equitably applied at the middle school level, with students of low social economic status (SES), minority students, and females often prevented from taking a higher-level mathematics courses, in spite of evidence of ability (Akos et al., 2007). In addition, students "may be inequitably distributed among hierarchies of mathematics courses on the basis of race and economic background, becomingly increasingly stratified within these tracks" (Akos et al., 2007, p. 2). "Differences in mathematics achievement are not simply the result of differences in student ability and effort, but also matters of social factors such as poverty and housing patterns that influences where a student happens to attend school" (Schmidt et al., 2010, p. 19). 
In the article, "For High-Risk Groups, Success Gap in College Hinges on Readiness,” Gewertz (2010) examined findings from Mind the Gaps: How College Readiness Narrows Achievement Gaps in College Success, a study written by ACT (2010). Findings indicated that a challenging high school education substantially closes the achievement gap of students from low-income families, as well as students from some racial and ethnic-minority groups. Robert Moses (1989), founder of the Algebra Project, a program aimed at helping low-income students and minority students gain mathematical skills, described mathematical literacy as essential to 21st century citizenship. Moses (1989; 2001) reported that technology, with its emphasis on abstract symbolic representations, has increased the need for all students to be given equal access to learn algebra. Furthermore, fewer opportunities to learn challenging mathematics correspond to lower achievement; lower achievement is an enormous barrier to attainment of a college degree, upward mobility, and future opportunities in life (Moses, 1989; 2001).

Female students transitioning to middle school often experience a significant decline in their self-described ability in mathematics and mathematics self-efficacy (Akos et al., 2007). Gilligan, Lyons, and Hammer (1990) proposed that girls experience a decrease in self-esteem because of conflicting messages of inferiority, exclusion, and perceived gender roles. Leder (1992) discussed the direct and indirect factors that impact the differences in males' and females' attitudes toward mathematics. Leder’s (1992) research also indicated how gender differences impact participation in the most demanding and advanced mathematical courses. According to Leder (1992) females are capable of doing mathematics. However, they are more likely than males to choose not to participate in the most rigorous math courses, and females are less likely than males to engage in occupations for which advanced mathematical skills are required (Leder, 1992). 
Hanna (1996) also explored social and psychological factors that affect student achievement within the classroom. According to Hanna (1996) female and male students display different levels of confidence which affect their ability to succeed. Hanna (1996) wrote that females often believe their success is based upon luck, while their failure is attributed to poor ability. On the other hand, male students tend to believe their success is because of ability, and their failure is related to other factors such as poor teaching. In addition, female students often exhibited a general lack of self confidence even when they were successful in the classroom. Steele (1997) found that expectations about success in mathematics are influenced by stereotypes of male and female appropriateness of the subject. Males are expected to achieve in subject areas that have been labeled masculine such as mathematics, while females are expected to achieve in subjects that have been categorized as more feminine such as English.

Psychologist Albert Bandura (1986) defined self-efficacy as a belief in our ability to succeed in specific circumstances. Students' sense of self-efficacy can play a primary role in how they approach schoolwork, educational goals, and class room tasks. Academic self-efficacy involves the students' confidence in their ability to learn new skills and tasks in content areas such as mathematics (Midgley et al., 1998). According to Bandura's theory (1986), beliefs influence behavior. Students' beliefs in their ability to perform certain tasks influence the goals that the students will set; moreover, their beliefs influence how much energy or effort they will put into a certain task or goal. Students with low self-efficacy are more likely to view difficult tasks as something to be avoided rather than something to be mastered.

Middle school and college planning. Middle school is a critical period for early postsecondary planning (Camblin, 2003). An ACT (2005) report on issues in college success stated that students should begin college and career planning during middle school. Camblin 
(2003) proposed that the middle grades have a significant relationship to college readiness and access. It is during the middle level years that parents, students, and schools begin initiating serious discussions on different careers, academic requirements for those careers, and college information relevant to career choices (Camblin, 2003).

According to Cabrera et al., (2006) when students establish college plans during middle school, it "triggers a series of behaviors that puts students in a better position to secure the academic, social, and economic resources needed for the successful accomplishment of that goal” (p. 81). This process "peaks by ninth grade, when most students have developed educational and occupational aspirations that are contingent on college enrollment” (Cabrera et al., 2006, p. 81). Moreover, Conley (2010) proposed that a college awareness curriculum should be in place at the middle school level, beginning in grade seven and continuing in each consecutive year.

Although most students have postsecondary goals, many students and their parents fail to take practical or timely steps toward achieving those goals at the middle school level. Wimberly and Noeth (2005) argued that college awareness and preparation should begin during middle school. Researchers propose that while middle school students often express interest in going to college, they fail to concentrate their efforts on appropriate courses selections and school support that will help them achieve their college goals (Cabrera \& La Nasa, 2000). Moreover, many students, particularly low income and minority students, tend to be the least likely to engage in early educational planning (Wimberly \& Noeth, 2005). Research provides evidence that underserved students, low-income, first generation to attend college, and minority students do not enroll in college or persist to graduation at the same rate as their white or more affluent peers 
(Riley, 1997). Research also suggests that this inconsistency is due, to a large degree, to the lack of opportunity for disadvantaged students beginning in middle school (Riley, 1997).

The National Middle School Association (2003) reported that the passage from elementary school to middle school has been associated with a decline in academic performance, motivation, and self-efficacy. Camblin (2003) suggested that students begin defining their worthiness in terms of competency and skills during middle school; these beliefs about their abilities influence whether students feel competent enough to take challenging courses during high school. Subsequently, these perceptions of being competent or possessing the required skills and qualifications further impact course selections during high school, and these decisions influence whether students believes they have the academic ability to pursue post-secondary education. In addition, parental involvement also typically tends to decrease during the middle and high school levels. As a result, parents may not have timely information about college planning or understand the importance of course selections upon college readiness; this lack of knowledge and involvement could adversely affect educational decisions that parents and students make during middle school (National Middle School Association, 2003).

Middle schools can play a keen role in initiating early preparation for college by promoting academic preparation and achievement, creating a college culture by providing college and career planning information, helping students understand the process for postsecondary planning, working with parents and students in creating a concrete plan for meeting their post-secondary goals, and encouraging parental involvement at the middle school level (Wimberly \& Noeth, 2005).

School counselors and mathematics course taking patterns. School counselors play an important role in implementing programs that help students make a successful transition from 
elementary to middle school and middle school to high school. School counselors can significantly influence decisions made regarding students' course placements in mathematics during the critical transition periods of elementary to middle school and middle school to high (Bowers \& Hatch, 2005). Akos et al., (2007) indicated that the transition to middle school has a major influence on a student's educational path in mathematics due to the typically sequential nature of the courses to which students are assigned. Research indicates that students are more likely to become knowledgeable of and prepared for education beyond high school when teachers, counselors, administrators, and members of the community work together with the students (Cabrera et al, 2006; Cabrera \& La Nasa, 2001).

Bowers and Hatch (2005) suggested that school counselors can be instrumental in ensuring that all students have equitable access toward courses and curricula that will prepare them for high school, as well as college. School counselors can also help students develop educational goals, identify career interests, and distribute information to students and their parents about postsecondary education. In addition, school counselors can help increase the selfefficacy beliefs of all students, including girls and minority students, regarding their ability to succeed with higher-level mathematics courses (Akos et al., 2007). School counselors can help students improve their academic achievement by implementing individual, group and classroom interventions that deal with cognitive, social, and self-management skills that are associated with academic success.

School counselors can inform and advise students and parents effectively by advocating for higher placements in mathematics for all students (Rosenbaum, 1999). School counselors can help students, parents, teachers, and educational leaders understand that higher mathematical expectations should be for all students, not just the most advanced students. Research supports 
that students who intend to pursue a four-year college degree but decide against taking rigorous math courses are jeopardizing their educational and career goals (Rosenbaum, 1999). Therefore, school counselors can help students discover the factors impacting the students' scheduling decisions and educational planning.

Trusty and Niles (2003) reported that school counselors have a critical role in knowing students' long term math achievement and aptitude and helping students develop individual plans that will help them succeed at the high school and post-secondary level. During high school, most students are required to take standardized tests in mathematics. School counselors can use assessment results to inform students and their parents of academic strengths and weaknesses, intervention options, and post-secondary expectations and requirements (Wimberly \& Noeth, 2005). In addition, counselors can use assessment data to guide students and their parents in appropriate course selections that will help them succeed at the post-secondary level (Wimberly, 2003). Moreover, individual advising and planning for students from lower socio-economic backgrounds or at-risk groups, such as Latino and African American, are essential if students are to understand the impact of taking advanced courses in mathematics during high school and college readiness (Trusty \& Niles, 2003).

Parental involvement and mathematical placement. Parents play a powerful role in providing academic assistance, encouragement, and support that can ultimately influence their child’s self-efficacy beliefs and behaviors about academic achievement, mathematical placement, and college readiness. (Friedel, Cortina, Turner, \& Midgley, 2010). In fact, parental involvement and encouragement are significant to whether or not students initiate the college planning process during their middle school years (Cabrera \& La Nasa, 2001). According to Horn, Chen, and Chapman (2003), almost all parents of middle school students have aspirations 
that their child will continue with their education past high school; moreover, almost all parents of middle school students believe that a college education is crucial for success in the $21^{\text {st }}$ century.

Parental involvement affects mathematics placement and performance of middle school students (Akos et al., 2007). Students from higher socioeconomic families are likely to be elevated in course placements in some degree because of their parents' efforts to ensure that they are enrolled in advanced coursework. Burris's (2003) study on math achievement indicated that parents significantly influence whether a child has access to algebra during middle school. Parents who have expectations that their children will attend college may intervene more in the children's educations, even contacting the school to discuss mathematical placement decisions (Dauber et al., 1996). Useem (1992) reported that significant correlations between parents’ educational levels and their children’s placement in mathematics courses. In fact, research suggests that parents' lack of involvement and reluctance to intervene has a greater influence on placement in a lower-level mathematics course than does mathematical ability (Useem, 1992).

Parents with four year or advanced college degrees tend to be more aware of the importance of academic choices and are more likely to be involved in the selection of their child's academic courses. Parents that are well-educated tend to be more aware of their child's mathematical placement, more apt to negotiate on the child's behalf concerning their placement, and assume a more confident and secure attitude about intervening in educational decisions made at the school level (Unseem 1991). Kelly’s (2001) research supported previous studies on parental involvement and mathematical placement, indicating that "students of higher social class have a huge advantage in attaining placement in elite mathematics sequences” (p. 19), regardless of their grades and standardized test scores. Heyns (1974) found that students from 
more affluent backgrounds are more likely to be placed in high mathematical classes than students from less advantaged socio-economic backgrounds due to parental involvement and influence.

Lareau (1989) used the concept of "cultural capital” to discuss how parents that have greater social status, through wealth or education, use their status to influence their child's placement in school. Lareau (1989) found that parents with higher levels of education are much more likely to be knowledgeable about school policies, their child's academic performance, and the formal and informal networks of communication that keep them abreast of school information that could potentially maximize their child's achievement and mobility in school. In contrast, parents who do not have post-secondary expectations for their children may not “believe that intervention in their children's school performance or placements is necessary or useful or even think to address educational issues that way” (Dauber et al., 1996, pp. 297-298). Moreover, students in the lowest tracks were more likely than students in higher mathematics tracks to live in a single parent household (Unseem, 1990).

Research indicates that high levels of parental involvement and support increase the rate of low-income students and students of color who are able to gain access to four year institutions (Cabrera \& La Nasa, 2001). According to Holcomb-McCoy (2010), parental awareness and knowledge about college planning are beneficial and fundamentally important for students, particularly low-income students and students of color, to gain college access and experience success at the post-secondary level.

Influence of teachers upon achievement in mathematics. Research indicates that teachers significantly influence student attitudes, cognitive development, and mathematical achievement (Schoenfeld, 2002; Morgan \& Ritter, 2002). According to Morgan and Ritter 
(2002), teachers' qualities and attributes have "significant and long-lasting effects on student achievement” (p. 7). Furthermore, the teachers' training and classroom experiences affect “teaching style, practice and materials used in the traditional classroom” (Morgan \& Ritter, 2002, p. 17). Unfortunately, not all schools in the United States have equal access to the most highly qualified teachers. Many students in secondary schools are taught mathematics by teachers who do not possess teacher certification in mathematics. In the report, Collaboration: Closing the Effective Teaching Gap, the authors concluded that achievement gaps in mathematics are due to a lack of highly qualified teachers in mathematics (Berry et al., 2009). At the middle school level, the number of individuals teaching out-of-field is more staggering (Ingersoll \& Gruber, 1996). Moreover, schools that serve high populations of economically disadvantaged and minority students have mathematics classrooms that are likely filled by uncertified and inexperienced teachers (Berry et al., 2009).

Schoenfeld (2002) reported that teaching mathematics is complex and difficult because it requires a thorough understanding of mathematics. Inexperienced and uncertified teachers, as well as certified mathematics teachers who learned a traditional mathematics curriculum, may lack a deep understanding of mathematics necessary to facilitating lessons that engage students in mathematical concepts and operations in significant or purposeful ways. Students who believe that their teacher expects them to solve a math problem in a specific way may stop trying to make sense of the concepts and will work toward meeting the teachers' expectations. On the other hand, math teachers need to be able to recognize when students are struggling in their mathematical thinking, confusing themselves or other students. When this occurs, the teacher needs to redirect students to keep them from confusion and frustration. 
Schoenfeld (2009) indicated that mathematics teachers influence student attitudes and achievement by how they teach. Additional research indicated that teachers at the secondary levels placed higher emphasis on performance goals and less on mastery goals than do elementary school teachers (Midgley et al., 1995). Other research provides evidence that classroom instruction that focuses almost entirely on the lowest levels of cognition, such as knowledge and recall, minimizes or limits students’ problem-solving capabilities, academic challenges and opportunities for mathematical development (Schoenfeld, 1992). Ojose (2008) suggested that students in upper middle school grades possess higher order thinking skills and abstract thought patterns that enable them to apply knowledge, generalize, make inferences, and evaluate. Cross (2008) wrote that teachers who foster the development of student-centered classroom environments that focus on the development of problem solving skills help students to become effective mathematical thinkers. Burns and Sibley (2000) suggested that a student's comprehension of mathematical operations can be enhanced through a variety of classroom experiences, including "hands-on experiences and multiple ways of representing a mathematical solution" (p. 55). Ojose (2008) explained that hands-on activities "provide students an avenue to make abstract ideas concrete, allowing them to get their hands on mathematical ideas and concepts as useful tools for solving problems” (pp. 27-28).

Schoenfeld (2009) suggested that a central component of teaching is about helping students to "become open-minded and inquisitive thinkers who are willing to — even hungry toask questions, gather evidence, and sort through ideas in a reasoned way” (p. 27). Schoenfeld reported, "it’s about questions as much as answers, about values as much as facts” (p. 27). Schoenfeld also maintained "every math class shapes the identities of the students within it" (p. 28). "When you understand a mathematical idea, it makes sense and there's almost no 
memorizing to be done” (p.28). Other research involving middle school students indicates that teachers have a pronounced role in proactively facilitating mathematical lessons that encourage students to use higher order thinking skills such as forming conclusions, judgments, or inferences from facts or arguments (Weber et al., 2010). Students who believe that their math teacher encourages discussion of mathematical ideas and reasoning skills are more likely to share mathematical ideas and processes during class (Weber et al., 2010).

On the other hand, teachers who insist that students memorize information without really understanding the mathematical ideas or principles involved can create feelings of intense frustration or helplessness about mathematical ability for their students (Schoenfeld, 2009). Teachers who place emphasis on knowledge, rote or memory skills deny students opportunities to develop as mathematical thinkers. Research indicates that secondary teachers can significantly influence student achievement in mathematics by creating classroom environments where student's mathematical conceptions are encouraged and respected and where emphasis is placed on mastery learning and improving understanding in mathematics. In engaging student learning environments, math teachers can increase students' low self-efficacy beliefs that may have resulted from negative experiences in previous math classes (Friedel, Cortina, Turner, Midgley, 2010). 


\section{Chapter Three: Research Design and Methodology}

The main problem addressed in this study was how educators can best prepare students for college readiness. Since college readiness is highly dependent upon math achievement in middle schools, post-secondary educators need more research that explores how middle school math curricula may ultimately impact the readiness of their college students. This chapter describes the research design that was employed in the study. It includes a description of the sample and the instruments, data collection and analysis techniques, and limitations of the study.

\section{Restatement of the Problem}

Middle school is a critical time for early postsecondary preparation (Wimberly \& Noeth, 2005). Students who enter high school unprepared for advanced course work in mathematics are unlikely to be college ready by the time they graduate from high school. Because completion of advanced mathematics courses is related to college readiness and degree completion, it is important to examine factors that significantly influence math-related college readiness as evidenced by coursework taken beyond Algebra I. Adelman’s (1999) work indicated that taking a full schedule of academically demanding courses in high school, including mathematics beyond Algebra II, is a strong predictor in determining if students will attain a baccalaureate degree.

\section{Significance of the Problem}

One of the strongest factors associated with attainment of a college degree is the completion of advanced secondary mathematics courses. According to Smith (1996) and Silver (1997) algebra is the gatekeeper course to advanced study in mathematics. Research indicates that the level of academic achievement that students attain by grade eight has a larger impact on their college readiness by the time they graduate from high school than anything that happens 
academically in high school (ACT, 2009). Adelman (1999) concluded that completion of an advanced high school course beyond Algebra II had greater influence on college degree completion than factors such as socioeconomic status, ethnicity, or parents' educational backgrounds. Therefore, mathematical programs must widen their goals to include, among others, algebraic thinking, statistical reasoning, probability, and problem solving in order to maximize students' opportunities for success in the $21^{\text {st }}$ century (English, 2002). Opportunities for all students to access these key mathematical concepts and processes should be a principal goal of all mathematics programs at the elementary and secondary education levels. The value of learning mathematics in today's global society—-a society of extraordinary and accelerating changes—-has never been greater and will continue to increase dramatically” (McKinney \& Frazier, 2008, pp. 207-208). A "lack of mathematical competence and credentials constitute a barrier to full participation in the economic mainstream” (Schoenfeld, 2002, p. 3).

One current practice that many school districts in the United States public schools use is traditional grouping practices or tracking within the middle school setting that significantly limit the number of students who have access to Algebra I during seventh or eighth grade. In school districts that use tracking methods, usually referred to as traditional or homogeneous grouping practices, algebra is not available to every student; only the students deemed the most advanced math students by their teachers or school counselors are encouraged to enroll in Algebra I by the eighth grade. Students who are not encouraged to take algebra are enrolled in a general gradelevel math class. These students then take Algebra I in grade nine. The course pattern for these students typically includes algebra in ninth grade, geometry in tenth grade, and a return to a more advanced algebra course in grade eleven (Schoenfeld, 2002). In this traditional curriculum, algebraic and geometric problems are not applied together, but as separate courses; only students 
who have access to Algebra I by the seventh or eighth grade will have the opportunity to take the highest level of math offered at the secondary level—calculus (Burns et al., 2004). A traditional mathematics curriculum encourages “differential participation” (Schoenfeld, 2002, p. 3); it becomes an issue of inequality and injustice, impacting students' educational opportunities and college readiness.

The National Association of Secondary School Principals (NASSP) report Making the Mathematics Curriculum Count indicates that increasing mathematics rigor across the nation will require widespread changes within school districts (Richardson \& Mero, 2007). Therefore, rather than placing only the most advanced students in algebra in middle school or worrying about whether students with less mathematical proficiency will receive lower grades, possibly, it would be more beneficial to expose all students to algebraic concepts and mathematical reasoning skills during elementary and early middle school grades so that all students have a greater level of preparedness for algebra during their middle school experience. Thus, the transition from middle school to high school would become just as important as the transition from high school to college (ACT, 2009).

\section{Research Question}

1. Which factors (math achievement, high school algebra score, curricular rigor, sequencing of math courses, and school attendance) are most closely associated with math-related college readiness as evidenced by advanced mathematics coursework taken beyond Algebra I for students in Allegany County Public Schools, Allegany County, Maryland? 
The following null and alternative hypotheses are used to address this research question:

\section{Null Hypothesis}

$\mathrm{Ho}_{1}$ : There is no statistically significant degree of association, as evidenced by CHAID analysis, between math-related college readiness, and a set of independent variables, including math achievement, high school algebra score, curricular rigor, sequencing of math courses, and school attendance.

\section{Alternative Hypothesis}

$H a_{1}$ : There is a statistically significant degree of association, as evidenced by CHAID analysis, between math-related college readiness, and a set of independent variables, including math achievement, high school algebra score, curricular rigor, sequencing of math courses, and school attendance.

\section{Research Design}

This study used a quantitative research design to determine the level of association between the dependent variable and independent variables. The study examined the factors that most significantly influence math-related college readiness as evidenced by advanced mathematics courses taken beyond Algebra I during high school. In addition, the degree of association between college readiness and a set of independent variables, including math achievement, curricular rigor, sequence of math coursework, and attendance, were analyzed. Moreover, the study considered the affect of homogeneous grouping or tracking during the students’ middle school experience upon subsequent math course selections of high school seniors.

Institutional approval. The researcher obtained written permission to conduct the research study from the Chief Academic Officer of the Allegany County Public School System, 
Allegany County, Maryland (Appendix A). The researcher applied and was approved for exempt status by the West Virginia University Institutional Review Board (IRB) for the Protection of Human Subjects (Appendix B).

Population and sample for the study. The participants in this study were the 2010 and 2011 high school graduates from three comprehensive high schools and a career center in the Allegany County Public Schools in Maryland. Students who received special education services and were identified as being on non-diploma status were excluded from the study. However, students who took the MOD-MSA or MOD-HSA were included. The MOD-MSA or MOD-HSA assessments are alternate assessments for students receiving special education services who meet eligibility requirements. These assessments are based upon grade level content standards and modified academic achievement standards. The alternative school was excluded from the study because twelfth-grade students do not attend the alternative school. Students in grades nine through 12 attend one of the three high schools: Allegany, Fort Hill, or Mountain Ridge. Students in grades 11 and 12 have the option of attending the Center for Career and Technical Education (CCTE). Students who attend CCTE during grades 11 and 12 receive both their academic classes and a technical skill area program.

A student in Allegany County, Maryland must earn a minimum of 21.5 credits beyond the eighth grade to graduate. Participants in the study were required to complete three years of high school mathematics as well as a high school assessment in algebra/data analysis. Advanced high school math courses included the following: Algebra II, Honors Algebra II, Geometry, Honors Geometry, Trigonometry/Pre-calculus, Honors Trigonometry/Pre-calculus, Honors Calculus, AP Calculus, College Algebra, and College Probability \& Statistics. College Algebra and College Probability and Statistics are dual enrollment courses. 
Students in Maryland schools are also required to take assessments during middle and high school. The Maryland School Assessment (MSA) is a test of reading and math achievement at the elementary and middle school levels that meets the testing requirements of the federal No Child Left Behind Act of 2001. The test is given each year in early March in grades three through eight. Students enrolled in eighth-grade mathematics and eighth-grade students enrolled in Algebra I take the MSA. The content and format of the MSA help prepare students for success on the high school assessment.

The Maryland High School Assessments (HSA) are tests that measure school and individual student progress toward Maryland's High School Core Learning Goals in the core areas of English, government, algebra/data analysis, and biology. Students take each test whenever they complete the course. Therefore, students who take algebra in eighth grade take both the MSA and HSA (Maryland State Department of Education, 2010).

The MSA and HSA contain multiple-choice questions and questions requiring written responses. The two assessments provide schools, teachers, and parents with information regarding student performance and subgroup performance. Questions on the assessments are based on the content outlined in Maryland's Core Learning Goals (Maryland State Department of Education, 2010).

\section{Data Analysis Method}

CHAID, Chi-square Automatic Interaction Detection, analysis was used to determine those variables that were most significantly associated with students’ math-related college readiness. CHAID, often used as an exploratory technique and as an alternative to multiple linear regression and logistic regression, was used to study the relationships between a dependent variable and a set of independent variables. CHAID can be used for prediction, similar to 
regression analysis, but it is also used for classification and detection of interaction between variables.

CHAID analysis is often used in data mining, the process of analyzing data from different perspectives and summarizing it into useful information. Luan (2002) defined data mining as the “purpose of uncovering hidden trends and patterns and making accuracy based predictions through higher levels of analytical sophistication” (p. 19). It is also used in direct marketing, medical and psychiatric research. In the business sector, CHAID statistical analysis is used to find correlations or patterns that can help predict future trends and behaviors within a company. Though CHAID analysis has not been used frequently in higher-education research, recent studies have demonstrated the value in using CHAID statistical analysis methods in educational research (Thomas \& Galambos, 2004; Grobler, Bisschoff, \& Moloi, 2002; Borden, 1995).

Thomas and Galambos (2004) used regression and CHAID to investigate how students’ experiences and characteristics affect student satisfaction. In their study, CHAID indicates that "social integration has more effect on the satisfaction of students who are less academically engaged” (251). Grobler, Bisschoff, and Moloi (2002) used CHAID analysis in their research on school effectiveness. CHAID was used to determine which independent variables, included in the study, were the strongest predictors of school effectiveness as indicated by the respondents' perceptions. Luan (2002) discussed CHAID analysis and its benefits to higher education. Luan found that CHAID can be used to monitor and predict community college students' transfer to four-year institutions, including the type of students who transfer and their course taking patterns. Luan also indicated "analyses of the outcomes of transferred students in upper divisions can influence the curriculum design back at the community colleges” (p. 29). 
CHAID belongs to a set of models called decision trees. It is used for classification and prediction (Okell, 1999). Classification seeks to identify what the categorical outcome will be given a set of criteria, while the purpose of prediction is to attempt to predict an outcome given a set of independent variables (Okell, 1999). CHAID diagrams can be thought of as a tree trunk with progressive splits into smaller and smaller branches. The initial tree trunk is all of the participants in the study. A series of predictor variables are assessed to see if splitting the sample based on these predictors leads to a statistically significant discrimination in the dependent measure (Okell, 1999).

Another way to think of CHAID analysis is that it is a modern, visually appealing variant of log-linear analysis, in which multiple variables are explored using Chi-Square analysis. One advantage of CHAID over log-linear analysis is that it helps determine significant "cutoff points" in continuous variables by finding where differences in variance are maximized among possible clusters along the continuum, thus helping the user define where these cutoff points may lie. It was anticipated that the visual outlay of the decision trees would be readily understood by laypersons who are not researchers or from the academic community. For this reason, CHAID analysis is a valuable tool when working with $\mathrm{K} 12$ and postsecondary education decision makers, who often need to substantiate high stakes curricular decisions based on complex statistical outputs. CHAID analysis, although complex in its methodological nature, provides simple and easy to understand decision tree outputs.

In this study, CHAID data analysis method enabled discovery of the independent variables that have significant associations with the dependent variable. The analysis also identified the most significant combination of variables. The independent variable that had the strongest association with the dependent variable became the first node in the tree with a branch 
for each category that was significantly different relative to the outcome variable. The process was repeated to find the predictor variable on each branch most significantly related to the outcome variable until no additional significant predictors remained. CHAID was used to identify the most significant variables associated with math-related college readiness. The dependent variable examined in this study was the number of advanced high school mathematics courses completed beyond Algebra I. The independent variables or predictors include the following: math achievement as evidenced by Maryland student assessment scores in middle school and high school assessment score in algebra; curricular rigor as considered by the number of advanced math and science courses students took during high school, the sequence of math courses as evidenced by whether or not students took Algebra I in middle school, and school attendance as indicated by a student's attendance during eighth grade. It was anticipated that the CHAID tree model would serve as a basis for structuring discussions about necessary changes to school policies, curriculum development and curriculum alignment in the early elementary and middle school mathematical programs.

When interpreting the results of the value of the test statistic, it was that the value or probability (p) is less than 0.05 . This criterion of $95 \%$ confidence was the basis of a statistically significant finding within the study. The Sig. value indicated the significance or probability level (p). If the probability is less than 0.05 , it was assumed that the results are statistically significant, and the experimental hypothesis was accepted and the null hypothesis was rejected.

\section{Variables Used in CHAID Analysis}

The table below illustrates the variables used in the CHAID analysis, their respective role as an independent or dependent variable, their scale of measurement, and a brief description of how they are actually measured. Each of these is discussed in more detail below. 
Table 1

Variables used in the CHAID Analysis

\begin{tabular}{|llll|}
\hline Variable & $\begin{array}{l}\text { Role of Variable } \\
\text { in } \\
\text { CHAID Analysis }\end{array}$ & $\begin{array}{l}\text { Scale of } \\
\text { Measurement }\end{array}$ & How Measured \\
\hline $\begin{array}{l}\text { College } \\
\text { Readiness }\end{array}$ & $\begin{array}{l}\text { Dependent } \\
\text { Variable }\end{array}$ & Continuous & $\begin{array}{l}\text { Number of advanced } \\
\text { mathematics courses taken } \\
\text { beyond Algebra I. }\end{array}$ \\
\hline $\begin{array}{l}\text { Math } \\
\text { Achievement }\end{array}$ & $\begin{array}{l}\text { Independent } \\
\text { Variable }\end{array}$ & Continuous & $\begin{array}{l}\text { Score on the Maryland School } \\
\text { Assessment (MSA) administered } \\
\text { during } 7^{\text {th }} \text { grade. }\end{array}$ \\
\hline $\begin{array}{l}\text { High School } \\
\text { Algebra Score }\end{array}$ & $\begin{array}{l}\text { Independent } \\
\text { Variable }\end{array}$ & Continuous & $\begin{array}{l}\text { Score on the Maryland High } \\
\text { School Assessment (HSA) in } \\
\text { Algebra. }\end{array}$ \\
\hline $\begin{array}{l}\text { Curricular } \\
\text { Rigor }\end{array}$ & $\begin{array}{l}\text { Independent } \\
\text { Variable }\end{array}$ & Continuous & $\begin{array}{l}\text { Number of advanced placement } \\
\text { (AP) mathematics and science } \\
\text { courses taken in high school. }\end{array}$ \\
\hline $\begin{array}{l}\text { Sequencing of } \\
\text { Math Courses }\end{array}$ & $\begin{array}{l}\text { Independent } \\
\text { Variable }\end{array}$ & $\begin{array}{l}\text { Categorical } \\
\text { (Yes or No) }\end{array}$ & $\begin{array}{l}\text { Whether a student completed } \\
\text { Algebra I by the end of 8 }\end{array}$ \\
\hline Attendance & Independent \\
& Variable & Continuous & $\begin{array}{l}\text { Number of days absent during } \\
\text { grade 8. }\end{array}$ \\
\hline
\end{tabular}

College readiness, a continuous dependent variable, was measured by the number of advanced mathematics and science courses taken beyond Algebra I. Advanced high school math courses in Allegany County Public Schools include the following: Algebra II, Honors Algebra, Honors Geometry, Trigonometry/Pre-calculus, Honors Trigonometry/Pre-calculus, Honors Calculus, College Algebra, and College Probability and Statistics.

Students who earn at least 12 credits in honors courses during their high school program and meet grade point average (GPA) requirements are eligible for an Honors Certificate, in addition to the Maryland High School Diploma. At the end of a student's junior year, a student 
with satisfactory credits, the HSA graduation requirement met, and a minimum GPA of 3.0 may enroll in a dual enrollment program. Students who are enrolled in the dual enrollment program are enrolled in two schools: Allegany County Public Schools and a college. Successful completion of dual enrollment courses outlined in the county’s program of study awards a student high school credit, college credit hours, and will be part of the high school GPA.

Math achievement, a continuous independent variable, was measured by two assessment scores: the Maryland School Assessment (MSA) score for mathematics administered during the seventh grade and by the Maryland High School Assessment (HSA) score in algebra/data analysis. The MSA is a criterion referenced test that measures student proficiency and advanced proficiency on the Maryland content standards embedded in the mathematics state curriculum. The assessment meets the testing requirements of the federal No Child Left Behind Act of 2001. The test is given each in grades three through eight. The mathematics test includes multiplechoice questions and questions requiring written responses. The MSA scores show how well students learned the mathematics skills in the Maryland Voluntary State Curriculum (Maryland State Department of Education). The Maryland Voluntary State Curriculum identifies the content standards as defined by the Maryland Core Learning Goals and aligns them with the Maryland Assessment Program. The state curriculum is formatted so that each begins with content standards or broad, measurable statements about what students should know and be able to do. Indicator statements provide the next level of specificity and begin to narrow the focus for teachers. The objectives provide clear information about what specific learning should take place (Maryland State Department of Education).

The Maryland School Assessment in mathematics during seventh grade tests the following areas of knowledge: Algebra, Patterns, and Functions, Geometry, Measurement, 
Statistics, Probability, Number Relationships and Computation/Arithmetic, and Processes of Mathematics.

Student accommodations on the MSA were consistent with a student's Individualized Education Program (IEP) or Limited English Proficiency (LEP) plan. In addition, a MOD-MSA is an alternate assessment in mathematics based on modified academic achievement standards designed for students receiving special education services who meet specific requirements.

An overall math score is reported by proficiency level: basic, proficient, or advanced. The score shows how well the child learned the subject matter. For seventh-grade students, a proficient score is 396, while an advanced score is 451 . Anything below a score of 396 is considered a basic score, the lowest level of performance. The goal is to have all students perform at the proficient or advanced level (Maryland State Department of Education, 2010).

Math achievement, a continuous independent variable, was measured by the Maryland High School Assessment (HSA) score in algebra/data analysis. The No Child Left Behind legislation also requires that each state administer and report results for high school assessments in mathematics. The high school assessment in algebra/data analysis is used for accountability purposes, determining whether schools and school systems have met their Adequate Yearly Progress (AYP) targets. High school mathematics instruction across the state of Maryland is also guided by a set of standards and learning expectations as defined by Maryland Core Learning Goals. The standards define the skills that students should know and be able to do mathematically throughout their elementary and secondary school experience. The standards are formatted so that each begins with content standards or broad, measurable statements about what students should know and be able to do. Indicator statements provide the next level of 
specificity for teachers, and the objectives provide clear information about specific learning outcomes (Maryland State Department of Education).

The algebra/data analysis assessment measures school and individual student progress toward achieving Maryland's High School Mathematics Core Learning Goals. There are two main sections on the algebra/data analysis assessment: Functions and Algebra, Data Analysis and Probability. On the assessment, students need to be able to demonstrate the ability to find solutions to mathematical problems using patterns, functions, and algebra (Maryland State Department of Education). In addition, students have to demonstrate the ability to apply probability and statistical methods (Maryland State Department of Education).

The time frame for taking the Algebra HSA varies; students take the test whenever they complete the course. Middle school students who take the Algebra I course would also take the algebra/data analysis HSA for their graduation requirement at the end of the course. For example, some students may take algebra in eighth grade while others may not take it until ninth grade. The assessment contains multiple choice questions; there are also student produced responses on the algebra/data analysis assessment. The Maryland State Department of Education requires students who entered grade nine in the fall of 2005 or later to pass the algebra/data analysis HSA, as well as meet other graduation requirements in order to earn a Maryland High School Diploma. The assessments provide schools, teachers, and parents with information regarding individual student performance and subgroup performance. To receive a proficiency rating, students must earn a minimum score of 412 for algebra/data analysis. The cutoff score for an advanced rating is 450 for algebra/data analysis. A score below 412 is considered a basic level of performance (Maryland State Department of Education). 
In addition, student accommodations on the HSA are consistent with a student's Individualized Education Program (IEP) or Limited English Proficiency (LEP) plan. Student accommodations on the HSA are also consistent with a student's Individualized Education Program (IEP) or Limited English Proficiency (LEP) plan. In addition, a MOD-HSA is an alternate assessment in mathematics based on modified academic achievement standards designed for students receiving special education services who meet specific requirements.

Curricular rigor, a continuous independent variable, was measured by the number of advanced placement mathematics and science courses taken in high school. The College Board's Advanced Placement Program, which began in 1955, allows students to pursue college-level studies while still in high school. Students can choose from advanced placement (AP) courses to demonstrate their knowledge of rigorous academic curriculum. College credit is awarded based on the AP test score and the standards set by the receiving college or university. The course syllabi for all AP courses have been approved by the College Board as meeting the criteria for content rigor. Students can prepare for an optional assessment that may award college credit, depending upon the college or university the student chooses to attend. AP courses and exams are developed by committees composed of an equal number of postsecondary academic faculty and experienced AP high school teachers for each core area. The members represent a full range of secondary and postsecondary institutions. In addition, professional test developers, who have expertise in the subject area, also participate in on the AP course and exam committees (College Board).

In Allegany County Public Schools (ACPS), a student must take the AP exam to receive the 5.0 weighted GPA; a student who does not take the AP examination will receive the 4.5 
weighted GPA. The following AP courses are offered in mathematics and science in ACPS: AP Calculus, AP Chemistry, AP Environmental Science, AP Biology, and AP Physics.

Sequencing of math courses, a categorical independent variable, was measured by whether or not a student completed Algebra I by the end of eighth grade. Allegany County Public Schools limit the number of students who have access to Algebra I in grade eight. Only those students who have demonstrated readiness or above-average mathematical ability and skills are permitted early access to Algebra I. Students who left ACPS elementary schools as low achievers in mathematics, typically determined by MSA math scores, math grades, teacher and school counselor recommendation, are scheduled into low-track math placements with students that have been determined as having similar abilities at the middle school level.

At the end of grade six, there are two scheduling options in mathematics for students: either students are enrolled in a grade-level math course during grade seven or students are enrolled in an accelerated math course in which students use an eighth-grade textbook. Only seventh-grade students who studied an eighth-grade curriculum had access to Algebra I during grade eight. However, a student can be removed from the accelerated course if adequate progress is not shown, as reflected by scheduled math benchmarks and nine-week grades. Typically, these decisions are made by the principal, school counselor, school improvement specialist, teacher, and parent prior to the second semester of school. Students who are removed from the accelerated course will be moved to the seventh-grade math course. If this occurs, the student will not have access to algebra during grade eight.

Attendance, a continuous independent variable, was measured by the number of days a students was absent during grade eight. Maryland state law mandates that students attend school regularly between the ages of 5 to 16; therefore, students are expected to attend school regularly 
in ACPS. At the elementary and secondary levels, a student services team meets weekly to address attendance concerns. The team consists of a pupil personnel worker (PPW) from the board of education, the principal and/or assistant principal, a school counselor, and/or school psychologist, a special education facilitator (SEF), a school nurse, and other support staff available to the school system. The team confers on attendance concerns and designates appropriate interventions to assist parents and students who accumulate excessive absences or who are truant from school.

ACPS also maintains communication with parents through attendance letters and parental contacts. ACPS mails letters to parents/guardians that provide attendance information at the following intervals: eight days, 12 days, and 15 days, regardless of reasons for the absences. In addition, principals or their designees are encouraged to contact parents regarding excessive absences, set up conferences with children and parents, identify, and assist students and their parents in accessing services that will help address the barriers that are preventing the student and their parents from meeting Maryland state attendance laws and ACPS attendance requirements.

There are two types of absences in the county attendance policy: lawful and unlawful. Students are considered lawfully absent (including absence for any portion of the day) under the following conditions: death in the immediate family, illness of the student, court summons, hazardous weather conditions, work or an approved school-sponsored activity during the day, observance of a religious holiday, state emergency, health exclusion, suspension, and lack of authorized bus transportation (not including students denied authorized bus transportation for disciplinary purposes). Unlawful absences are defined as truancy or failure to attend school regularly without a lawful reason (Allegany County Public Schools). 


\section{Limitations of the Study}

A primary limitation of this study is external validity, specifically, the inability to generalize results to other middle and high schools and/or other student populations. Therefore, the following limitations of the study are articulated:

1. This study and sample is limited to three high schools, one career center, and four middle schools that serve students in Allegany County Public Schools, Allegany County. Since the study is conducted within one school district, the results may not be representative of other school districts in Maryland.

2. Data is collected from a sample during middle school and high school. As a result, the participants in this sample may not be representative of the entire student body.

3. Because the school district where this study is conducted practiced homogeneous grouping or tracking systems at the middle school level that limited access to algebra during eighth grade, future research should replicate this study in a heterogeneous environment to explore whether the same results would occur.

4. Other independent variables exist beyond those examined here that may ultimately be associated with college readiness.

5. This study examined typical achievement and attendance data from a public school district. As such, this body of data experienced incomplete entries for students if they withdrew or transferred in or out of the Allegany County Public Schools.

6. There may be some errors in data entry based on typical workloads in a public school district. However, the investigator does not anticipate that these are problematic. 


\section{Chapter Four: Results}

The main problem addressed in this study was how educators can best prepare students for college readiness. Since college readiness is strongly associated with math achievement, post-secondary educators need more research that explores how K-12 math curricula may ultimately impact the readiness of their college students. Prior research indicates that middle school is a critical time for early postsecondary preparation (Wimberly \& Noeth, 2005). Students who enter high school unprepared for advanced course work in mathematics are unlikely to be college ready by the time they graduate from high school. Because completion of advanced mathematics courses is related to college readiness and degree completion, it is important to examine factors that significantly influence math-related college readiness. Adelman’s (1999) work indicated that taking a full schedule of academically demanding courses in high school, including mathematics beyond Algebra II, is a strong predictor in determining if students will attain a baccalaureate degree.

\section{Research Question and Hypotheses}

This study examined factors that were most significantly associated with math-related college readiness as evidenced by advanced mathematics courses taken beyond Algebra I during high school. The degree of association between college readiness and a set of independent variables, including math achievement, curricular rigor, sequence of math coursework, and attendance, were analyzed. Math course patterns of high school seniors who completed either Algebra I or a general math course during middle school were investigated. In question was whether students who had early access to algebra during middle school took more advanced mathematics courses in high school, including AP courses in mathematics and science courses such as AP Calculus, AP Biology, and AP Physics. The following question guided this research: 
Which factors (math achievement, high school algebra score, curricular rigor, sequencing of math courses, and school attendance) are most closely associated with math-related college readiness as evidenced by advanced mathematics coursework taken beyond Algebra I for students in Allegany County Public Schools, Allegany County, Maryland? The following null and alternative hypotheses were used to address this research question: Null Hypothesis

$\mathrm{Ho}_{1}$ : There is no statistically significant degree of association, as evidenced by CHAID analysis, between math-related college readiness, and a set of independent variables including math achievement, high school algebra score, curricular rigor, sequencing of math courses, and school attendance.

\section{Alternative Hypothesis}

$H a_{1:}$ There is a statistically significant degree of association, as evidenced by CHAID analysis, between math-related college readiness, and a set of independent variables including math achievement, high school algebra score, curricular rigor, sequencing of math courses, and school attendance.

\section{Data Selection and Procedures}

To address the purpose of this study, a number of specific variables were selected and used for the CHAID statistical analysis. The study population consisted of the 2010 and 2011 graduates of Allegany County Public School System (ACPS), Allegany County, in Western Maryland. Within the district, there are three comprehensive high schools and a career center. Students who receive special education services and are identified as being on non-diploma status were removed from the study. A total of 1,334 student records were included in the sample. With written permission from the school district, the data collected from the 2010 and 
2011 high school graduates included the following: number of advanced mathematics courses taken beyond Algebra 1, number of AP courses taken in mathematics and science, MSA mathematics score in grade seven, HSA algebra score, and number of days absent during grade eight.

Table 2

Descriptive Data

\begin{tabular}{|l|l|l|}
\hline Year of Graduation & Student Records & Percentage \\
\hline 2010 & 652 & 48.9 \\
\hline 2011 & 682 & 51.1 \\
\hline
\end{tabular}

\section{Exhaustive CHAID Analysis}

Student data were analyzed using exhaustive CHAID (Chi-squared Automatic Interaction Detection) in SPSS Answer Tree (Version 3.1). CHAID provides a modern and visually appealing variant of log-linear analysis, in which multiple variables are explored using ChiSquare analysis. CHAID analysis determines how variables best combine to explain the outcome in a given dependent variable. The CHAID algorithm is used to construct a classification tree by employing the Chi-square test to determine the optimal next split at each step. Exhaustive CHAID was selected over the original CHAID algorithm because it examines all possible splits for each independent variable and it determines the optimal association between the dependent variable and independent variables by continuously testing all possible category subsets in order to merge related pairs until only one single pair remains. 


\section{Advantages of CHAID}

In this study, CHAID is a valuable tool for discovering the relationship between variables. The CHAID decision tree illustrates how different independent variables affect the subgroups in a different way as it descends from each level. Exhaustive CHAID analysis explores data thoroughly, which provides the researcher with a more accurate and comprehensive data analysis. CHAID analysis also provides significant "cutoff points" in continuous variables by finding where differences in variance were maximized among clusters along the continuum, thus helping the researcher identify where the cutoff points lie.

It was anticipated that the visual outlay of the decision trees will be readily understood by laypersons. For this reason, CHAID analysis is a valuable tool when working with K-12 and postsecondary education decision makers who often need to substantiate high stakes curricular decisions based on complex statistical outputs. CHAID analysis, although complex in its methodological nature, provides simple and easy to understand decision tree outputs. A description of the CHAID data analysis and rationale for the selection of CHAID are discussed in the next section.

\section{Description of CHAID Variables}

Exhaustive CHAID analysis as implemented in the SPSS Answer Tree Program (Version 3.1) belongs to a set of models called decision trees. CHAID analysis enables the discovery of the input variables that have the most significant associations with the dependent variable. The analysis also identifies the most significant combination of variables. CHAID analysis was used to determine which independent variables, included in the study, were the strongest predictors of the outcome variable. In this study, CHAID was used to identify the most significant variables associated with math-related college readiness. 
The dependent variable examined in this study was the number of advanced high school mathematics courses completed beyond Algebra I. The independent or input variables included the following: math achievement as evidenced by Maryland student assessment scores in seventh grade and high school assessment score in algebra; curricular rigor as considered by the number of AP math and science courses students took during high school; the sequence of math courses as evidenced by whether students had early access to Algebra I during middle school; and school attendance as indicated by a student's attendance in eighth grade.

\section{CHAID Decision Tree Process}

CHAID diagrams can be thought of as a tree trunk with progressive splits into smaller and smaller branches. The initial branch of the tree includes all the participants in the study. A series of independent variables are assessed to see if splitting the sample based on these variables leads to a statistically significant discrimination of the dependent variable. The independent variable that has the most significant discrimination or strongest association with the dependent variable defines the first split of the sample. The first split is indicated by the first branching of the tree.

From the first node in the tree, additional splits may form by analyzing other independent variables that are significantly different relative to the dependent variable in order to determine if splitting the sample leads to a statistically significant effect on the outcome variable. The split is based on a variable that has the lowest p value if two or more variables have the same

value. The process is repeated to find the independent variable on each branch most significantly related to the dependent variable until no additional significant predictors remain. The CHAID decision tree illustrates how different independent variables affect the subgroups in a different way as it descends from each level. 


\section{Interpreting CHAID Results}

When interpreting the results, the value of the test statistic was that the probability (p) is less than 0.05 . The Sig. value indicated the significance or probability level. The lower the probability value, the less likely the result is attributed to chance alone; therefore, a criterion of 95\% confidence formed the basis of a statistically significant finding within the study. If the probability is less than 0.05 , it was postulated that the results are statistically significant, unlikely to have occurred by chance, and the hypothesis was accepted.

The tree growing procedure ends when one of the following occurs in the CHAID algorithms: maximum tree depth is reached or the minimum number of cases in each node cannot be split any further. These terminal points are predetermined by the researcher. The CHAID algorithm applied in this study uses an alpha value equal to 0.05 , fixing at five the maximum depth of the tree, at 50 the minimum dimension of a parent node, and 50 the minimum dimension of a son node. The final result is that the researcher has a series of groups that are maximally different from another on the dependent or outcome variable. 
Figure 1

CHAID Analysis in SPSS Answer Tree (Version 3.1)

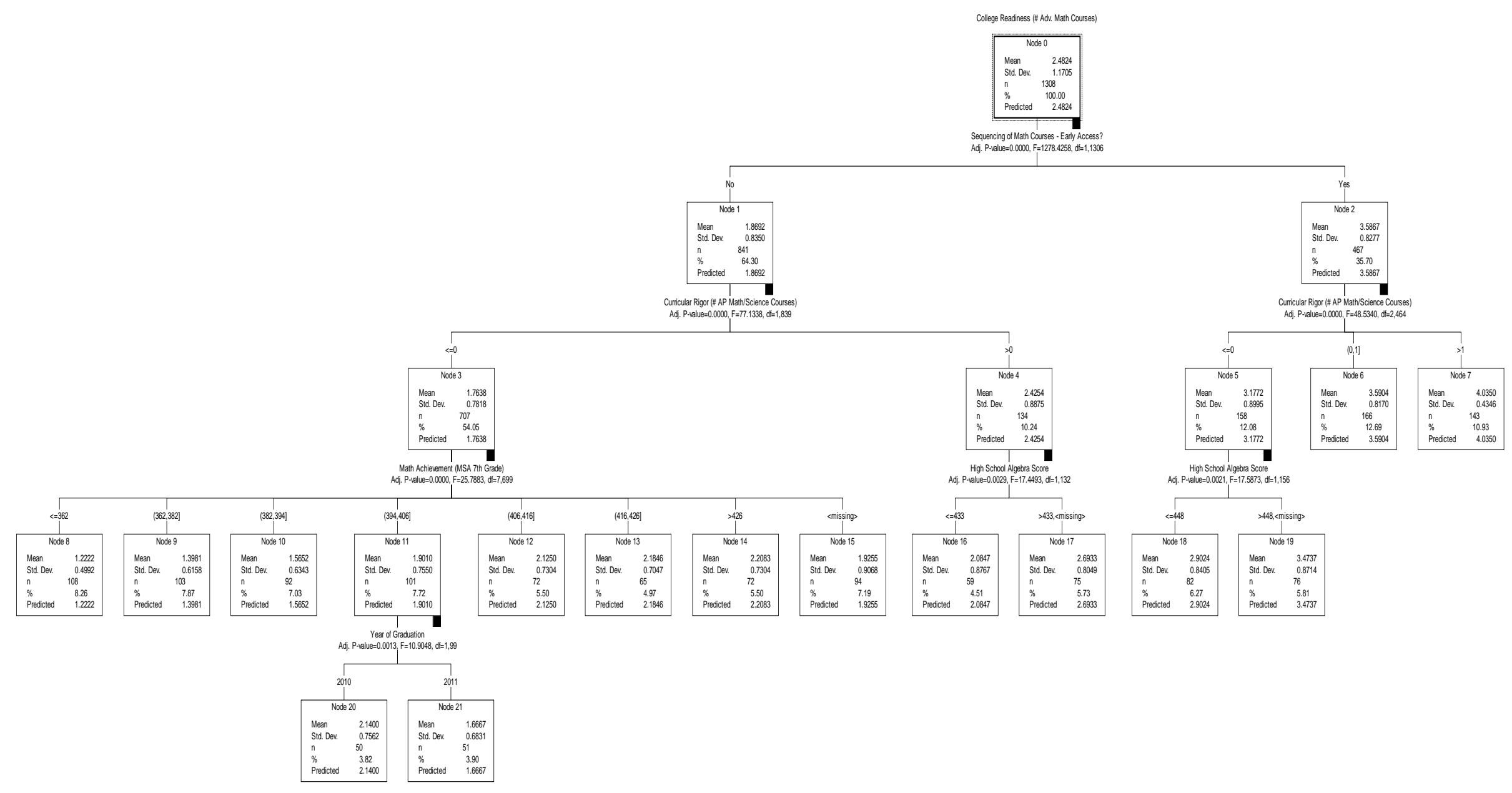


In this study, CHAID data analysis enabled discovery of the independent variables that had statistically significant associations upon the dependent variable. Each split was created by determining the strongest combinations between the independent variables and the dependent variable at each level until all the independent variables were exhausted. Categories of the independent variables were merged if there was no statistical difference between categories with respect to the dependent variable. In order to understand the results of the decision tree, this section provides an overview of statistical information found in each of the nodes.

Figure 2

Explanation of CHAID decision tree nodes

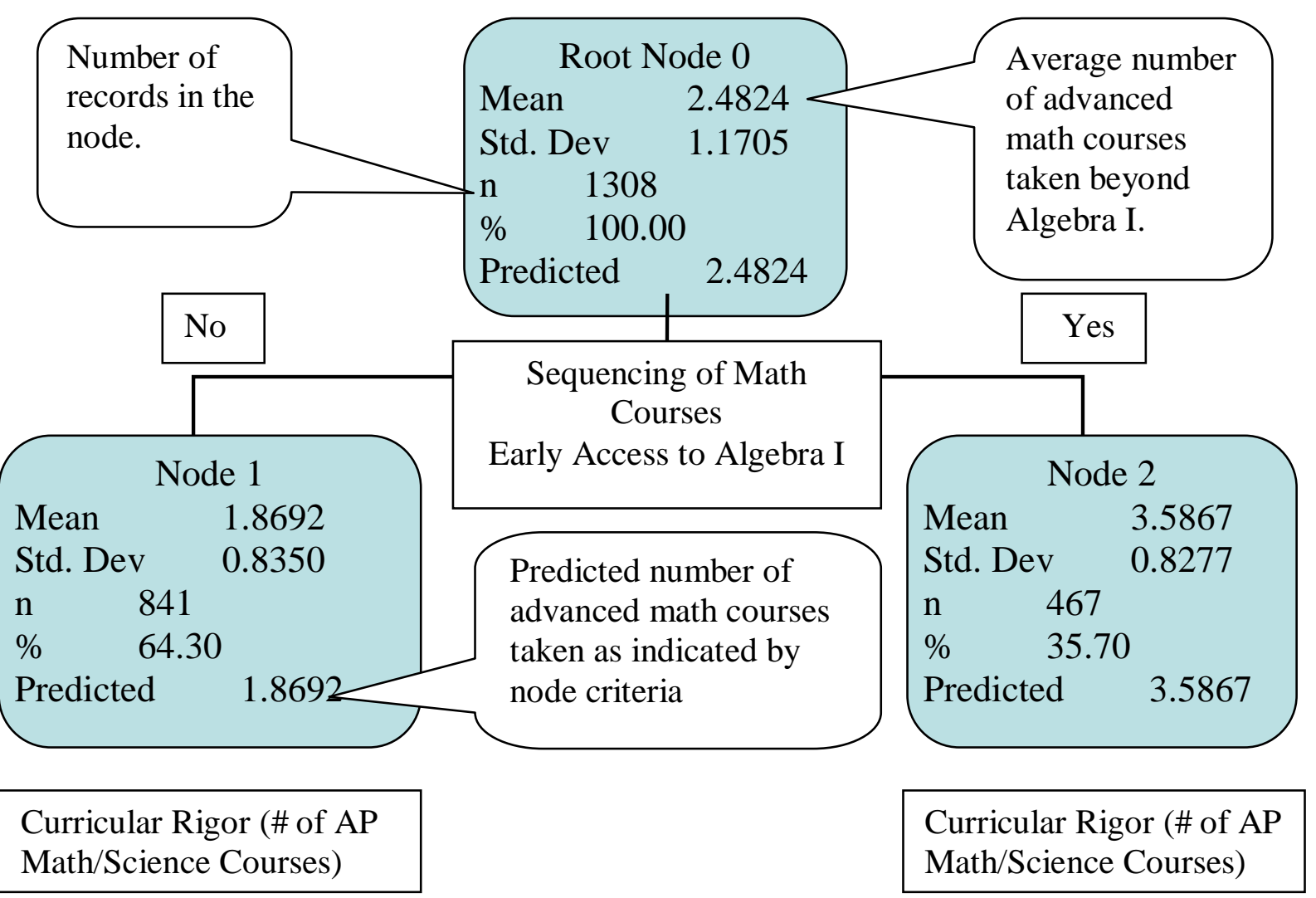


The following section provides a detailed explanation on how the independent variables were assessed in the CHAID analysis and provides a description of which independent variables had the most significant association with the dependent variable in the study.

Root node of the decision tree. The decision tree resulting from the CHAID analysis grew to five levels, and the sample was divided into 21 subgroups (nodes). The root node at the top of the decision tree (Figure 3) represents the sample population of 1,308 respondents who were divided into two categories regarding sequencing of math courses.

Figure 3

Identification of Root Node

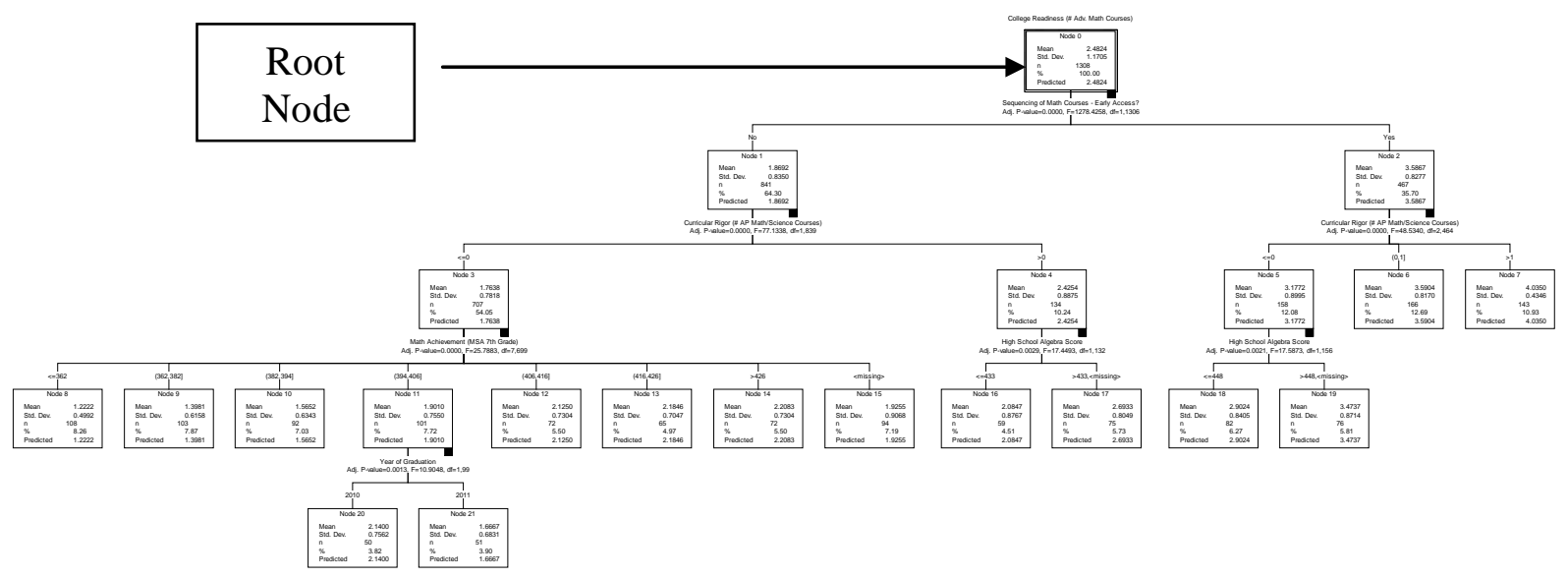

Division of root node into two branches. From the initial root node, the decision tree was divided into two main branches based upon whether or not a student had early access to Algebra I during middle school. Students who did not have early access to Algebra I during middle school (node 1, n=841, 64.3\%) were distributed higher than that of students who had early access to Algebra I during middle school (node 2, n=467, 35.7\%). 
Figure 4

Identification of Level Two Nodes

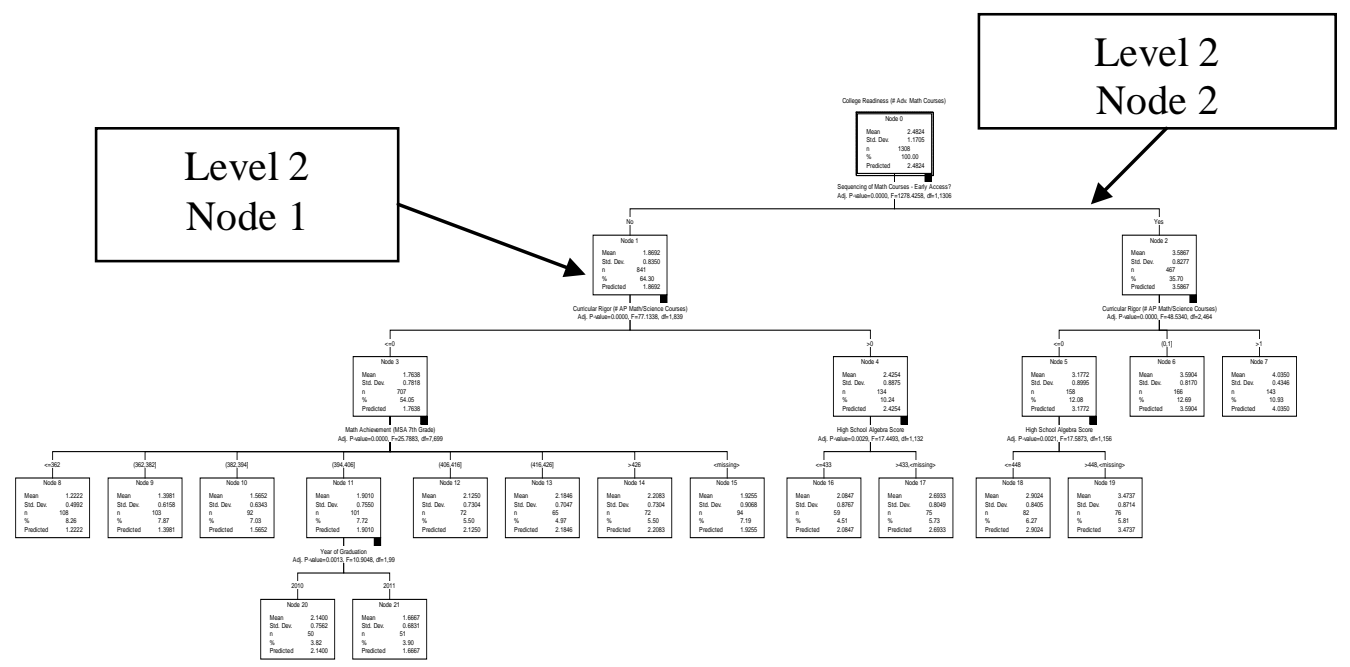

Second level node one. The second branch of the decision tree indicates that if students didn’t have early access to algebra during middle school, then curricular rigor, as determined by the number of AP math and science courses taken during high school, was most closely associated with math-related college readiness ( $m=1.76, n=707,54.05 \%)$.

Second level node two. CHAID results revealed that sequencing of math courses as defined by early access to Algebra I during middle school (node zero) was most closely associated with the dependent variable, the number of advanced mathematics courses taken beyond Algebra I in high school. The second node of the decision tree revealed that if students had early access to algebra by eighth-grade, then students were more likely to take three or more AP courses in mathematics or science during high school $(m=3.59, n=467,35.70 \%)$. From node two, the process was repeated to determine the independent variable on each branch most significantly related to math-related college readiness until no additional significant predictors remain. Three child (subgroup) nodes emerged from node two. 
Figure 5

Identification of Node 2 and Splits

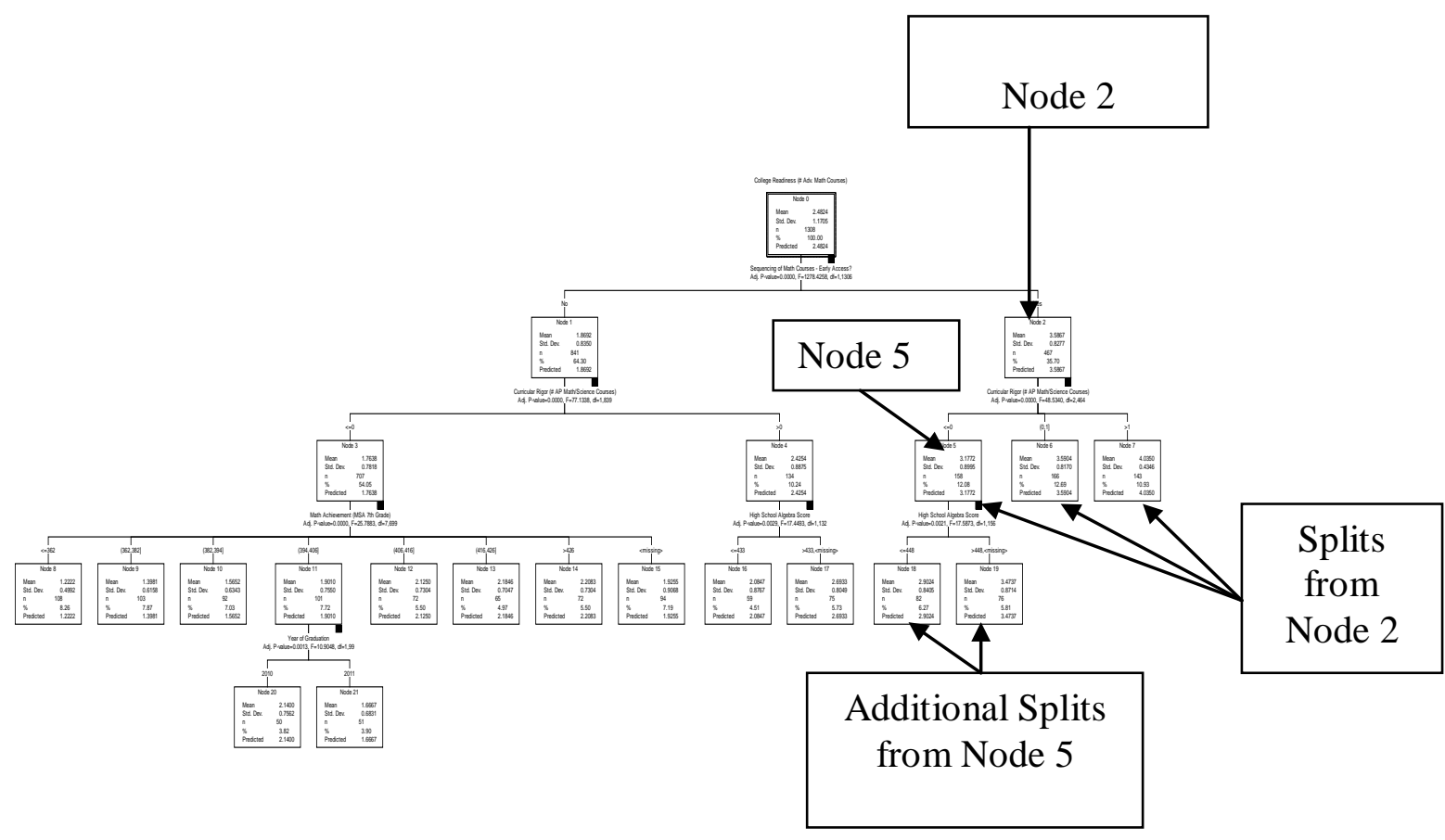

Split from node two. At node two, three child nodes split from the parent node. Nodes

five, six, and seven suggest a strong association between curricular rigor, as identified by the number of AP courses students took in math and science, and math-related college readiness. Node five points out that students who didn’t take any AP courses in high school, but had early access to algebra during middle school averaged just over three advanced mathematics courses (m=3.18, $n=158,12.08 \%$ ). Node six illustrates the relationship between those students who had one AP course in mathematics or science and their math-related college readiness $(\mathrm{m}=3.59$, $\mathrm{n}=166,12.69 \%$ ). Node seven suggests an even stronger association if students took more than one AP course and their math-related college readiness ( $m=4.04, n=143,10.93 \%)$.

Additional split from node five. As indicated above, node five indicates the average number of courses for students who had early access to Algebra I during middle school, but didn’t take any AP courses during high school. Node five splits and two additional child nodes 
(nodes 18,19 ) which were made of a group of homogeneous values of a selected independent variable emerged as having a statistically significant association with math-related college readiness. Nodes 18 and 19 reveal a strong association between the high school assessment score in algebra and math-related college readiness for students who didn't take any AP mathematics or science courses. Node 18 indicates that students who achieved a score of 448 or below on the Maryland HSA in algebra averaged nearly three advanced mathematics courses $(m=2.90, n=82,6.27 \%)$, while node 19 combines two sets of values, HSA scores above 448 and missing values which were treated as a single valid category in CHAID. Students who scored above 448 on the HSA averaged 3.47 advanced courses in mathematics beyond Algebra I $(m=3.47, n=76,5.81 \%)$.

Interpretation of HSA assessment scores. On the Maryland HSA in algebra, a score of 412 is considered proficient, while a score of 450 is considered an advanced level of performance; therefore, students who achieved proficiency or advanced levels of proficiency on the HSA took more advanced mathematics courses during high school even if they did not take any AP courses.

Figure 6 Identification of Node 3 and Splits

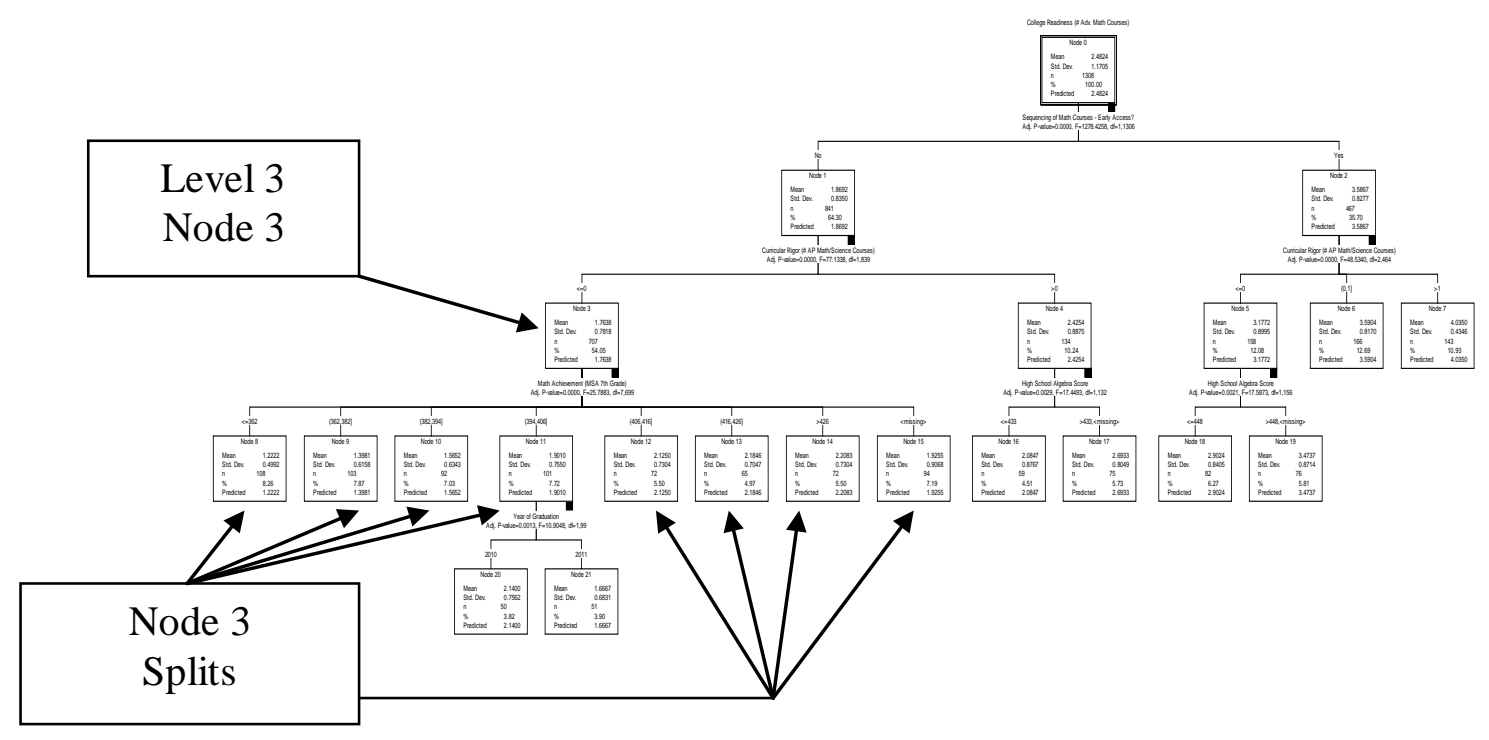


Third level node three. Node three on the decision tree indicates that math achievement on the seventh-grade MSA was identified as another factor most significantly associated with math-related college readiness as defined by the number of advanced mathematics courses students took during high school. On node three, several additional splits were defined and significant cutoff points were identified by finding where differences in variance were maximized among clusters along the continuum. This process was repeated on node three until no additional significant differences were identified.

Node three splits. As previously explained, node three indicates that math achievement on the seventh-grade MSA was identified as a factor significantly associated with college readiness. From node three, several additional splits emerged and significant cut off points were identified. Nodes eight through 10 illustrate the level of association between node three (the MSA math score in seventh grade) and the number of advanced mathematics courses students took during high school.

MSA scores and nodes eight through 10. Node eight indicates that students who had a score equal to 362 or less on the MSA in mathematics during grade seven averaged 1.22 math courses beyond Algebra I ( $\mathrm{m}=1.22, \mathrm{n}=108,8.26 \%)$. If students scored above 362 but less than or equal to 382 on the MSA in grade seven, then students averaged 1.40 math courses beyond Algebra I during high school ( $m=1.40, \mathrm{n}=103,7.87 \%)$. Node 10 reveals that students averaged 1.57 math courses beyond Algebra I if their seventh-grade MSA score in mathematics was greater than 382 but less than or equal to 394 (m=1.57, $n=92,7.03 \%)$.

Interpretation of MSA assessment scores. The MSA in mathematics in seventh grade assesses the following areas of knowledge: Algebra, Patterns, and Functions, Geometry, Measurement, Statistics, Probability, Number Relationships and Computation/Arithmetic, and 
Processes of Mathematics. The Maryland performance standard determines where the cut score is for students considered to be performing at proficient or advanced levels on the seventh grade MSA mathematics test; a score of 395 or below is considered a basic or unsatisfactory level of performance. The mean score for nodes eight, nine, and 10 indicates that 303 students in the sample whose MSA mathematics score in grade seven didn't reach the proficient level averaged about 1.57 advanced math courses beyond Algebra I. In the ACPS school system, geometry is required for graduation. Therefore, the data suggests that these students basically took the minimum core requirements for mathematics.

Relationship of node three to nodes 11-15. Nodes 11 through 15 indicate an increase in the level of association between node three (the MSA math score in seventh grade) and the number of advanced mathematics courses students took during high school. Nodes 11 indicates that students who scored higher than 394 to 406 took nearly two mathematics courses beyond Algebra I (m=1.90, n=101, 7.72\%). Node 12 suggests that students who scored higher than 406 and less than or equal to 416 on the seventh-grade MSA in mathematics took an average of two advanced math courses beyond Algebra I $(m=2.13, n=72,5.50 \%)$. The outputs for nodes 13 and 14 show a slight increase when the MSA score for mathematics in grade seven ranges above 416 to $426(m=2.18, n=65,4.97 \%)$. Node 14 indicates if students scored above 426 on the MSA mathematics test then students took an average of 2.20 advanced mathematics courses beyond Algebra I ( $\mathrm{m}=2.21, \mathrm{n}=72,5.50 \%)$. Node 15 displays missing values by treating them as a single valid category (m=1.93, $\mathrm{n}=94,7.19 \%)$.

Interpretation of assessment scores. The Maryland performance standard on the MSA mathematics test for grade seven where the cut score is considered to be at a proficient level of performance is 396, while an advanced level of performance on the MSA mathematics exam in 
grade seven is 451 . Students who achieved a proficient or advanced level of performance on the MSA in grade seven averaged nearly two or more advanced mathematics courses, while students who scored at a basic level of performance (nodes eight through ten) were significantly below the mean. According to the CHAID analysis, there were no additional statistically significant cut-off points in the continuous variables, so the procedure stopped for analyzing cut-off scores for the MSA score in mathematics for grade seven.

Figure 7

Identification of Splits from Node 11

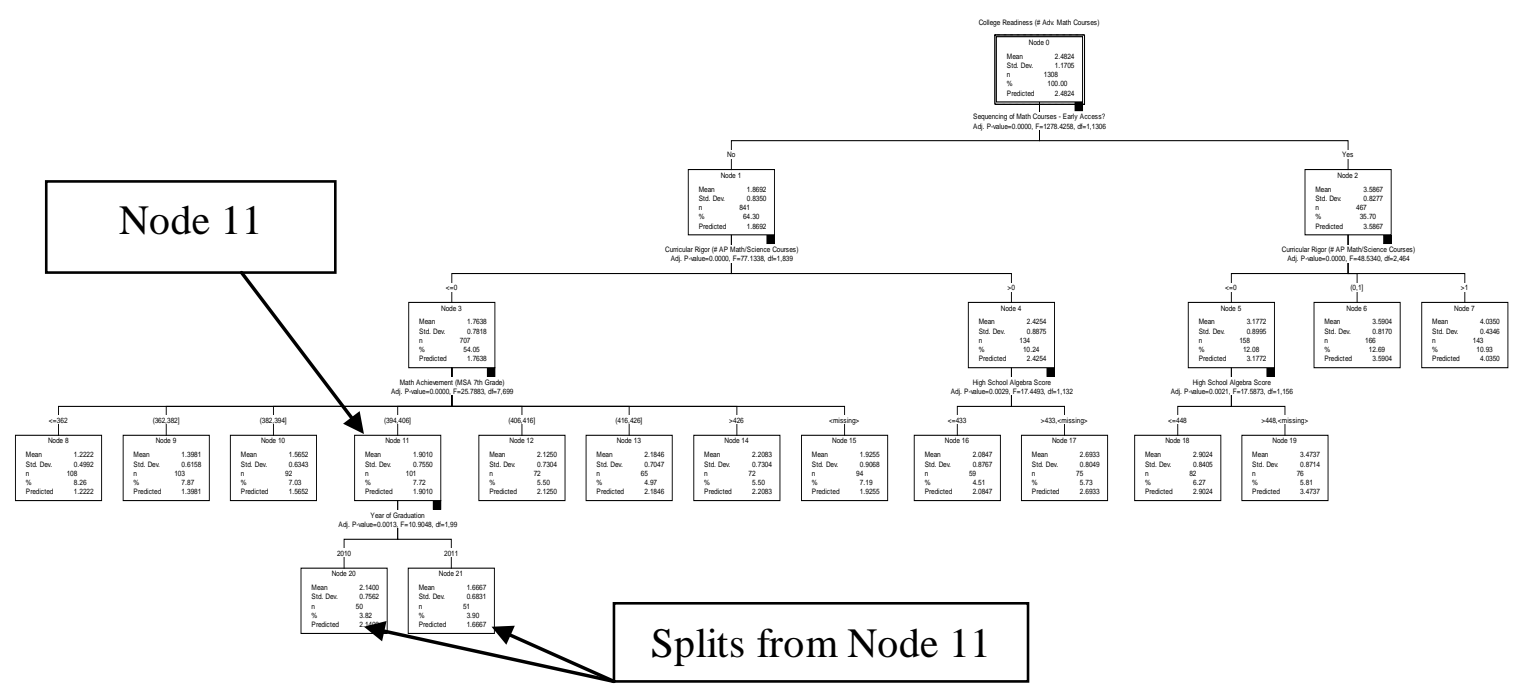

Fourth level node 11 split. At node 11, there is an additional significant split on the subgroup by another of the independent variables upon the dependent variable identified in the study. Two child nodes (subgroups) emerged from node 11 (students who scored higher than 394 to 408 on the MSA) and an independent variable that was identified as the students' year of graduation was identified as a factor having a statistically significant relationship on math-related college readiness. Node 20 indicates that the 2010 graduates of the ACPS system who scored above 394 to 406 on the seventh-grade MSA averaged nearly 2.14 math courses beyond Algebra I $(m=2.14, n=50,3.82 \%)$. However, the 2011 graduates who scored above 394 to 406 on the 
MSA during grade seven averaged only 1.67 math courses beyond Algebra I ( $\mathrm{m}=1.67, \mathrm{n}=51$, 3.90\%). Since there were no additional statistically significant cut-off points in the continuous variables, the procedure stopped for analyzing the relationship between the cut scores on the MSA and the association with the students' year of graduation.

Interpretation of results for nodes 20 and 21. The Maryland performance standard on the MSA mathematics test for grade seven where the cut score is considered to be at a proficient level of performance is 396. The 2010 and 2011 graduates who scored within the range of 394 to 406 are students who scored either just below or slightly above the proficiency level. The 2010 graduates who scored from 394-406 on the MSA averaged 2.14 advanced mathematics courses beyond Algebra I (m=2.14, $\mathrm{n}=50,3.82 \%)$.

However, the 2011 graduates who scored within the same range on the MSA during grade seven averaged only 1.67 advanced mathematics courses beyond Algebra I (m=1.67, $\mathrm{n}=51$, 3.90\%). In the ACPS school system, students do not have to take any courses beyond the core academic requirements for a Maryland high school diploma in their senior year. The difference between the mean score of nodes 20 and 21 suggests that the graduates of 2011 took fewer advanced mathematics courses during their senior year. 
Figure 8

Identification of Node 4 and Splits

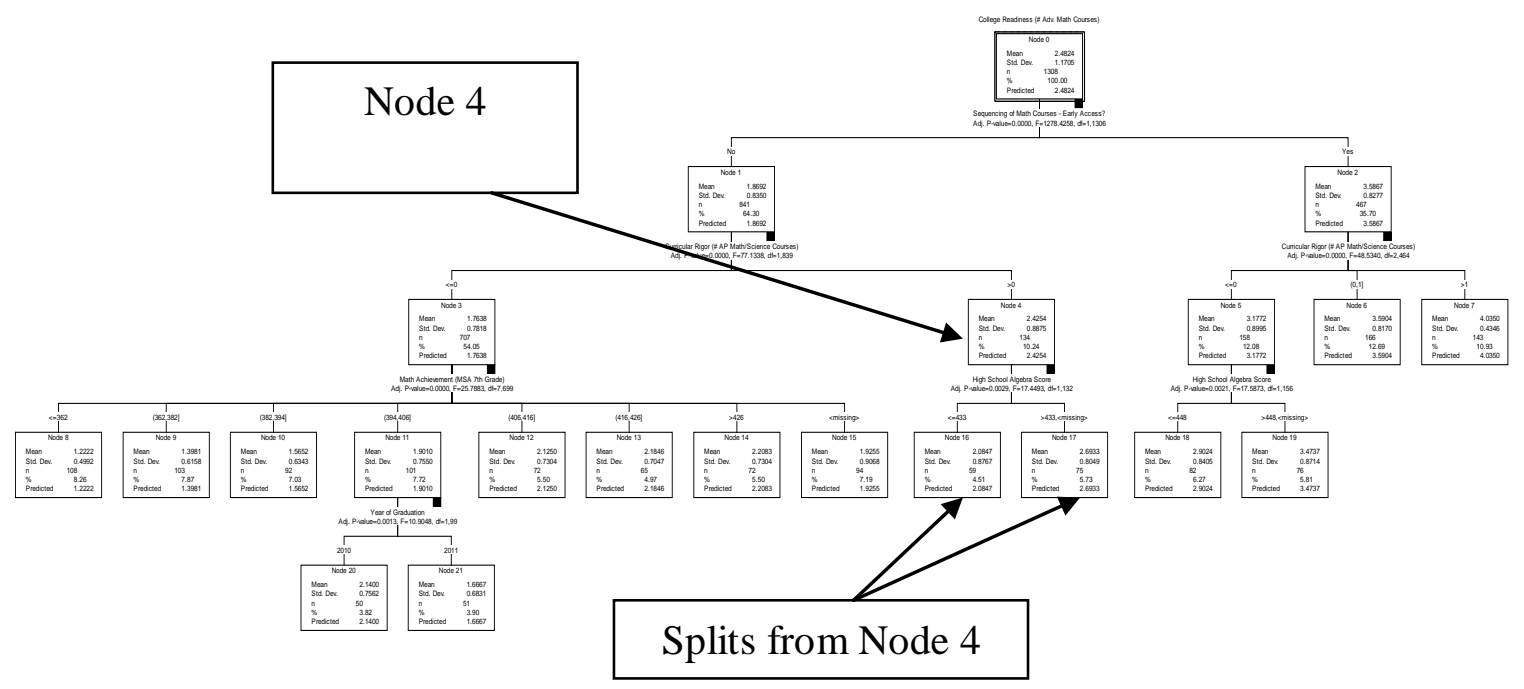

Third level node four. For students who did not have early access to algebra in middle school, the most significant predictor of math-related college readiness was curricular rigor (node one) as defined by the number of AP math and science courses that students took during high school. Node four identifies a strong association between curricular rigor and students' achievement on the Maryland HSA in algebra/data analysis (m=2.42, $n=134,10.24 \%)$. The CHAID analysis then selected the best independent variables to be used for splitting the node, such that two child nodes (nodes 16 and 17) were formed from the parent node (node four).

Third level node four split. As indicated above, node four identifies a strong association between curricular rigor and the students’ score on the Maryland HSA in algebra/data analysis. At node four, two additional splits emerged and significant cut off points were identified. Node 16 indicates that students averaged two advanced courses in mathematics if their HSA score was less than or equal to $433(m=2.08 n=59,4.51 \%)$. Node 17 combines two sets of values; HSA scores higher than 433 and missing values which were treated as a single 
valid category the CHAID analysis. Students who scored above 433 on the HSA averaged 2.69 advanced courses in mathematics beyond Algebra $1(m=2.69, n=75,5.73 \%)$.

Interpretation of nodes 16 and 17. A score of 412 is considered a proficient level of performance on the Maryland Algebra HSA, while a score of 450 is considered an advanced level of performance. The difference in the mean score between nodes 16 and 17 suggests that students who scored at the highest levels on the Algebra HSA took more advanced courses in mathematics than students who were identified as proficient on the HSA.

\section{Limitations of the Study}

A primary limitation of this study is external validity, specifically, the inability to generalize results to other middle and high schools and/or other student populations. Since the study was conducted within one school district, the results may not be representative of other school districts in Maryland. In addition, data was collected from a sample during middle school and high school. As a result, the participants in this sample may not be representative of the entire student body. Moreover, this study examined typical achievement and attendance data from a public school district. As such, this body of data experienced some missing entries for some students within the sample population. Furthermore, Algebra I and geometry are both graduation requirements in the ACPS system. It may be difficult to generalize these results to other high schools that have different graduation requirements in mathematics.

In addition, another limitation of this study is that there may be other factors beyond mathematical ability and achievement that are significantly associated with college readiness and success. For example, research also indicates that psychological and social factors affect student achievement, and the affective domain that includes factors such as student motivation, attitudes, perceptions and value may also be associated with college readiness. For example, Hanna 
(1996) reported that female and male students display different levels of confidence that affect their ability to succeed. In addition, Bandura (1986) reported that a students' sense of selfefficacy can play a primary role in how they approach school work, educational goals, and tasks. According to Bandura's theory (1986), beliefs influence behavior. Students' beliefs in their ability to perform certain tasks influence the goals that the students will set; moreover, their beliefs influence how much energy or effort they will put into a certain task or goal. 


\section{Chapter Five: Summary, Conclusion, and Recommendations for Future Practice and Research}

\section{Summary and Major Findings}

This study examined factors that were most significantly associated with math-related college readiness as evidenced by advanced mathematics courses taken beyond Algebra I during high school. The degree of association between college readiness and a set of independent variables, including math achievement, curricular rigor, sequence of math coursework, and attendance, were analyzed. Math course patterns of high school seniors who completed either Algebra I or a general math course during middle school were investigated. In question was whether students who had early access to Algebra I during middle school took more advanced math courses in high school, including AP courses in mathematics and science.

The most significant predictor identified in the analysis was early access to Algebra I during middle school. Results from this study support previous research discussed in chapter two of the literature review. This finding aligns with research that indicates that the level of academic achievement that students attain by grade eight has a larger impact on their college readiness by the time they graduate from high school than anything that happens academically in high school (ACT, 2009). The finding also coincides with other research that indicates the importance of early access to algebra. Gamoran and Hannigan (2000) reported that completion of Algebra 1 by eighth grade increases mathematical ability of middle school students.

Competence in algebra is increasingly recognized as an important accomplishment in a student's middle school experience (Star \& Rittle-Johnson, 2009). Atanda (1999) indicated that students who took algebra in eighth grade were more likely to enroll in higher-level math classes in high school than those students who did not enroll in algebra in eighth grade. Kuh (2007) wrote that 
students who "do not attain grade-level proficiency in math by the end of the eighth-grade are much less likely to be college ready at the end of high school” (p.4). Moreover, an understanding of algebra by the end of one's middle years was instrumental for higher-level mathematics courses to be taken in high school; thereby increasing their chances that they would be college ready by high school graduation (Kuh, 2007). Recommendations from a recent study on middle school education identified the necessity for all students to take an essential algebra course by the end of eighth grade (Maryland State Department of Education, 2008).

Secondly, the findings of this study indicate that completion of AP courses in the areas of mathematics and science are strongly associated with math-related college readiness. This finding also coincides with previous research on college readiness. The National Science Foundation (2007) found that college readiness among high school students will increase if the number of students who take AP courses in mathematics and science increases. According to Adelman (2006), completion of AP courses in high school is strongly linked to pre-college preparation and college readiness. Findings of the study also indicated that students who took more than one AP course during high school averaged four advanced mathematics courses taken beyond Algebra I. This finding aligns with Adelman's (2006) recommendation that students complete coursework in at least two or more AP courses. Moreover, Adelman (2006) reported that one of the strongest factors associated with attainment of a college degree is the completion of AP coursework in mathematics and science.

The third finding in the study indicates a strong association between the students' level of proficiency on the high school assessment in algebra/data analysis and the number of advanced courses in mathematics that students took during high school. This finding aligns with Adelman's research on the impact of advanced mathematics upon postsecondary enrollment and 
completion; students who take rigorous mathematics courses are more likely to go to college than those who do not (Adelman, 1999; 2006). Adelman (1999; 2006) reported that advanced mathematics is the major factor associated with bachelor degree completion. In fact, research on course-taking patterns has consistently shown that enrollment in advanced-level mathematics is related to college attendance, persistence, and degree attainment (Adelman, 1999; 2006). Adelman (1999) indicated that completion of an advanced high school mathematics course beyond Algebra II had greater influence on college degree completion than factors such as socioeconomic status, ethnicity, or parents’ educational backgrounds. Furthermore, Adelman (1999) reported that "of all the components of curriculum intensity and quality, none has such an obvious and powerful relationship to ultimate completion of degrees as the highest level of mathematics one studies in high school” (p. 6).

The fourth finding in the study suggests the importance of high schools increasing graduation requirements in the area of mathematics. In the CHAID analysis, the 2010 graduates who scored 394 to 406 on the MSA averaged 2.14 math courses beyond Algebra I. However, the 2011 graduates who scored within the same range on the MSA in grade seven averaged only 1.67 math courses beyond Algebra I. In the ACPS school system, students do not have to take any courses beyond the core academic requirements for a Maryland high school diploma in their senior year. Students in the ACPS system are only required to take three mathematics courses: one in algebra/data analysis, a geometry course, and an additional mathematics course offered in the school's program of study. The difference between the two means indicates that the graduates of 2011 took fewer advanced mathematics courses during their senior year. This finding suggests that students within this subgroup had achieved the core academic requirements by their senior year and did not take advantage of other advanced mathematics courses offered at 
the respective schools in the ACPS system. This finding coincides with previous research that students in states with more rigorous graduation requirements are more likely to enroll in more advanced mathematical courses during their high school experience (Schiller \& Muller, 2003). According to an ACT (2009) report, students who complete high-level mathematics and science courses beyond the required graduation requirements are more prepared for college and careers than those who only complete mathematics and science courses required in the core curriculum.

\section{Recommendations for Future Practice}

The findings from this study suggest that a principal goal of all K-12 school systems is to provide optimal opportunities for all students to acquire a firm foundation in mathematics during students' elementary experience so that students will be prepared for early access to algebra during their middle school years. The findings also indicate that if students have early access to Algebra I during middle school then they are more likely to take AP mathematics and science courses in high school. The findings of this study also underscore the importance of having qualified elementary teachers in classroom who are knowledgeable and skillful in the areas of mathematics, and the need for institutions of higher learning to dramatically increase the level of mathematical preparation for elementary and middle level teacher education programs.

The first recommendation for future practice is that higher education institutions must ensure that prospective mathematics teachers are proficient in their knowledge of mathematics content as well as skillful in their ability to delivery quality mathematics instruction. Prospective mathematics teachers across the K-12 continuum must be adequately prepared to teach mathematics with understanding; this is crucial for ensuring attainment of high-quality school mathematics programs. Without a deep and broad understanding of mathematical content, including the specialized knowledge needed for teaching, it is impossible to teach mathematics 
effectively. Since teacher education programs at the elementary and middle levels tend to place less emphasis on mathematics preparation for prospective teachers, it is imperative to strengthen the nexus between elementary and middle school mathematics instruction. Most elementary teachers are generalists; they teach all core subjects. As a result, they may not possess in-depth mathematics knowledge and expertise in teaching elementary mathematics. Therefore, postsecondary institutions should consider changing the academic requirements for all prospective mathematics teachers at the elementary level to include a sequence of math courses that will help them develop their mathematical knowledge and skills as well as their ability to teach mathematics effectively in the classroom. If students are to gain a strong foundation in mathematics in the elementary years of their education, it is important that the students have skillful teachers who can equip them with the mathematical knowledge and skills that will enable the student to make a successful transition to advanced mathematical skills required at the middle school level.

The second recommendation is that higher education institutions should examine the quality of field-based experiences for prospective mathematics teachers. Although planning is difficult and both higher education and public school faculty members are overloaded with professional responsibilities, it is imperative that higher education and K-12 educators form a stronger partnership in analyzing and evaluating the prospective teachers' abilities and skills in the areas of mathematics content, instructional planning, instructional delivery processes, and assessment. Palmer (2007) discussed the importance of observing teaching and talking to each other about teaching. According to Palmer, an educator's growth depends on "shared practice and honest dialogue among the people who do it” (p. 148). Palmer also indicated that “involvement in a community of pedagogical discourse” (p. 148) is not an option for educators, 
but a "professional obligation that educational institutions should expect of those who teach" (p.148).

Although a prospective mathematics teacher may be able to satisfactorily pass a teacher exam, it is not a substantial indicator of the prospective teacher's ability to teach mathematics with understanding or to evaluate and provide instruction that meets the needs of all the students in the classroom. Therefore, higher education mathematics faculty and public school math specialists should form a strong partnership in improving prospective mathematics teachers' field-based experiences. It is essential that both a higher education faculty member in mathematics and a K-12 math specialist assess prospective teachers’ abilities and skills throughout the field-based experiences. If the goal of mathematics instruction is to improve students' academic achievement in mathematics, then the field-based experience should appropriately measure whether prospective teachers possesses a strong understanding of the subject matter and the ability to make appropriate decisions regarding instructional delivery, sequencing, remediation, and assessment of students' progress.

The third recommendation for future practice is that higher education institutions and K-12 systems work together to provide quality professional development for teachers who are currently teaching mathematics at the elementary and middle school levels, but who do not possess the abilities or skills needed to teach mathematics effectively. Teachers need a deep and broad understanding of mathematical content, including the specialized knowledge needed for teaching. Therefore, high-quality professional development on mathematic processes and skills and algebraic thinking that supports deep mathematical understanding should be accessible to all mathematics teachers. Part of the challenge of effectively teaching mathematics is helping students examine systemic relationships that are essential to mathematical understanding. 
Students at the middle level should be able to make and understand connections between their elementary mathematical experiences with numbers and operations leading to abstract and symbolic awareness and the ability to make generalizations, draw conclusions, and justify solutions. If K-12 schools are to provide the most effective mathematical learning experiences for their students, then a firm commitment of involvement is needed by higher education faculty in facilitating professional development that will help current mathematics teachers improve their mathematical knowledge, skills, and teaching ability. Neither K-12 educators nor higher education faculty should neglect their shared responsibility in making sure that both current and future mathematics teachers are not only qualified to teach mathematics, but are skillfully effective in helping students comprehensively learn mathematics.

The fourth recommendation for future practice, based on the previous recommendations, is that postsecondary institutions should develop a formal and committed relationship with public schools. In essence, it is impossible for higher education to address college readiness and retention without directly examining K-12 performance. Kirst and Bracco (2004) assert that students are entering college unprepared for college-level work due, in part, to a "historical split between levels of our educational system and the subsequent lack of communication and connection” (p. 2) between secondary and postsecondary educational systems. Higher education and K-12 public education should not exist in disconnection to each other if the goal is to improve student learning so that all students have the mathematical skills to be college ready.

Therefore, it is imperative that a K-16 curriculum, particularly in mathematics, be developed across the nation between higher education institutions and K-12 schools. In addition, although many postsecondary institutions in the United States have established college-ready standards, there are still too many institutions that have not clearly identified the skills that 
students must possess to be college ready. Conley (2010) defined college readiness as the "level of preparation a student needs in order to enroll and succeed—without remediation—in a creditbearing course at a postsecondary institution that offers a baccalaureate degree or transfer to a baccalaureate program” (p. 21). If students are to exit high school college-ready, then higher education and public school systems should share the responsibility of developing college-ready standards that articulate what students must know and be able to do in order to meet the challenges of post-secondary education.

In addition, leaders within higher education should serve as role models for their organization by connecting the goals and mission of their institution with the collective purpose of education: student learning and success. Higher education leaders play a critical role in breaking down barriers that exist between post-secondary institutions and K-12 schools as well as establishing collaborative partnerships with administrators and supervisors in K-12 education. Higher education and K-12 schools will mutually benefit when they work together to provide opportunities for college and K-12 faculty to teach, learn, and work together as a team. Conley (2010) asserted that higher education administrators and leaders, along with public school administrators and leaders, need to collaborate in order to improve the disconnect on "what it takes to make students ready for learning beyond high school” (p. 42).

Moreover, higher education leaders should consider analyzing whether the learning experiences that are being provided for students in graduate and doctoral programs in administration and leadership are promoting a collaborative orientation between higher education and K-12 education. Conley (2010) concluded that K-12 education and higher education will not evolve until they take into "account the ways in which the two learning environments differ along a number of dimensions” (p. 42). Kuh et al. (2005) promoted the importance of shared 
leadership among administrators and faculty. "Shared leadership among administrators, students, faculty, and staff can be most effective when mutual goals are well defined and student success is at the center of the work” (Kuh et al., 2005, p.161). Student learning should be the primary focus of education; therefore, leaders within higher education and K-12 education should examine and judge their effectiveness in building a seamless and quality educational system for all students through a K-16 educational partnership.

In addition, leadership at every level in education is needed for creating and sustaining a culture of assessment within K-16 education. Huba and Freed (2000) suggested that educational institutions improve their accountability when they "incorporate the evaluation of student learning into the way they operate on a regular basis” (p. 19). Huba and Freed (2000) defined assessment in the following manner:

Assessment is the process of gathering and discussing information from multiple and diverse sources in order to develop a deep understanding of what students know, understand, and can do with their knowledge as a result of their educational experience; the process culminates when assessment results are used to improve subsequent learning. (p. 8)

If students are to exit high school prepared for the rigors of higher education, then it is essential that academic leaders from both educational systems share the responsibility of ensuring that assessment practices are an integral component of K-16 education. According to Banta, Jones, and Black (2009), “Academic leaders—including presidents, provosts, deans, department chairs, and leaders in student affairs—-must be public advocates for assessment and provide appropriate leadership as well as support for faculty and staff closest to the assessment process” ( p. 11). Assessment is critical to improving student learning in mathematics and 
providing interventions that need to take place as students advance to more challenging mathematics courses. Both program assessments in mathematics and classroom assessments are essential to providing data for informed decision making. Therefore, academic leaders within higher education and K-12 education should work closely together in the assessment process if continuous improvement in students' mathematical achievement is to occur.

Moreover, another recommendation for future practice is for K-12 schools to increase the level of communication and support given to parents and students about educational preparation, course selections, and college readiness. Parents play a critical role in providing academic assistance, encouragement, and support that can ultimately influence their child's academic achievement, mathematical placement, and college readiness. Therefore, K-12 systems must teach parents how to effectively advocate for their children in the college readiness process. Although most students have postsecondary goals, many students and their parents fail to take practical or timely steps toward achieving those goals at the middle school level. Parents may not have timely information about college planning or understand the importance of mathematics course selections upon college readiness; this lack of knowledge and involvement could adversely affect educational decisions that parents and students make during middle and high school. K-12 schools can play a keen role in helping parents initiate early preparation for college by promoting academic preparation and achievement, creating a college culture by providing college and career planning information, helping parents and students understand the process for postsecondary planning, working with parents and students in creating a concrete plan for meeting their post-secondary goals, and encouraging parental communication and involvement at the middle school level. 
The final recommendation for future practice is that post-secondary leaders should consider exploring how efficacious attempts at remediation are at the various educational levels: elementary, middle, secondary, and post-secondary. The demands for a data-driven culture of accountability and transparency within our educational systems increase the need for return on investment (ROI) studies that inform from a policy perspective where resources in dealing with mathematical college readiness and retention are most effectively utilized. In addition, these studies are particularly necessary as higher education faces increasing economic hardships that force higher education leaders to make difficult budgetary concessions. Therefore, these studies will be instrumental in helping define best practices for monitoring and measuring the efficacy of remedial education across the K-16 continuum, as well as informing how teacher preparation programs and teacher professional development programs are contributing to college readiness and retention.

As mentioned previously, the costs of college remediation to students, the institutions, and states are significant. Conservative estimates placed the cost of remedial programs at postsecondary institutions at one to two billion dollars annually, and the public and private costs at nearly 17 billion dollars annually (Brenneman \& Haarlow, 1998). Research indicates that students require remediation in mathematics more than any other subject (Adelman, 2006). About one third of high school graduates in the U.S. who enroll in college are required to take one or more remedial mathematics courses (Strong American Schools, 2008).

However, remedial education is not just a K-12 problem; it is a K-16 crisis caused in large part to elementary and middle level teachers who do not have a deep and appropriate level of mathematical content knowledge and understanding to effectively teach students who have varying levels of mathematical ability. Elementary school mathematics instruction must focus 
greater attention on algebraic concepts and algebraic thinking, and it should prepare students for Algebra I during middle school. A report from the National Commission on Teaching and America’s Future (2004) discusses the impact of teachers' lack of mastery skills on student

achievement and suggests the importance of collaborative efforts and resources toward improving the quality of teacher education programs:

Teaching requires justifying, explaining, analyzing errors, generalizing, and defining. It requires knowing ideas and procedures in detail, and knowing them well enough to represent and explain them skillfully in more than one way. This is mathematics. The failure to appreciate that this is substantial mathematical work does teachers-and the improvement of teaching - a disservice. (Ball, 2003, p.3)

Higher education may improve college readiness by making critical improvements in prospective and current teachers’ opportunities to learn mathematical problem solving skills, representation skills, and reasoning skills that will increase their mastery level and allow them to teach mathematics effectively so that all students, regardless of their diverse backgrounds, will be academically prepared to take algebra during middle school, as well as more advanced mathematics and science courses during high school.

\section{Recommendations for Future Research}

In many school districts, students who leave elementary school as low achievers in math are scheduled into low-track placements with students that have been determined as having similar abilities. Low-track placement, such as tracking or homogeneous grouping, involves separating students by academic ability into groups for all subjects. In this tracking system, students are assigned to a course according to whether their achievement is considered high, average, or low. Because the school district where this study was conducted utilized 
homogeneous groupings at the middle school level that limited access to algebra during eighth grade, future research should replicate this study in a heterogeneous environment to explore whether the same results would occur.

According to an ACT (2009) report, students who complete high-level mathematics and science courses beyond the required graduation requirements are more prepared for college and careers than those who only complete mathematics and science courses required in the core curriculum. Therefore, additional research is needed to investigate whether states that have more rigorous graduation requirements in the area of mathematics and science have higher levels of mathematical achievement and increased levels of math-related college readiness.

The National Science Foundation (2007) reported that high school students who pass an AP exam are three times more likely to persist until degree attainment than those who do not pass the AP exam. For African American students, the percent is even greater; passing an exam makes it four times more likely that the student will earn a college degree (National Science Foundation, 2007). Therefore, a future study could build on this present study by assessing whether students' scores on the advanced placement test in a mathematics or science course is significantly associated with math-related college readiness or degree attainment.

As indicated by the report of the National Commission on Teaching and America's Future (1996), there is much research about the connection between teacher quality and student learning. However, there is limited research that focuses on the role of the elementary teacher on student achievement in mathematics. Teachers make the most significant contribution to student learning; what teachers know and how they teach critically influence student learning. A future study that assesses elementary teachers' coursework in mathematics content and teaching methods and the impact of their knowledge and skills upon student achievement in mathematics 
should be explored. Additionally, future research in the area of certification and licensure standards of elementary teachers in low performing school districts in the area of mathematics should be investigated to determine the impact upon student mathematics achievement.

This study suggests that a strong relationship exists between early mathematics achievement and college readiness. Preventive measures within the formative years of the students' education will most likely be more successful than post-secondary mathematics remediation. Therefore, additional research is needed in the areas of teaching, learning, and assessment that will inform pedagogical approaches in the K-12 mathematics curriculum so that all students, regardless of their diverse backgrounds, will be academically prepared to take rigorous mathematics courses.

In addition, there is limited research that explores the culture of math in American education. When people think about their mathematics education, it is typically from their own personal experiences and viewpoints, the way they experienced their education and their own individual achievement in mathematics. However, student learning in a $21^{\text {st }}$ century mathematics education program requires a shift in how parents, policy makers, and students think about mathematics. A $21^{\text {st }}$ century mathematics education moves students beyond memorization of mathematics facts and formulas, to construction of mathematical knowledge through higher order thinking skills such as application, analysis, synthesis, and research. Assessment moves from paper and pencil exams to demonstration of understanding through application and evaluation in a variety of mathematical contexts and formats. Therefore, qualitative ethnographic research is needed to explore the culture of mathematics in American education and how it impacts mathematical achievement in our education system. 
The costs of college remediation to students, the institutions, and states are significant. Conservative estimates placed the cost of remedial programs at postsecondary institutions at one to two billion dollars annually, and the public and private costs at nearly 17 billion dollars annually (Breneman \& Haarlow, 1998). Research indicates that students require remediation in mathematics more than any other subject (Adelman, 2006). Yet, research also indicates that students who take a challenging curriculum, beginning in the middle school, tend to perform better academically in high school and are better prepared for college than those who take less rigorous courses (ACT 2004a). Middle school students who take rigorous courses such as Algebra I can enroll in advanced mathematics courses in high school that align with courses necessary for college admission and success (Wimberly \& Noeth, 2005). Therefore, a body of research is needed to examine whether there is an appropriate balance in federal and state level funding for post-secondary remediation in mathematics and K-12 mathematics preparation and professional development that supports teaching and learning at the elementary and middle school levels so that all students can be prepared for high school and higher education.

\section{Conclusion}

As this dissertation study has illustrated, the foundation for $\mathrm{K}-12$ mathematics is formed in the critical years of elementary and middle school. The hierarchical structure of mathematics dictates that certain math processes and skills must be taught before other advanced mathematical concepts can be learned and mastered. For students to succeed in advanced mathematics, students must develop a strong foundation in mathematical reasoning and problem solving skills during the early years of their education. Early access to algebra has a significant association upon advanced math course completion during high school and subsequent college

readiness. An elementary teacher who possesses a strong mathematical background and skillful 
teaching abilities will be able to prepare students for early access to algebra during middle school and for the challenges of advanced mathematics courses beyond Algebra I.

Educational experiences at all academic levels are interconnected. Elementary education lays the foundation for future mathematics achievement in middle school. Early access to algebra in middle school impacts students' opportunities for advanced mathematics coursework in high school. High school course taking patterns in mathematics impact a students' level of college readiness. As this dissertation study has indicated, mathematical skills acquired in elementary, middle school, and high school are strongly associated with college success.

Higher education and K-12 public education cannot afford to work in isolation of each other. Students are entering higher education unprepared for the rigors of college-level work which is due in part to a lack of communication and connection between the two levels of our educational systems (Kirst and Bracco, 2004). Higher education and K-12 education are not disparate; they are connected. Palmer (2004) suggests that separation diminishes the quality of learning while shared observations, inquiry, and communication enhance a sense of community and connection. Higher education institutions and K-12 schools are connected and should collectively work together by engaging in a cohesive K-16 partnership for the advancement of student learning and performance, teaching, curricula, and assessment in order to produce the highest levels of achievement and success for all students. 


\section{References}

Achieve, Inc. (2005). Rising to the challenge: Are high school graduates prepared for college and work. Retrieved from www.achieve.org/RisingtotheChallenge

Achieve, Inc. (2006). Closing the expectations gap: An annual 50- state progress report on the alignment of high school policies with the demands of college and work. Washington, DC.

Achieve, Inc. (2009). What is college-and career-ready? America Diploma Project. Retrieved from http://www.achieve.org/files/CollegeandCareerReady.pdf

Achieve Policy Brief (2008). The building blocks of success: Higher-level math for all students. Retrieved from http://www.achieve.org/BuildingBlocksofSuccess

ACT, Inc. (2005a). Career planning: Students need help starting early and staying focused. Iowa City, IA: Author. Retrieved from http://www.act.org/path/policy/pdf/crisis_report.pdf

ACT, Inc. (2005b). Crisis at the core: Preparing all students for college and work. Iowa City, IA: Author. Retrieved from http://www.act.org/path/policy/pdf/crisis_report.pdf

ACT. (2008a). The forgotten middle: Ensuring that all students are on target for college and career readiness before high school. Iowa City, IA: Author.

ACT, Inc. (2008b). What we know about college success: Using ACT data to inform educational issues. Retrieved from http://www.act.org/research/policymakers/pdf/what_we_know.pdf

ACT, Inc. (2009a). Measuring college and career readiness: The class of 2009. Maryland. Retrieved from http://www.act.org

ACT, Inc. (2009b). The condition of college readiness 2009. Retrieved from http://www.eric.ed.gov/PDF/ED506751.pdf 
ACT, Inc. (2010). Mind the gaps: How college readiness narrows achievement gaps in college success. Retrieved from http://www.act.org/research/policymakers/pdf/MindTheGaps.pdf ACT, Inc. (2010). The Condition of college and career readiness. Retrieved from http://web.ebscohost.com.www.libproxy.wvu.edu/ehost/

Adelman, C. (1999). Answers in the tool box: Academic intensity, attendance patterns, and bachelor's degree attainment. Office of Educational Research and Improvement, Washington, DC: U.S. Department of Education. Retrieved from http://www2.ed.gov/pubs/Toolbox/index.html

Adelman, C. (2006). The toolbox revisited: Paths to degree completion from high school through college. Washington, D.C.: U.S. Department of Education. Retrieved from http:/www.ed.gov/rschstat/research/pubs/toolboxrevisit/index.html

Akos, P., Shoffner, M., \& Ellis, M. (2007). Mathematics placement and the transition to middle school. Professional School Counseling, 10, 238-244.

Allegany County Public Schools. (2010). ACPS. Retrieved from http://acps.allconet.org/

Amey, M.J., \& Long, P.N. (1998). Developmental coursework and early placement: Success strategies for underprepared community college students. Community College Journal of Research and Practice. 22(1), 1-8.

Anderman, E., Maeher, M., \& Midgley, C. (1999). Declining motivation after the transition to middle school: Schools can make a difference. Journal of Research and Development in Education, 32, 131-147.

Astin, A. (2000). An interview: Alexander W. Astin. National Crosstalk, 8(1), 2-3. Retrieved from http://www.highereducation.org/crosstalk/ct0100/interview0100.shtml 
Atanda, R. (1999). Do gatekeeper courses expand education options? Washington, DC: U.S. Department of Education, National Center for Education Statistics. Retrieved from http://nces.ed.gov/pubs99/1999303.pdf

Attewell, P., Lavin, D., Domina, T., \& Levey, T. (2006). New evidence on college remediation. The Journal of Higher Education, 77(5), 886-924. doi: 10.1353/jhe.2006.0037

Baker, D. B., Clay, J. N., \& Gratama, C. A. (2005). The essence of college readiness: Implications for students, parents, schools, and researchers: A research review. Berg group, LLC.

Ball, D. L. (2003). Mathematics in the $21^{\text {st }}$ century: What mathematical knowledge is needed for teaching mathematics. Retrieved from http://www2.ed.gov/rschstat/research/progs/mathscience/ball./html

Bandura, A. (1986). Social foundations of thought and action: A social cognitive theory. Englewood Cliffs, NJ: Prentice Hall.

Banta, T.W., Jones, E.A., \& Black, K. E. (2009). Designing effective assessments: Principles and profiles of good practice. San Francisco, CA: Jossey-Bass.

Berry, B., Daughtrey, A., \& Wieder, A. (2009). Collaboration: Closing the effective teaching gap. Center for Teaching Quality. Retrieved from http://www.eric.ed.gov/PDFS/ED509717.pdfhttp

Berry, R. (2003). Mathematics standards, cultural styles, and learning preferences: The plight and the promise of African American students. The Clearing House, 76(5), 244-249.

Bettinger, E. P., \& Long, B. T. (2005). Remediation at the community college: student participation and outcomes. New Directions for Community Colleges, 129, Spring. 
Bill \& Melinda Gates Foundation. (2003). Closing the graduation gap: Toward high schools that prepare all students for college, work, and citizenship. Seattle: Author. Retrieved from http://www.gatesfoundation.org/nr/downloads/ed/policy.pdf

Bowers, J., \& Hatch, P. (2005). The ASCA national model: A framework for school counseling programs (2nd ed.). American School Counselor Association.

Boylan, H.R., Bonham, B.S., \& White, S.R. (1999). Developmental and remedial education in postsecondary education. New Directions for Higher Education, 108, Winter.

Brenneman, D., \& Haarlow, W. (1998). Remediation in higher education: A symposium featuring remedial education: Costs and consequences. Fordham Report, 2(9). Washington, DC: Thomas B. Fordham Foundation. Retrieved from http://www.eric.ed.gov/PDFS/ED422770.pdf

Brigman, C. \& Campbell, C. (2003). Helping students improve academic achievement and school success. Professional School Counseling, 7(2), 91-98.

Burns, M. \& Sibley, R. (2000). So you have to teach math? Sound advice for K-6 teachers. Sausalito, CA: Math Solutions Publications.

Burris, C. C. (2003). Providing accelerated mathematics to heterogeneously grouped middle school students: The longitudinal effects on students of differing initial achievement levels. (Doctoral dissertation). Available from Dissertations Abstracts International, 64(5), 1570. 
Burris, C.C., Heubert, J. P., \& Levin, H.M. (2004). Math acceleration for all. Improving Achievement in Math and Science, February, 61(5), 68-71. Burris, C.C., Heubert, J.P., \& Levin, H.M. (2006). Accelerating mathematics achievement using heterogeneous grouping. American Educational Research Journal, 43(1), 105-136, doi: $10.3102 / 00028312043001105$

Camblin, S. J. (2003). The middle grades: Putting all students on track for college. Honolulu, HI: Pacific Resources for Education and Learning.

Cabrera, A. F., \& La Nasa, S. M. (2000). Understanding the college-choice process. In A. F. Cabrera \& S. M. La Nasa (Eds.). San Francisco, CA: Jossey-Bass.

Cabrera, A. F., \& La Nasa, S. M. (2001). On the path to college: Three critical tasks facing America's disadvantaged students. Research in Higher Education, 42(2), 119-149.

Cabrera, A. F., Deil-Amen, R., Prabhu, R., Terenzini, P.T., Lee, C., \& Franklin, R. E. (2006). Increasing the college preparedness of at-risk students. Journal of Latinos and Education, 5(2), 79-97. doi: 10.1207/s1532771xjle0502_2

Camblin, S.J. (2003). The middle grades: Putting all students on track for college. Pacific Resources for Education and learning, Department of Education: Washington, DC.

Conley, D. T. (2005). College knowledge: What it really takes for students to succeed and what we can do to get them ready. San Francisco, CA: Jossey Bass.

Conley, D. T. (2008). Redefining college readiness. New Directions for Higher Education, 144, Winter, Wiley Periodicals.

Conley, D. T. (2010). College and career ready: Helping all students succeed beyond high school. San Francisco, CA: Jossey-Bass 
Corbett, G. C. \& Huebner, T. A. (2007). Rethinking high school. WestEd: San Francisco, CA. Retrieved from http://www.wested.org/online_pubs/gf-07-02.pdf

Cross, D. (2008). Creating optimal mathematics learning environments: Combining argumentation and writing to enhance achievement. International Journal of Science and Mathematics Education. doi: 10.1007/s10763-008-9144-9.

Csikszentmihalyi, M., \& Schneider, B. (2000). Becoming adult: how teenagers prepare for the world of work. New York: Basic Books.

Dauber, S. L., Alexander, K.L., \& Entwisle, D.R. (1996). Tracking and transitions through the middle grades: Channeling educational trajectories. Sociology of Education, 69, October, 290-307.

Day, P. R., \& McCabe, R. H. (1997). Remedial education: A social and economic imperative. Washington, DC: American Association of Community Colleges.

Diplomas count 2010: Graduation by the numbers-putting data to work for student success. Education Week, 29(34), Retrieved from http://www.edweek.org/ew/articles/2010/06/10/34execsum.h29.html

English, L.D. (Ed). (2002). Handbook of International Research in Mathematics Education, Mahwah, NJ.

Evan, A., Gray, T., \& Olchesfke, J. (2006). The gateway to student success in mathematics and science. Washington, DC: American Institutes of Research.

Fong, A. B., Huang, M., \& Goel, A. M. (2008). Examining the links between grade 12 mathematics coursework and mathematics remediation in Nevada public colleges and universities. Washington, DC: U.S. Department of Education. 
Friedel, J. M., Cortina, K. S., Turner, J. C., \& Midgley, C. (2007). Achievement goals, efficacy beliefs, and coping strategies in mathematics: The roles of perceived parent and teacher goal emphases. Contemporary Educational Psychology, 32, 434-458.

Friedel, J.M., Cortina, K.S., Turner, J.C., Midgley, C. (2010). Changes in efficacy beliefs in mathematics across the transition to middle school: Examining the effects of perceived teacher and parent goal emphases. Journal of Educational Psychology. 102(1), 102-114, doi: 10.1037/a0017590102

Gaither, G. H. (1999). What the future holds. New Directions for Higher Education, 108, Winter.

Gamoran, A., \& Hannigan, E.C. (2000). Algebra for everyone? Benefits of college-preparatory mathematics for students with diverse abilities in early secondary school. Educational Evaluation and Policy Analysis, 22(3), 241-254.

Gewertz, C. (2010). For high-risk groups, success gap in college hinges on readiness. Education Week, 30(7), 8. Retrieved from http://www.edweek.org/ew/toc/2010/10/13/index.html

Gilligan, C., Lyons, N.J., \& Hanmer, T.J. (Eds.). (1990). Making connections: The relational world of adolescent girls at Emma Willard School. Cambridge: MA: Harvard University Press.

Greene, J.P., \& Forster, G. (2003). Public high school graduation and college readiness rates in the United States. Education Working Paper, 3, September, 1-23.

Grobler, B.R., Bisschoff, T.C., \& Moloi, K.C. (2002). The chaid-techique and the relationship between school effectiveness and various independent variables. International Studies in Educational Administration. 30(3), 44-56.

Grubb, W.N. \& Associates. (1999). Honored but invisible: An inside look at teaching in community colleges. New York: Routledge. 
Gutman, L., \& Midgley, C. (2000). The role of protective factors in supporting the academic achievement of poor African American students during the middle school transition. Journal of Youth and Adolescence, 29, 223-248.

Hallinan, M.T. (1994). Further thoughts on tracking. Sociology of Education, 67(2), 89-91.

Hanna, G. (Ed.) (1996). Towards gender equity in mathematics education: An ICMI Study. Klewer Academic Publishers, Springer: Netherlands.

Heyns, B. (1974). Social selection and stratification within schools. American Journal of Sociology, 79, 1434-1451.

Hoffer, T.B. (1992). Middle school ability grouping and student achievement in science and mathematics. Educational Evaluation and Policy Analysis, 14(3), Fall, 205-227.

Holcomb-McCoy, C. (2010). Involving low-income parents and parents of color in college readiness activities: An exploratory study. Professional School Counseling, 14(1), 115124.

Horn, L., Xianglei, C., \& Chapman, C. (2003). Getting ready to pay for college: What students and their parents know about the cost of college tuition and what they are doing to find out. Washington, DC: National Center for Education Statistics, Institute of Education Sciences, U.S. Department of Education. Retrieved from http://nces.ed.gov/pubs2003/2003030.pdf

Huba, M. E. \& Freed, J. E. (2000). Learner-centered assessment on college campuses: Shifting the focus from teaching to learning. Needham Heights, MA: Allyn \& Bacon.

Ingersoll, R. M. \& Gruber, K. (1996). Out-of-field teaching and educational equality: Statistical analysis report. American Institutes for Research in the Behavioral Sciences, Washington, DC. Retrieved from http://www.eric.ed.gov/PDFS/ED402302.pdf 
Ingersoll, R.M. (1999). The problem of underqualified teachers in American secondary schools. Educational Researcher, 28(2). Retrieved from http://www.eric.ed.gov/PDFS/ED402302.pdf

Jerald, C.D. (2002). All talk, no action: Putting an end to out-of-field teaching. Education Trust, Washington, DC. Retrieved from http://www.eric.ed.gov/PDFS/ED468741.pdf

Kelly, S. (2001). Do increased levels of parental involvement account for social class differences in track placement? Retrieved from http://www.eric.ed.gov/PDFS/ED451447.pdf

Kenney, P. A. \& Silver, E. A. (Eds.) (1997). Results from the Sixth Mathematics Assessment of the National Assessment of Educational Progress. Reston, Virginia: National Council of Teachers of Mathematics.

King, A. (1998). Transactive peer tutoring: Distributing cognition and metacognition. Educational Psychology Review, 10, 57-74.

Kirst, M. W., \& Bracco, K. R. (2004). Bridging the great divide: How the K-12 and postsecondary split hurts students, and what can be done about it. From high school to college: Improving opportunities for success in postsecondary education (1-30). San Francisco, CA: Jossey Bass.

Kuh, G. D. (2007). What student engagement data tells us about college readiness. Peer Review, (Winter), 9(1), 4-8.

Kuh, G. D., Kinzie, J., Buckley, J. A., Bridges, B. K., \& Hayek, J. C. (2007). Piecing together the student success puzzle: Research, propositions, and recommendations. ASHE Higher Education Report, 32(5), San Francisco, CA: Jossey Bass.

Kuh, G. D., Kinzie, J., Schuh, J. H., Whitt, E. J., and Associates (2010). Student success in college: Creating conditions that matter. San Francisco, CA: Jossey Bass. 
Kulik, J. A., \& Kulik, C. L. (1984a). Effects of accelerated instruction on students. Review of Educational Research, 54(3), 409-425. doi: 10.3102/00346543054003409

Johanning, D. I. (2004). Supporting the development of algebraic thinking in middle school: A closer look at students’ informal strategies. Journal of Mathematical Behavior, 23(4), 371-388.

Lareau, A. (1987). Social class differences in family-school relationships: The importance of cultural capital. Sociology of Education, 60, 73-85.

Leder, G. (1992). Mathematics and gender: Changing perspectives. In D. A. Grows (Ed.), Handbook of research in mathematics teaching and learning: A project of the National Council of Teachers of Mathematics, 597-622.

Luan, J. (2002). Data mining and its applications in higher education. New Directions for Institutional Research, 2002(13), doi: 10.1002/ir.35, 17-36.

Maryland Higher Education Commission. (2009). Student outcome and achievement report (SOAR): College performance of new Maryland high school graduates. Annapolis, MD. Maryland State Department of Education. (2008). The Critical Middle: A reason for hope. Baltimore: MD Maryland Middle School Steering Committee, 1-64.

Maryland State Department of Education. (2010). Retrieved from www.mdk12.org McCabe, R. (2003). Yes we can: A community college guide for developing America's underprepared. Phoenix, AZ: League for Innovation/American Association of Community Colleges.

McCarthy, M. M., and G. D. Kuh. (2006). Are students ready for college? What student engagement data say. Phi Delta Kappan 87, 664-669. 
McKenney, S., \& Frazier, W. (2008). Embracing the principals and standards for school mathematics: An inquiry into the pedagogical and instructional practices of mathematics teachers in high-poverty middle schools. The Clearing House, 81(5), 201-209.

Melguizo, T., Hagedom, L.S., \& Cypers, S. (2008). Remedial/developmental education and the cost of community college transfer: A Los Angeles County Sample. The Review of Higher Education, 31(4). doi: 10.1353/rhe.0.0008

Mervis, J. (2007). U.S. expert panel sees algebra as key to improvements in math. Science. 318, 1534-1535. doi: 10.1126/science.318.5856.1534

Midgley, C., Anderman, E., \& Hicks, L. (1995). Differences between elementary and middle school teachers and students: A goal theory approach. Journal of Early Adolescence, 15(1), 90-113.

Moles, O.C. (2000). Reaching all families: Creating family-friendly schools, beginning of school year activities. Washington, DC: U.S. Department of Education.

Morgan, P., Ritter, S. (2002). An experimental study of the effects of cognitive tutor Algebra I on student knowledge and attitude. Retrieved from http://www.carnegielearning.com/research/research_reports/morgan_ritter_2002.pdf

Moses, R.P., Kamii, M., Swap, S. M., \& Howard, J. (1989).The algebra project: organizing in the spirit of Ella. Harvard Educational Review, 59(4), 423-443.

Moses, R. P. 2001. Radical equations: Math literacy and civil rights. Boston, MA: Beacon Press.

Mulkey, L.M., Catsambis, S., Steelman, L.C., \& Crain, R. L. (2005). The long-term effects of ability grouping in mathematics: A national investigation. Social Psychology of Education, 8, 137-177. doi: 10.1007/s11218-005-4014-6 
Napoli, A.R., \& Wortman, P. M. (1996). A meta-analysis of the impact of academic and social integration on persistence of community college students. Journal of Applied Research in the Community College, 4, 5-21.

Nathan, M. J., \& Koedinger, K. R. (2000). Teachers’ and researchers’ beliefs of early algebra development. Journal of Mathematics Education Research, 31(2), 168-190.

National Commission on Teaching \& America’s Future (2004). Helping students learn: An online anthology on student achievement. Retrieved from http://www.absbj.com/achievement/ci/ci3.html

National Middle School Association. (2003). This we believe. Successful schools for young adolescents. Westerville, $\mathrm{OH}$.

National Council of Teachers of Mathematics. (2000). Principles and standards for school mathematics. Reston, VA: National Council of Teachers of Mathematics

National Science Foundation. (2007). Executive summary: Rising above the gathering storm. Retrieved from http:www. sciencedems.house.gov/Media/File/Reports/natacad_compete_exsum_6feb06.pdf

Oakes, K. (1992). Can tracking research inform practice? Technical, normative, and political considerations. Educational Researcher, 21(4), 12-21.

Oakes, J. (2005). Keeping track: How schools structure inequality (2nd ed.). New Haven, CT: Yale University Press.

Organization for Economic Cooperation and Development. (1999). Measuring Student Knowledge and Skills: A new framework for assessment. Paris: OECD. Retrieved from http://www.oecd.org/dataoecd/45/32/33693997.pdf 
Ojose, B. (2008). Applying Piaget's theory of cognitive development to mathematics instruction. The Mathematics Educator, 18(1), 26-30.

Olsen, L. (2006). Views differing on college prep. Education Week, 25(13), 1-29.

Oudenhoven, B. (2002). Remediation at the community college: Pressing issues, uncertain solutions. New Directions for Community Colleges, 117.

Palmer, P. J. (2004). A hidden wholeness: The journey toward an undivided life. San Francisco, CA: Jossey-Bass.

Palmer, P. J. (2007). The courage to teach: Exploring the inner landscapes of a teacher's life. (10th anniversary ed.). San Francisco, CA: Jossey-Bass.

Partnership for Family Involvement in Education (1998). Think college? Me? Now? A handbook for students in middle school and junior high school. Washington, DC: Office of Postsecondary Education.

Pascarella, E. T., \& Terenzini, P. T. (2005). How college affects students: A third decade of research (Vol. 2). San Francisco, CA: Jossey-Bass.

Piaget, J. (1970). Science of education and the psychology of the child. New York: Viking. Radcliffe, R., \& Stephens, L.C. (2008). Preservice teachers are creating a college culture for atrisk middle school students. RMLE Online: Research in Middle Level Education, 32(4), $1-15$.

Richardson, J., \& Mero, D. (2007). Making the mathematics curriculum count: A guide for middle and high school principals. National Association of Secondary School Principals. Riley, R. (1997). In math and college, middle school makes all the difference. Middle School Journal, 29(2), 3-7. 
Roderick, M., Nagaoka, J., \& Coca, V. (2009). College readiness for all: The challenge for urban high schools. The Future of Children, 19(1), 185-210.

Roe, M. F., \& Radebaugh, M. (1993). One middle school's elimination of homogeneous grouping: A qualitative study. Research in Middle Level Education, 17(1), 47-62.

Rose, H. \& Betts, J. R. (2001). Math matters: The links between high school curriculum, college graduation, and earnings. Public Policy Institute of California. Retrieved from www.ppic.org/content/pubs/report/R_701JBR.pdf

Rosenbaum, J. E. (1999). If tracking is bad, is detracking better? American Educator, 23(4), 24-47.

Rouse, C. E., \& Kemple, J. J. (2009). Introducing the issue. The Future of Children, 19(1) 3-15. doi: 10.1353/foc. 0.0022

Saha, L. (1983). Social structure and teacher effects on academic achievement: A comparative analysis. Comparative Education Review, 27(1), 69-88.

Schielack, J., \& Seeley, C. L. (2010). Transitions from elementary to middle school math. Teaching Children Mathematics, 16(6), 358-362.

Schiller, K. S., \& Muller, C. (2003) Raising the bar and equity? Effects of state high school graduation requirements and accountability policies on students' mathematics course taking. Educational Evaluation and Policy Studies, 25(3), 299-318. Retrieved from http://www.jstor.org/stable/3699497 Accessed: 29/09/2008 14:02

Schiller, K.S., Schmidt, W.H., Mueller, C., \& Houang, R.T. (2010). Hidden disparities: How courses and curricula shape opportunities in mathematics during high school. Equity \& Excellence in Education, 43(4), 414-433. doi: 10.1080/10665684.2010.517062 
Schmidt, W. H., Cogan, L.S., \& McKnight, C. C. (2010/2011). Equality of educational opportunity: Myth or reality in U.S. Schooling? American Educator, 34(4), 12-19. Retrieved from http://www.aft.org/pdfs/americaneducator/winter1011/Schmidt.pdf

Schoenfeld, A. H. (2002a). Looking for leverage: Issues of research on “algebra for all” In: Proceedings of the International Conference on the Teaching of Mathematics (at the Undergraduate Level) (2nd ed.). Crete, Greece, 1-6.

Schoenfeld, A. H. (2002b). Making mathematics work for all children: Issues of standards, testing, and equity. Educational Researcher, 31(1), 3-15.

Schoenfeld, A. H. (2004). The math wars. Educational Policy, 18(1), 253-286.

Schoenfeld, A.H. (2009). Why do we teach? Kappa Delta Pi Record. Fall, 46(1), 26-29.

Silver, E. A. (1997). “Algebra for all”-Increasing student’s access to algebraic ideas, not just algebra courses. Mathematics Teaching in the Middle School. National Council of Teachers of Mathematics, 2(4), 204-207.

Singh, K., \& Granville, M. (1998). Factors that affect enrollment in eighth grade algebra for African American students. Research in Middle Level Education Quarterly. 22, 57-73.

Smith, J. (1996). Does an extra year make a difference? The impact of early access to algebra on long-term gains in mathematics achievement. Educational Evaluation and Policy Analysis, 18, 141-153.

Soliday, Mary (2002). The Politics of remediation: Institutional and student needs in higher education. Pittsburgh, PA: The University of Pittsburgh Press. 
Spears, R. C. (1994). Teacher perceptions of ability grouping practices in middle level schools. Research in Middle Level Education, 18(1), 117-130.

Spellings, M. (2006). A test of leadership: Charting the future of U.S. higher education. Washington, DC: U.S. Department of Education. Retrieved from http://www.ed.gov/about/bdscomm/list/hiedfuture/reports/pre-pub-report.pdf

Spence, D. (2009) State college readiness initiatives and community colleges. New Directions for Community Colleges, 145, 95-101. doi: 10.1002/cc.358

Spielhagen, F. (2006). Closing the achievement gap in math: Considering eighth-grade algebra for all students. American Secondary Education, 34(3), 29-42.

Spielhagen, F. R. (2006). Closing the achievement gap in math: The long-term effects of eighthgrade algebra. Journal of Advanced Academics, 18(1), 34-59.

Star, J. R., \& Rittle-Johnson, B. (2009). Making algebra work: Instructional strategies that deepen student understanding within and between algebraic representations. ERS Spectrum, 27(2).

Steele, C. M. (1997). A threat in the air: How stereotypes shape intellectual identity and performance. American Psychologist, 52(6), 613-629. doi: 10.1037/0003-066X52.6613

Strong American Schools (2008). Diploma to nowhere. Washington, DC. Retrieved from http://www.deltacostproject.org/resources/pdf/DiplomaToNowhere.pdf

Terry, M. H., Fenster, M. J., \& Fowler, T. B. (2007). Algebra for all? An evaluation of academic achievement of college and tech prep students. Paper presented at the annual meeting of the American Educational Research Association, Chicago, IL.

The American Heritage dictionary (2nd college ed.). (1982). Boston, MA: Houghton Mifflin Company. 
The National Commission on Excellence in Education. (1983). A nation at risk: The imperative for educational reform. Washington, DC: U.S. Department of Education.

Thomas, E. H., \& Galambos, N. (2004). What satisfies students? Mining student-opinion data with regression and decision tree analysis. Research in Higher Education, 45(3), doi: 10.1023/B:RIHE.0000019589.79439.6e 251-269.

Trusty J., \& Niles, S.G. (2003). High-school math courses and completion of the bachelor's degree. Professional School Counseling, 7(2), 99-107. Retrieved from http://www.schoolcounselor.org/files/7-2-99\%20Trusty.pdf

Tyminski, A. M. (2010). Teacher lust: Reconstructuring the construct for mathematics instruction. Journal of Mathematics Teacher Education, 14(4), 295-300. doi: 10.1007/s10857-009-9135-y

Unseem, E.L. (1990). Social class and ability group placement in mathematics in the transition to seventh grade: The role of parental involvement. Paper presented at the annual meeting of the American Educational Research Association, Boston, MA.

Unseem, E.L. (1991). Student selection into course sequences in mathematics: The impact of parental involvement and school policies. Journal of Research on Adolescence, 1, 231-250.

Unseem, E.L. (1992). Middle schools and math groups: Parents' involvement in children’s placement. Sociology of Education, 65, 263-279.

U.S. Department of Education. (2010). Reward excellence and promote innovation:

Reauthorizing the elementary and secondary education act. Jessup, MD Retrieved from http://www.edpubs.gov 
U.S. Department of Education (2003). Remedial education at degree-granting postsecondary institutions in the fall 2000. National Center for Education Statistics. Washington, DC: U.S. Government Printing Office.

Vogel, C. (2008). Algebra: Changing the equation. District Administration, May, 34-40.

Weber, K., Radu, I., Mueller, M., Powell, A, \& Maher, C. (2010). Expanding participation in problem solving in a diverse middle school mathematics classroom. Mathematics Education Research Journal, 22(1), 91-118.

Wimberly, G.L. (2003). Report to the ACT Assessment planning committee: How urban schools facilitate college planning. Iowa City, IA: ACT.

Wimberly, G. L., \& Noeth, R. J. (2004). Schools involving parents in early postsecondary planning. Iowa City, IA: ACT.

Wimberly, G.L., \& Noeth, R. J. (2005). College readiness begins in middle school. Iowa City, IA: American College Testing.

Zelkowski, J. (2010). Secondary mathematics: Four credits, block schedules, continuous enrollment? What maximizes college readiness? The Mathematics Educator, 20(1), 8-21. 


\section{Appendix A}

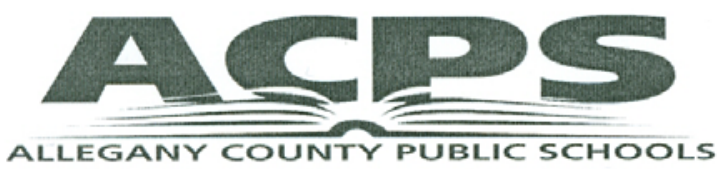

108 Washington Street - P.O. Box 1724 • Cumberland, MD 21501-1724 Telephone (301) 759-2000 • www.acps.allconet.org

\author{
Members of the Board of Education \\ Michael A. Llewellyn, Esq., Presiden \\ Sara-Beth James, Vice President \\ Laurie P. Marchini \\ Jeffery T. Metz \\ Edward L. Root, Ed.D. \\ Superintendent of Schools \\ David A. Cox, Ed.D.
}

September 12, 2011

\section{Ms. Green,}

Your request to conduct research in the Allegany County Public School System has been reviewed. I am pleased to inform you that your request has been approved. I trust that your request will be within the parameters you specified for maintaining confidentiality.

We look forward to the information and conclusions you will find that will help students succeed or that will improve our services to students.

Good luck with your research.

Sincerely,

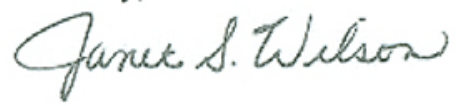

Janet Wilson

Chief Academic Officer

Allegany County Public Schools 


\section{Appendix B}

From: wvuecomp@wvu.edu [mailto:wvuecomp@wvu.edu]

Sent: Thursday, October 20, 2011 5:57 PM

To:srdiaz@mail.wvu.edu; kgreen12@mix.wvu.edu

Subject: BRAAN2: IRB Protocol: Not Human Subjects Research

The following has been determined Not Human Subjects Research.

Tracking \#: H-23515

PI: Diaz, Sebastian

Title: Relationship of Early Access to Algebra on High School Math Course Completion and College Readiness

Determination Date: 10/20/2011

The BRAAN2 website can be accessed by clicking the following link: BRAAN2 Login 